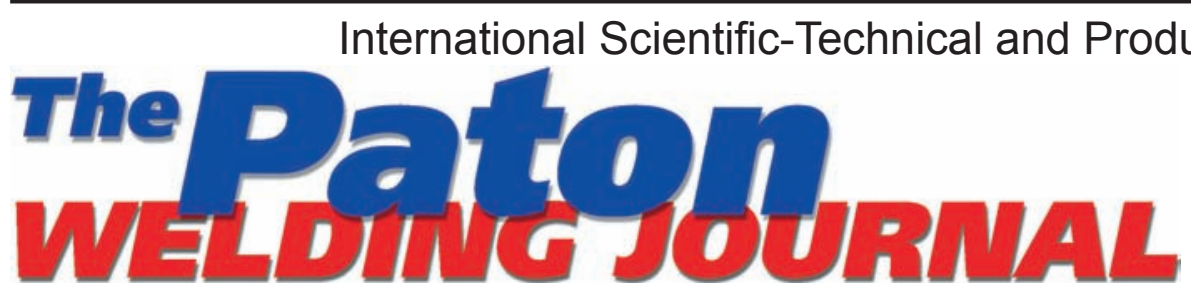

\section{EDITORIAL BOARD \\ Editor-in-Chief B.E. Paton}

Scientists of PWI, Kyiv S.I. Kuchuk-Yatsenko (vice-chief ed.), V.N. Lipodaev (vice-chief ed.)

Yu.S. Borisov, G.M. Grigorenko A.T. Zelnichenko, V.V. Knysh,

I.V. Krivtsun, Yu.N. Lankin, L.M. Lobanov, V.D. Poznyakov, I.A. Ryabtsev, K.A. Yushchenko

Scientists of Ukrainian Universities V.V. Dmitrik, NTU «KhPI», Kharkov V.V. Kvasnitsky, NTUU «KPI», Kyiv E.P. Chvertko, NTUU «KPI», Kyiv

Foreign Scientists

N.P. Alyoshin

N.E. Bauman MSTU, Moscow, Russia Guan Qiao

Beijing Aeronautical Institute, China M. Zinigrad

Ariel University, Israel V.I. Lysak

Volgograd STU, Russia Ya. Pilarczyk

Welding Institute, Gliwice, Poland U. Reisgen

Welding and Joining Institute, Aachen, Germany G.A. Turichin

St. Petersburg SPU, Russia

Founders

E.O. Paton Electric Welding Institute, NASU

International Association «Welding» Publisher

International Association «Welding» Translators

A.A. Fomin, O.S. Kurochko, I.N. Kutianova Editor

N.G. Khomenko

Electron galley

D.I. Sereda, T.Yu. Snegiryova Address

E.O. Paton Electric Welding Institute, International Association «Welding» 11 Kazimir Malevich Str. (former Bozhenko Str.), 03150, Kyiv, Ukraine

Tel.: (38044) 20060 16, 2008277

Fax: (38044) 20082 77, 2008145

E-mail: journal@paton.kiev.ua

www.patonpublishinghouse.com

State Registration Certificate

KV 4790 of 09.01.2001

ISSN 0957-798X

DOI: http://dx.doi.org/10.15407/tpwj Subscriptions

$\$ 348,12$ issues per year

air postage and packaging included. Back issues available.

All rights reserved.

This publication and each of the articles contained herein are protected by copyright.

Permission to reproduce material contained in this

journal must be obtained in writing from the Publisher.

\section{CONTENTS}

\section{SCIENTIFIC AND TECHNICAL}

Ryabtsev I.A., Pereplyotchikov E.F., Bartenev I.A., Gordan G.N., Bogajchuk I.L. and Kapitanchuk L.M. Effect of amplitude and frequency of plasmatron oscillations on chemical and structural inhomogeneity of metal deposited by plasma-powder method

Dmitrik V.V., Glushko A.V., Syrenko T.A. and Grigorenko S.G.

Peculiarities of welded joints weakening in operating steam

pipelines

Serebryanik I.P., Atroshenko M.G. Poleshchuk, M.A., Puzrin A.L. and Shevtsov A.V. Properties of steel-copper bimetal produced by brazing in autonomous vacuum

Kuskov Yu.M., Biktagirov F.K., Grishchenko T.I. and Evdokimov A.I.

Electroslag surfacing of high-chromium cast iron with $110 \mathrm{G} 13$ l steel

\section{INDUSTRIAL}

Barvinko A.Yu., Barvinko Yu.P., Yashnik A.N. and Miryanin V.N.

Application of leak before break criterion for prevention of avalanche

fracture of the wall of vertical welded tanks

Kuskov Yu.M. Influence of electric parameters of surfacing with discrete

filler in current-supplying mould on speed of slag pool rotation

Lobanov L.M., Makhlin N.M., Korotynsky A.E., Vodolazsky V.E. and

Buryak V.Yu. Modern hardware-software complexes for training of

welders

\section{INFORMATION}

On the occasion of the 175th birthday anniversary of N.N. Benardos, the inventor of electric arc welding 37

Unique complex for automatic arc welding at large depth ...................... 40

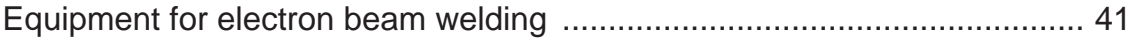

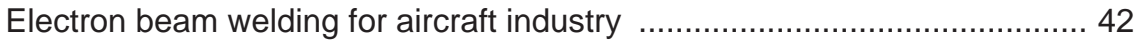

Electron beam welding for engine repair ....................................... 43

Laser technology and equipment for manufacture of multilayer bellows ..... 44 


\title{
EFFECT OF AMPLITUDE AND FREQUENCY OF PLASMATRON OSCILLATIONS ON CHEMICAL AND STRUCTURAL INHOMOGENEITY OF METAL DEPOSITED BY PLASMA-POWDER METHOD
}

\author{
I.A. RYABTSEV ${ }^{1}$, E.F. PEREPLYOTCHIKOV ${ }^{1}$, I.A. BARTENEV ${ }^{2}$, \\ G.N. GORDAN ${ }^{1}$, I.L. BOGAJCHUK ${ }^{1}$ and L.M. KAPITANCHUK ${ }^{1}$ \\ ${ }^{1}$ E.O. Paton Electric Welding Institute of the NAS of Ukraine \\ 11 Kazimir Malevich Str., 03150, Kyiv, Ukraine. E-mail: office@paton.kiev.ua \\ ${ }^{2}$ Karaganda State Technical University \\ 56 Mira Ave., 100027, Karaganda, Kazakhstan. E-mail:igor_svar@mail.ru
}

\begin{abstract}
Effect of amplitude and frequency of plasmatron oscillations on formation of deposited beads, nature of base metal penetration as well as structural and chemical inhomogeneity in zone of joining of deposited and base metals was investigated. The plasmatron oscillation frequency has the largest effect on bead shape and its microstructure, increase of amplitude rises bead width and decreases its height. Effect of plasmatron oscillation frequency on nature of base metal penetration and chemical and structural inhomogeneity in zone of joining of base and deposited metals along surfacing direction was also investigated. In deposition with plasmatron oscillations there is a wavy configuration of interface of deposited and base metals in longitudinal direction with higher frequency of projections and cavities, which repeats plasmatron oscillation frequency. It is determined that increase of plasmatron oscillation frequency on projections as well as cavities in fusion line promotes decrease of deposited and base metals stirring and content of main alloying elements rapidly changes. 6 Ref., 11 Figures.
\end{abstract}

Keywords : plasma-powder surfacing, oscillations of plasmatron, amplitude and frequency of oscillations, base metal penetration, chemical and structural inhomogeneity, formation of deposited metal

It is known that plasma-powder surfacing in the most cases is carried out with plasmatron oscillations. This allows depositing beads of set width and height with minimum penetration of a base metal in one pass [1-6]. An analysis shows that if electric indices of surfacing mode and rate of wire feed are not taken into account than amplitude and frequency of plasmatron oscillations as well as surfacing rate have the main effect on these characteristics of deposited beads. Moreover, all these characteristics are interconnected and at change of one of them and in order to get quality deposited beads it is necessary to adjust two other characteristics.

The aim of the present work was to study an effect of amplitude and frequency of plasmatron oscillations on formation of deposited beads, nature of base metal penetration as well as structural and chemical inhomogeneity in joining zone of deposited and base metals.

Effect of amplitude and frequency of plasmatron oscillations as well as surfacing current on formation of deposited metal beads was studied at the first stage. At that the amplitude was changed in a range of 0-7 mm, frequency - 30-90 $\mathrm{min}^{-1}$, current 210-270 A. Surfacing rate made $10 \mathrm{~m} / \mathrm{h}$, powder feed $3.3 \mathrm{~kg} / \mathrm{h}$, filler powder PR-10R6M5. Deposition of single beads was carried out on $15 \mathrm{~mm}$ thick plates of steel St3. Investigations of bead shape and their structure were carried on macro- and microsections.

The most significant effect on bead shape and its microstrucutre has a plasmatron oscillation amplitude. Increase of the amplitude rises bead width and reduces its height (Figure 1, a), During surfacing without oscillations $(A=0)$ at 240-245 A current the bead is high and has small roll (coefficient of bead shape equals to 1.8), however, in whole formation is good. With $2-3 \mathrm{~mm}$ amplitude the formation is good, bead cross-section is of half-round shape with wetting angle not less than $90^{\circ}$. Further increase of oscillation amplitude promotes rise of bead width $b$ and its height $h$ reduces and bead becomes flatter.

Effect of surfacing current on bead shape is regular, i.e. rise of current makes bead lower and wider (Figure 1,b). However, even at sufficiently high values of current (270 A) and powder feed (3.3 kg/h) for $10 \mathrm{~m} / \mathrm{h}$ rate, surfacing with oscillations allows eliminating noticeable penetration of base metal.

Increase of plasmatron oscillation frequency has very small effect on coefficient of bead shape (Figure 2), at that it rises due to very insignificant decrease of bead 

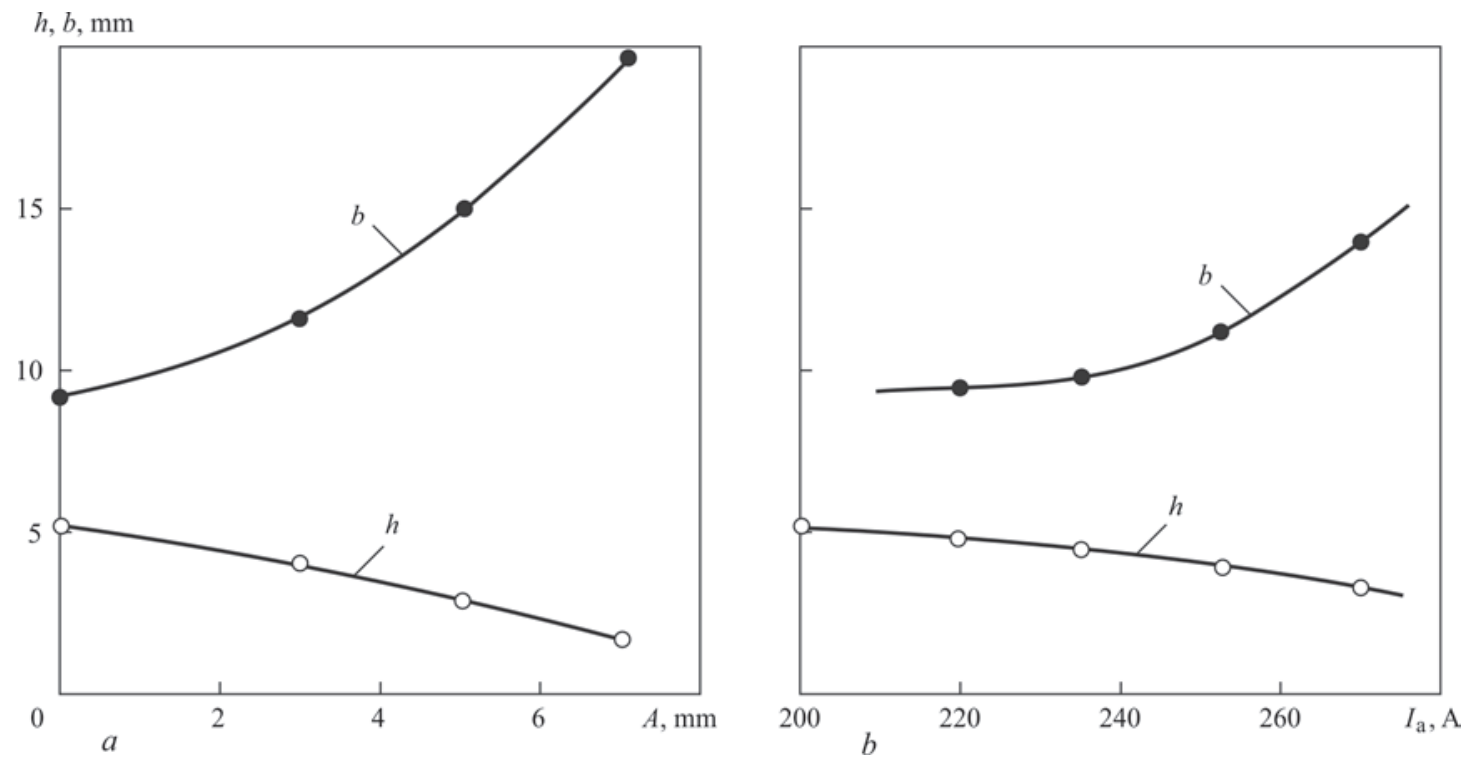

Figure 1. Effect of oscillation amplitude A $\left(I_{\mathrm{a}}-245 \mathrm{~A}\right.$; oscillation frequency $\left.f=70 \mathrm{~min}^{-1}\right)(a)$ and current $I_{\mathrm{a}}\left(A=3 \mathrm{~mm} ; f=70 \mathrm{~min}{ }^{-1}\right)$ (b) on height $h$ and width $b$ of deposited bead

height, i.e. bead becomes flatter. Good formation of bead edges is noted at more than $60 \mathrm{~min}^{-1}$ frequency.

A microstructure of deposited metal at values of plasmatron oscillation amplitude $0-3 \mathrm{~mm}$ differs by coarse grain (Figure 3,a). Portion of fine, almost equiaxial grains (Figure $3, b$ ) rises considerably at $5 \mathrm{~mm}$ amplitude. In surfacing without oscillations they are only present in insignificant amount close to fusion line and in beads' surface zone.

The next step was dedicated to investigation of effect of plasmatron oscillation frequency on nature of base metal penetration and chemical and structural inhomogeneity in zone of joining of base and deposited metal along surfacing direction. The experiments were carried out on the following modes, namely oscillation amplitude $A=10 \mathrm{~mm}$; oscillation frequency $f$; sam-

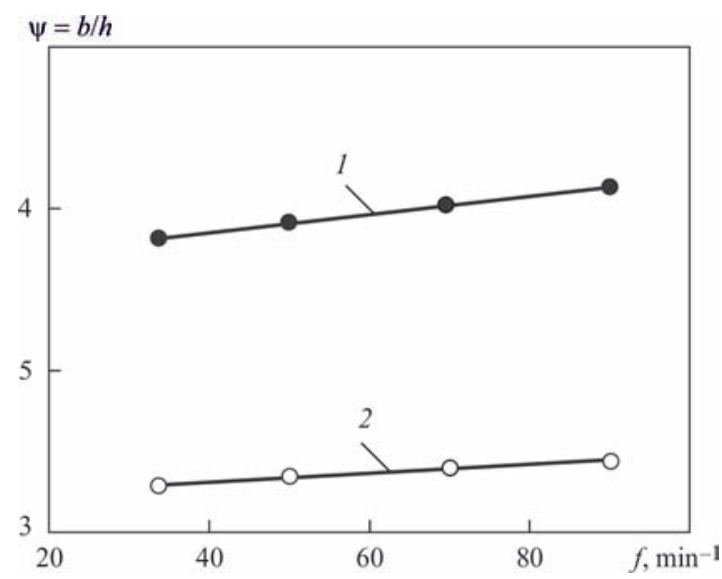

Figure 2. Effect of amplitude $A$ and plasmatron oscillation frequency $f$ on shape of deposited bead $\left(I_{\mathrm{a}}=245 \mathrm{~A}\right): 1-A=5$; $2-25 \mathrm{~mm}$ ple $1-40 \mathrm{~min}^{-1}$, sample $2-60 \mathrm{~min}^{-1}$, sample $3-$
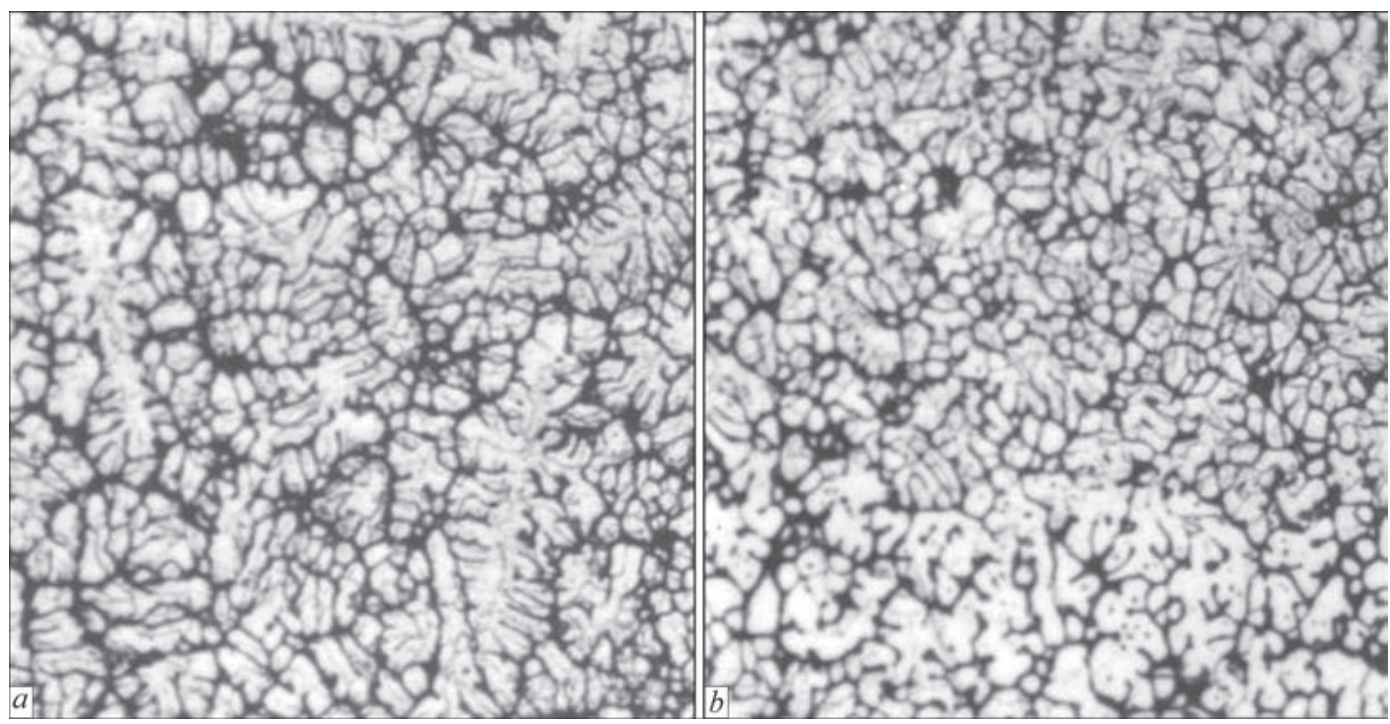

Figure 3. Microstructure $(\times 300)$ of deposited metal of steel R6M5 type at $I_{\mathrm{a}}=245 \mathrm{~A}: a-A=0 \mathrm{~mm}, f=0 \mathrm{~min}^{-1} ; b-\mathrm{A}=5 \mathrm{~mm}, f=$ $=70 \mathrm{~min}^{-1}$ 


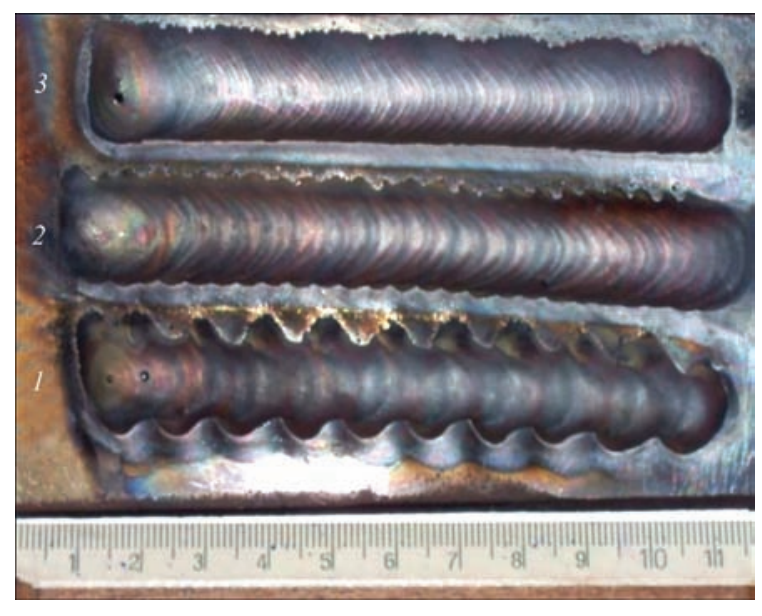

Figure 4. Appearance of beads deposited by plasma-powder method with plasmatron oscillation at frequency, $\min ^{-1}: 1-40$; 2 - 60; 3 - 90) amplitude of oscillations - $10 \mathrm{~mm}$ )

$90 \mathrm{~min}^{-1}$; current $-180 \mathrm{~A}$, surfacing rate $-10.5 \mathrm{~m} / \mathrm{h}$; powder feed $-3.0 \mathrm{~kg} / \mathrm{h}$, filler powder PR-Kh18N9. Figure 4 shows the appearance of deposited beads.

It can be seen from Figure 4 that increase of plasmatron oscillations frequency at constant amplitude of plasmatron oscillation and rate of surfacing improves formation of deposited beads, they become smoother. At that ripples on the bead surface correspond to plasmatron oscillation frequency.

Deposited beads were cut in the center along longitudinal axis. After grinding and polishing the samples were etched by electrolytic method in a solution of chromic acid and their metallographic examinations were carried out. Such preparation of the samples allowed evaluating structural and chemical inhomogeneity in joining zone of base and deposited metals along deposited beads' length.

Clear and relatively straight fusion line with small cavities (increase of penetration) in places of plasma arc

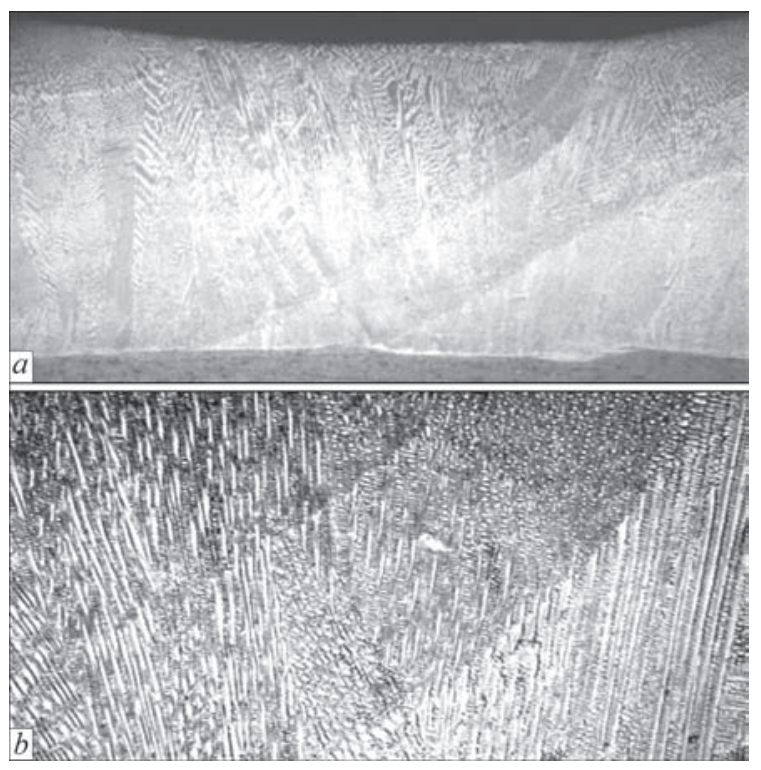

Figure 5. Longitudinal section of deposited bead 1: $a-$ macrostructure $(\times 20) ; b-$ microstructure $(\times 100)$ passing is registered at $\times 20$ magnification on longitudinal microsection of deposited bead 1 (Figure 5, a).

Crystallization of deposited metal is dendritic (Figure 5, b). The microstructure consists of austenite matrix and $\delta$-ferrite precipitations along crystallite boundaries. Width of crystallites makes 20-35 $\mu \mathrm{m}$. During transverse plasmatron movement at deposition of one layer on other there is a boundary between them and area of overlapping, moreover the boundary between two layers is preserved from the surface of deposited metal to fusion line with base metal.

A transition layer is located from the side of deposited metal. It has intermediate hardness between deposited and base metal hardness. Width of this layer makes 5-50 $\mu \mathrm{m}$ and depends on base metal penetration, i.e. change of composition of deposited layer in stirring of base and deposited metal. HAZ width for deposited bead 1 makes 2600-2700 $\mu \mathrm{m}$.

Figure 6 shows macro- and microstructure of deposited bead 2. In this case the fusion line of deposited metal with base one has wavy nature with alternating cavities and projections, repeating plasmatron oscillations (Figure 6, a). At that the cavities (local increase of penetration depth) correspond to places of direct passing of plasma arc and projections (local reduction of penetration depth) is the result of effect of periphery arc zone on base metal. Crystallization of deposited metal is dendritic, in the cavities the deposited metal has more dispersed cellular structure. Columnar crystallites grow from the fusion line with base metal to a sample surface and have 15-20 $\mu \mathrm{m}$ width.

In transverse movement of plasmatron at deposition of one layer onto another one, the obvious boundary between the neighbour layers (in contrast to bead 1) is not registered that indicate good stirring

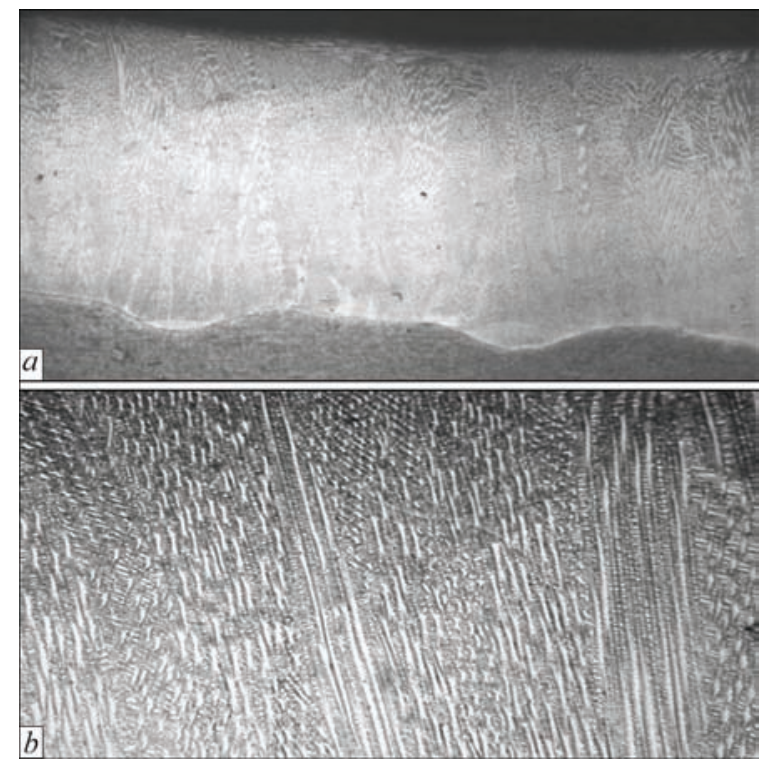

Figure 6. Longitudinal section of deposited bead 2: $a-$ macrostructure $(\times 20)$; $b-$ microstructure $(\times 100)$ 


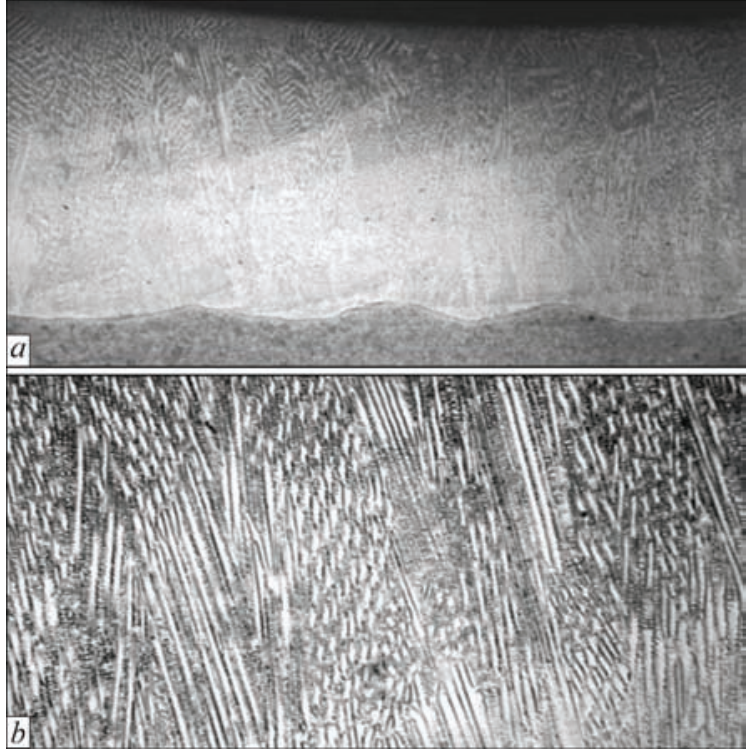

Figure 7. Longitudinal section of deposited bead 3: $a$ - macrostructure $(\times 20) ; b-$ microstructure $(\times 100)$

of deposited metal (Figure $6, b$ ). Width of the transition layer along the fusion line makes $2-40 \mu \mathrm{m}$. HAZ width is $3700-3800 \mu \mathrm{m}$.

Figure 7 presents macro- and microstructure of deposited bead 3. The fusion line of deposited and base metal also has wavy nature, but with higher frequency of projections and cavities than in deposited bead 2 that is explained by high plasmatron oscillation frequency (Figure 7, a). A thin layer of alternating width from 2 to $20 \mu \mathrm{m}$ is observed along the joining line with steel St3. HAZ width makes 4200-4500 $\mu \mathrm{m}$. The extended crystallites are clearly seen. They are located normal to the fusion line and have 15-20 $\mu \mathrm{m}$ width. A microstructure of deposited metal of bead 3 is similar to the microstructure of deposited beads 1 and 2 and consists of austenite and $\delta$-ferrite located on the crystallites boundaries.

Composition of deposited and base metal across their fusion line was investigated. The distance between neighbor measurements made approximately $2 \mu \mathrm{m}$ (Figure 8). The examinations were carried out using Auger-microprobe Jamp-9500F of JEOL company, equipped with energy-dispersive X-ray spectrometer INCA Penta FETx3. Energy of primary electron beam made $10 \mathrm{keV}$ at probe current $500 \mathrm{pA}$. Cleaning of sample surface by argon ions $\mathrm{Ar}^{+}$with $500 \mathrm{eV}$ energy during $10 \mathrm{~min}$ (etching rate made 1 $\mathrm{nm} / \mathrm{min}$ ) was performed before the examination.

Sample 1 was used for investigation of distribution of main alloying elements (nickel and chromium) on straight section, projection and cavity in the fusion line of base and deposited metals (Figure 9).

In samples 2 and 3 deposited with higher plasmatron oscillation frequency it was difficult to choose straight sections of sufficient extension in the fusion

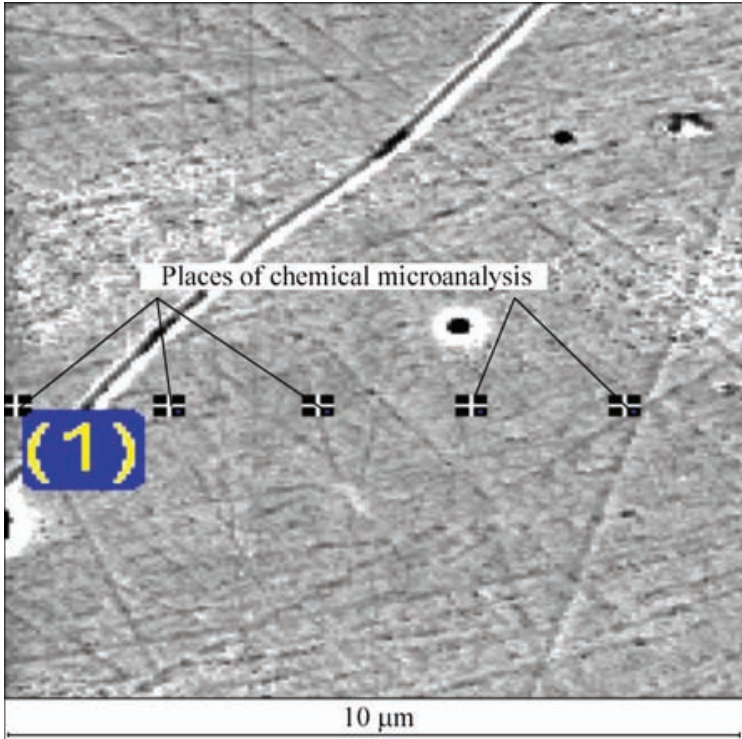

Figure 8. Illustration of performance of chemical microanalysis on Auger-microprobe

line for analysis performance. This is the reason why distribution of main alloying elements (nickel and chromium) in these samples was investigated in a projection and cavity on the base and deposited metal fusion line (Figures 10, 11). These samples, in compar-
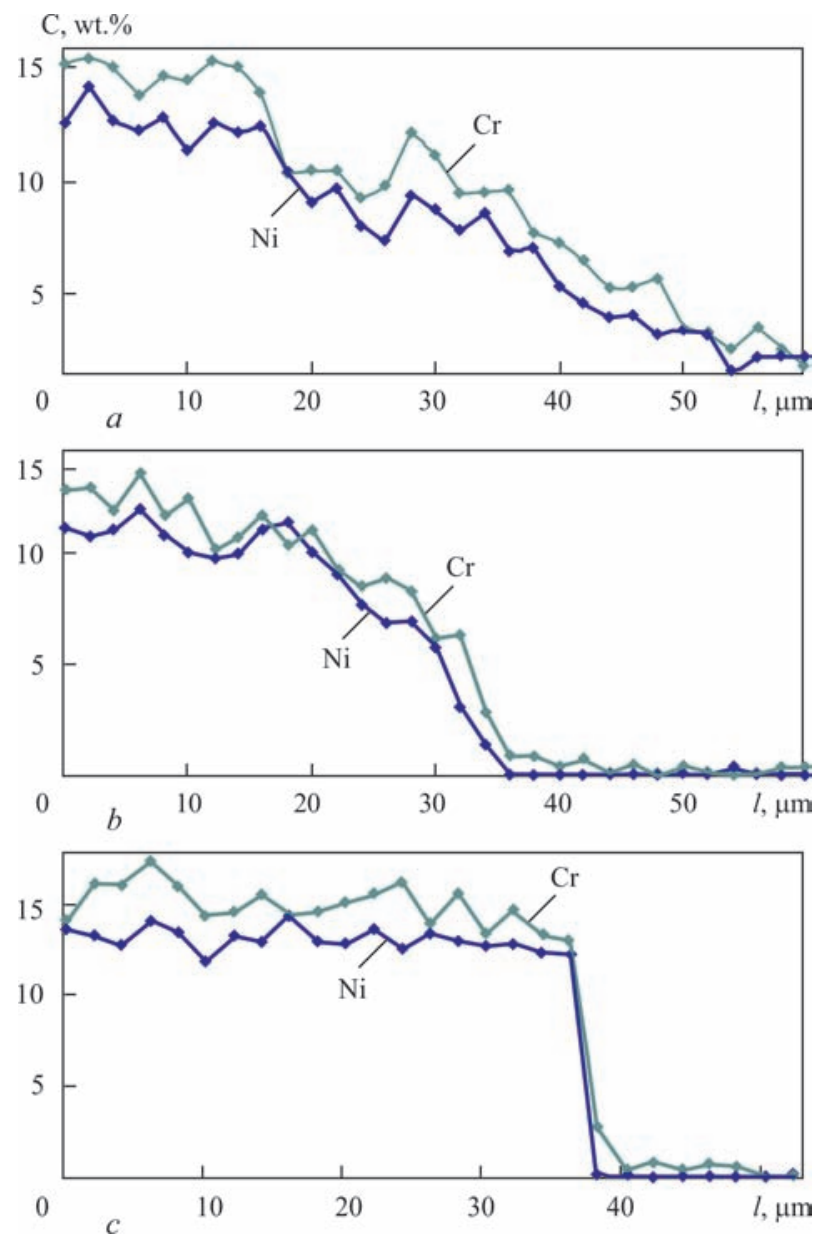

Figure 9. Distribution of chromium and nickel in sample 1 in fusion zone: $a$ - straight section on fusion line; $b$ - cavity on fusion line; $c$ - projection on fusion line 

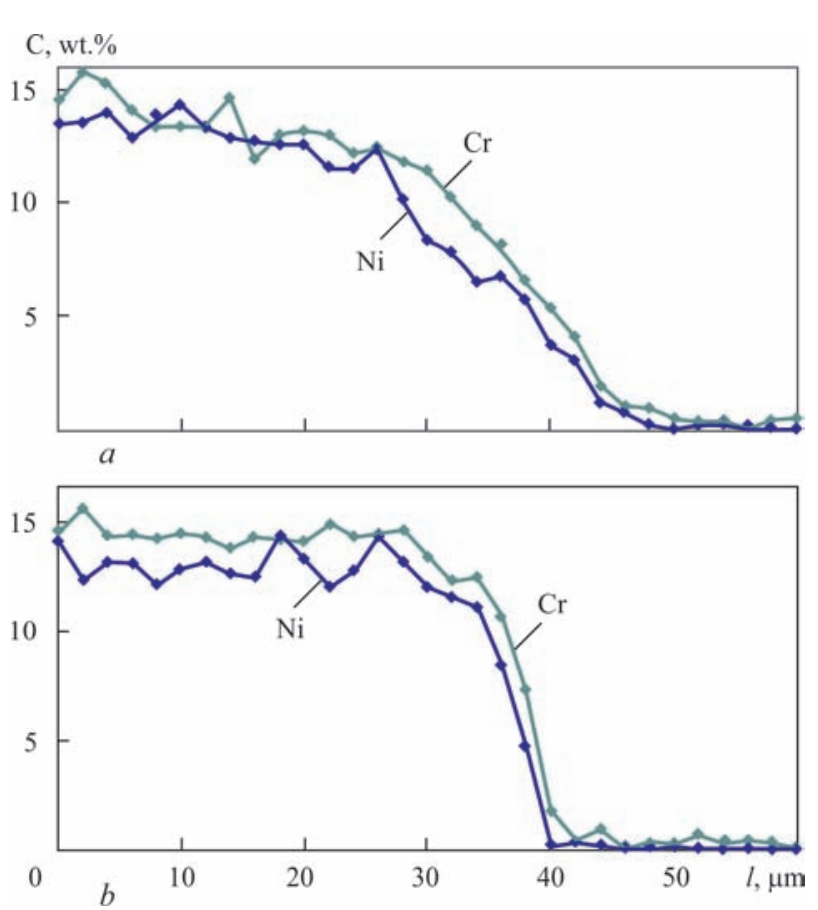

Figure 10. Distribution of chromium and nickel in sample 2 in fusion zone: $a$ - cavity on fusion line; $b$ - projection on fusion line

ison with sample 1 , demonstrate more rapid change of content of the main alloying elements of deposited metal on the fusion boundary.

It should be noted that increase of oscillation frequency rises a rate of plasmatron transverse displacement, thus time of direct effect of plasma arc on the base metal is reduced. Apparently, it can be used for explanation of a fact that increase of plasmatron oscillation frequency promotes decrease of stirring of deposited and base metals in the projections as well as cavities on the fusion boundary and content of the main alloying elements rapidly changes from the deposited to base metal.

\section{Conclusions}

1. Effect of amplitude and frequency of plasmatron oscillations on formation of deposited beads was investigated in plasma-powder surfacing. At all other indices of surfacing mode being constant (deposition rate, current, powder feed rate) the most important effect on bead shape has the plasmatron oscillation frequency, i.e. its rise promotes increase of bead width and decrease of its height.

2. Investigations of effect of the plasmatron oscillation frequency on structural inhomogeneity of metal deposited by plasma-powder surfacing showed that:

- fusion line of deposited and base metals in longitudinal direction has wavy nature with frequency of projections and cavities repeating frequency of plas-
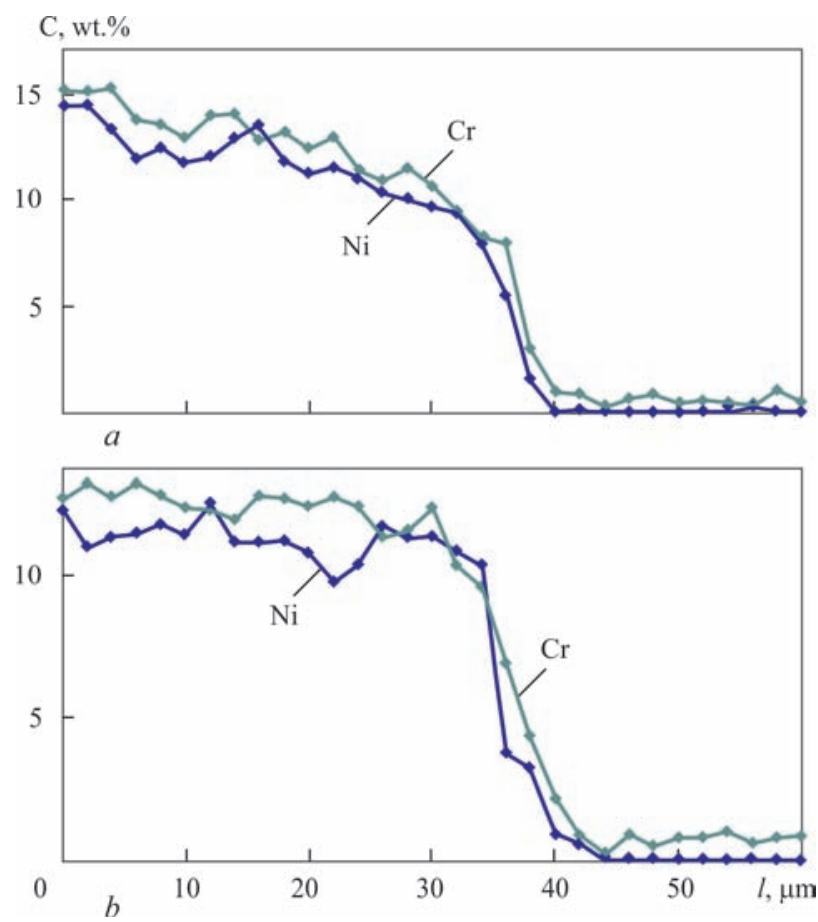

Figure 11. Distribution of chromium and nickel in sample 3 in fusion zone: $a$ - cavity on fusion line; $b$ - projection on fusion line

matron oscillation; at that the cavities (local increase of penetration depth) correspond to trajectory of direct passing of plasma arc and the projections (local reduction of penetration depth) are the result of effect arc periphery zone on base metal;

- increase of plasmatron oscillation frequency from 40 to $90 \mathrm{~min}^{-1}$ promotes better stirring of deposited metal layers, balancing and refinement of structure on its section.

3. Increase of the plasmatron oscillation frequency provokes decrease of stirring of the deposited and base metals in the projections as well as cavities on the fusion boundary and content of the main alloying elements on this boundary rapidly changes from the deposited to base metal.

1. Gladky, P.V., Frumin, I.I. (1965) Plasma surfacing. Avtomatich. Svarka, 3, 23-27 [in Russian].

2. Vajnerman, A.E., Shorshorov, M.Kh., Veselkov, V.D., Novosadov, V.S. (1969) Plasma surfacing of metals. Leningrad, Mashinostroenie [in Russian].

3. Vajnerman, A.E., Zakharov, V.F., Syutiev, A.N. (1975) Surfacing with constricted arc of stainless steel on low-carbon and low-alloy steels. Leningrad, LDNTP [in Russian].

4. Pereplyotchikov, E.F., Ryabtsev, I.A. (2007) Plasma-powder surfacing in reinforcement engineering. Kiev, Ekotekhnologiya [in Russian].

5. Gladky, P.V., Pereplyotchikov, E.F., Ryabtsev, I.A. (2007) Plasma-powder surfacing. Kiev, Ekotekhnologiya [in Russian].

6. Ryabtsev, I,A., Senchenkov, I.K. (2013) Theory and practice of surfacing operations. Kiev, Ekotekhnologiya [in Russian]. 


\title{
PECULIARITIES OF WELDED JOINTS WEAKENING IN OPERATING STEAM PIPELINES
}

\author{
V.V. DMITRIK ${ }^{1}$, A.V. GLUSHKO ${ }^{1}$, T.A. SYRENKO ${ }^{2}$ and S.G. GRIGORENKO ${ }^{3}$ \\ ${ }^{1} \mathrm{NTU}$ «KhPI» \\ 2 Kirpicheva Str., 61002, Kharkov, Ukraine. E-mail: svarka126@ukr.net \\ ${ }^{2}$ Kharkiv Machine Building College \\ 79 Plekhanovskaya Str., 61068, Kharkiv, Ukraine \\ ${ }^{3}$ E.O. Paton Electric Welding Institute of the NAS of Ukraine \\ 11 Kazimir Malevich Str., 03150, Kyiv, Ukraine. E-mail: office@paton.kiev.ua
}

\begin{abstract}
The development of recovery in metal of welded joints of heat-resistant pearlitic steel steam pipelines, which are operating for a long time in the creep conditions, is characterized by certain structural changes. Such changes cause the weakening in metal of welded joints. The article considers the peculiar features of structural and deformational changes, as well as the development of diffusion which occur in the process of recovery and leads to weakening in metal of welded joints of steam pipelines at their service of over 270 thou h. 10 Ref., 7 Figures.
\end{abstract}

Ke y w or d s : welded joints of steam pipelines, recovery, structural state, weakening, dislocations, diffusion, heat-affected zone

The processes of weakening and damaging of metal of the TPP steam pipelines, which are operating for a long time under creep conditions, are of great practical importance. In the metal of steam pipelines (mostly in their welded joints), which are operating for a long time at the temperature of $545-585^{\circ} \mathrm{C}$ and at a stress of 20-25 MPa, certain structural changes, deterioration of properties, damage and fracture take place.

The structural changes at the first and second stages of creep are caused by manifestations of recovery, polygonization and recrystallization processes. Each of the mentioned processes should be considered with account for peculiar features of the other process as that associated with the process being considered. Revealing the features of the recovery, polygonization and recrystallization processes is urgent for reducing the rate of their propagation, and, consequently, for decrease in the level of structure degradation and damage of metal.

The aim of the work is to study the peculiar features of the recovery process, which controls the structural state of the metal of the steam pipeline welded joints, operated for a long time in the creep conditions.

In the steam pipelines, both thermal and dispersion-strengthened steels (12Kh1MF, 15Kh1M1F) are applied. The stability of their structure under the operating conditions depends not only on the free energy of the metal, but also on the presence and distribution of defects in the crystalline lattice. In this regard, it is not possible to describe the kinetics of the process of weakening the welded joint metal using the known exponential law.

The metal of welded joints is characterized by the presence of third-kind stresses, formed in the $\alpha$-phase crystals at a certain absence of coherence with the precipitation of the second phases $\left(\mathrm{M}_{3} \mathrm{C}, \mathrm{M}_{7} \mathrm{C}_{3}, \mathrm{M}_{23} \mathrm{C}_{6}\right)$, to a lesser extent $\mathrm{Mo}_{2} \mathrm{C}$ and VC. The absence of coherence is increased at the presence of coagulation of $\mathrm{M}_{7} \mathrm{C}_{3}$ and, especially, $\mathrm{M}_{23} \mathrm{C}_{6}$. Let us note that the feature of coagulation of carbides of the group I, located along the grain boundaries, should be specified, since the processes of their coalescence are essentially different (Figure 1) [1].

The difference between the recovery, which takes place in the metal of operating steam pipelines, from the recovery, which is the removal of cold-hardening in the deformed metal, consists in the fact that when the cold-hardening is removed, the evolution of the previously stored energy occurs, and the recovery in metal of the steam pipelines is realized at simultaneous input of energy (predominantly) and at its insignificant (5-7\%) release. The recovery in the considered structure is provided only by thermal activation and characterized by the absence of an incubation period. In the process of recovery in structure of steam pipelines metal (and their welded joints), the crystallographic orientation of the $\alpha$-phase is not changed, but there are fine structural changes and some changes in the spot defects. The level of recovery depends on the initial structural state of the welded joints metal, 


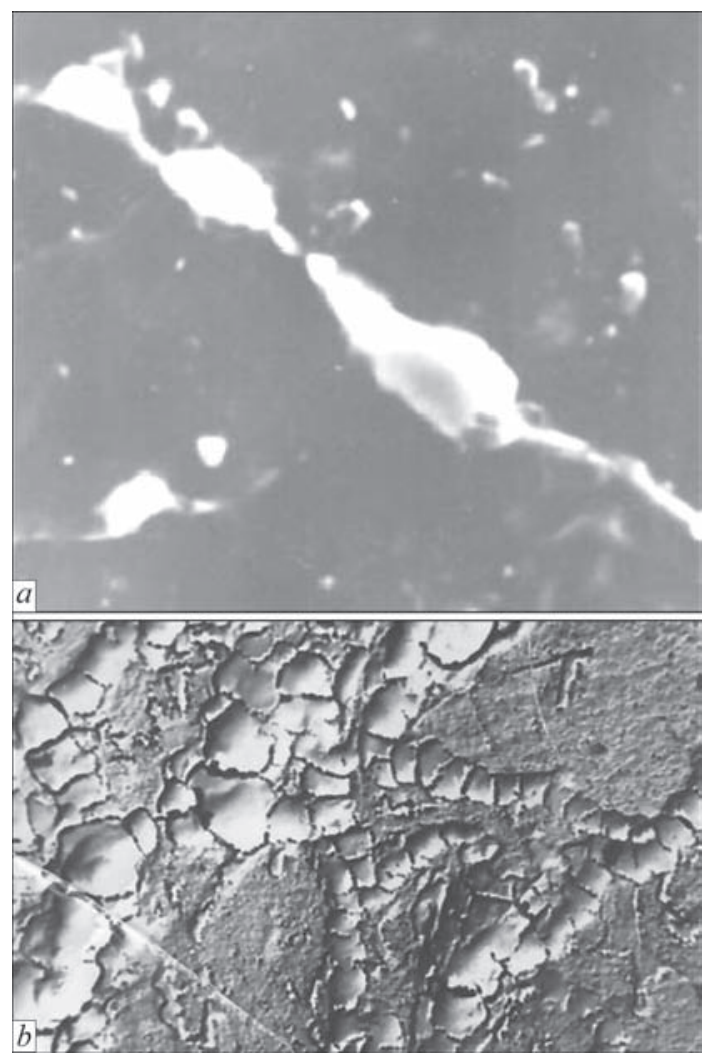

Figure 1. Coagulation of carbides by coalescence: $a$ - carbides $\mathrm{M}_{23} \mathrm{C}_{6}(\times 7500) ; b$ - carbides $\mathrm{M}_{7} \mathrm{C}_{3}(\times 6000)$

including that from the previous distribution of dislocations.

The phenomenon of recovery, in general, is peculiar to the metal of the considered welded joints as-applied to their time of service from about 250 thou $\mathrm{h}$. In our opinion, it is very difficult to study the peculiarities of structural changes, caused by the recovery processes applying the known methods of measuring
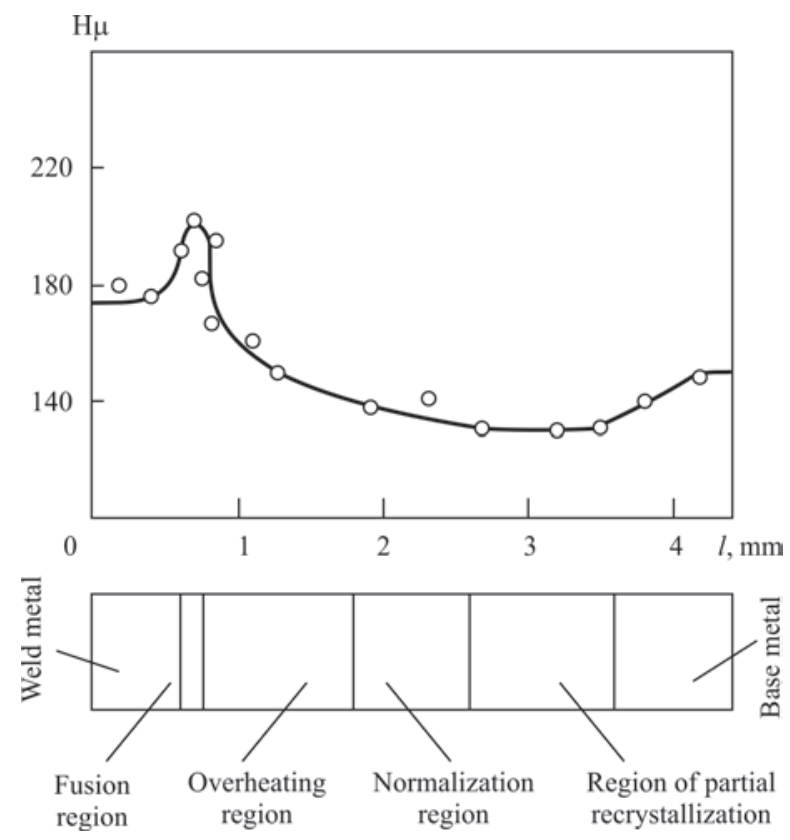

Figure 2. Microhardness of welded joints of steel 15Kh1M1F (life -280 thou h) the electrical resistance in the areas of the heat-affected zone (HAZ) of welded joints. The recovery of welded joints metal is characterized by the presence of local weakening (Figure 2) and decrease in the yield strength by $15-20 \%$, which is associated with the structural heterogeneity of their HAZ. In the process of recovery the diffusion displacement of chromium, molybdenum, vanadium, silicon and manganese occurs in the welded joint metal from the central zones of $\alpha$-phase grains to their near-boundary zones, which provides the formation of segregations [2, 3]. An increase in the diffusional mobility of chromium, molybdenum and vanadium leads to increase in the amount of $\mathrm{Mo}_{2} \mathrm{C}$ and VC, as well as $\mathrm{M}_{7} \mathrm{C}_{3}, \mathrm{M}_{23} \mathrm{C}_{6}$. The amount of chromium, molybdenum and vanadium in carbides is increased at coresponding their decrease in the $\alpha$-phase crystals.

It was established that in the metal of the HAZ regions, as well as in weld metal and in base metal, the processes of weakening occur at different intensity. Locally, at the HAZ regions, the metal can also harden, however, the predominant effect is the weakening (Figure 2). The greatest relative weakening is characteristic for the region of partial recrystallization of the HAZ metal.

Considering the recovery as a slow process of weakening with time, as-applied to the welded joint, let us write the specified dependence [4] in the following form:

$$
X=1-\exp \left[-k m t \exp \left(-\frac{E}{R T}\right)\right],
$$

where $X$ is the fraction of weakened metal with time $t$; $E$ is the activation energy; $T$ is the temperature; $R$ is the Boltzmann constant; $k$ is the parameter, exponentially dependent on temperature; $m$ is the parameter dependent on structural state of welded joint.

The components of the recovery mechanism are the formation, movement and annihilation of spot defects. In the conditions of operating temperatures and stresses the excessive vacancies are mobile. The vacancies move mainly to grain boundaries, to a lesser extent to the boundaries of subgrains and fragments, as well as to dislocations. It is rational to reveal the sink of vacancies to the grain boundaries, which will allow reducing their concentration.

In the process of recovery, the diffusion movement of chromium, molybdenum and vanadium has a directed nature and occurs according to the vacancy mechanism. The self-diffusion is provided by the gradient of chemical potential of the mentioned elements. The effect of self-diffusion of chromium is noticeably pronounced from $530{ }^{\circ} \mathrm{C}$, and that of molybdenum - from $540{ }^{\circ} \mathrm{C}$. Let us note that the coefficients 
of self-diffusion of chromium and molybdenum are variable and depend on their chemical properties, as well as on the creep conditions.

The jumps of chromium and molybdenum atoms in the vacancies (dumbbell mechanism of diffusion) occur at different intensity, which is connected with their self-diffusion coefficients $D_{\mathrm{Cr}}$ and $D_{\mathrm{Mo}}$, which were determined by revealing the level of chromium and molybdenum in segregations [3]. The self-diffusion is represented as a totality of flows of atoms of chromium $I_{\mathrm{Cr}}$, molybdenum $I_{\mathrm{Mo}}$, and also vanadium $I_{\mathrm{v}}$.

In the metal of the considered welded joints as-applied to their time of service over 270 thou h, the plastic deformation exceeds $0.3 \%$, which is characteristic for logarithmic creep. The peculiarity of the transition of welded joints metal from the second to the third stage of creep requires study. Following Andrade [4], describing the deformation with time $t$ according to the parabolic law, let us write the expression for determining the deformation $\varepsilon$ of metal of the welded joints after their time of service over 270 thou h.

$$
\varepsilon=\varepsilon_{0}\left(1+\beta t^{1 / 3}\right) \exp \left(k^{\prime} t\right)
$$

where the factor $\exp \left(k^{\prime} t\right)$ reflects the contribution of the established creep, caused by plastic deformation. The value $\beta$ depends on the stress and temperature, accounts for their excess and change (emergency steam dumping, starts-stops). $\varepsilon_{0}$ is the deformation of welded joints metal up to 270 thou h of their time of service, which is, for example, $0.5 \%$ for the weld metal.

It was assumed that the level of deformation in the subgrain can depend on the density of dislocations which are adjacent to the subgrain. It was established that decrease in the dislocation density leads to decrease in the stress level in the subgrain. Relatively, as the density of dislocations increases, the stress level $\sqrt{n \sigma_{1}}$ increases. At the second stage of the creep, at the presence of self-diffusion of chromium and molybdenum, the displacement of dislocations will occur from the central zones of the $\alpha$-phase grains to their near-boundary regions in an accelerated manner, at the constant working parameters, stress and temperature.

The weakening of metal of HAZ regions of welded joints of steam pipelines during their operation in the creep conditions for $280-290$ thou $\mathrm{h}$ is about 5-8\% [1-8]. Accordingly, the weakening of HAZ partial recrystallization region is about $10-15 \%$ (Figure 2). Let us note that weakening during operation of welded joints over 280 thou h occurs with some acceleration. The nature of the metal deformation of the HAZ regions after operation of 270 thou h, can be linear $[5,6]$ or differ from the linear one (Figure 3 ), which depends on their structural state and requires clarification.

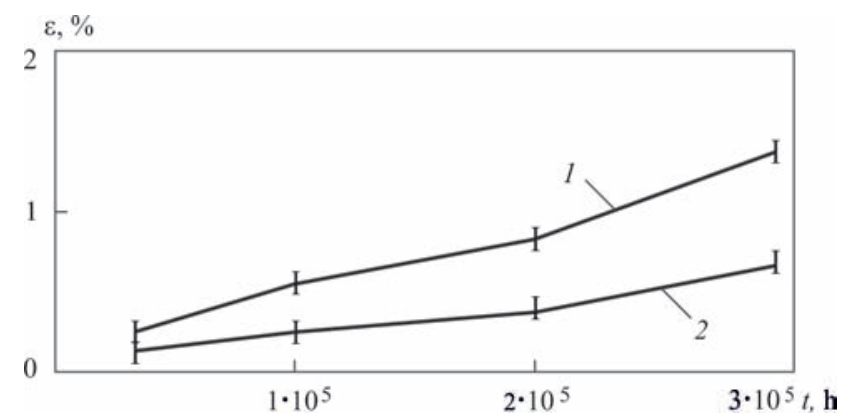

Figure 3. Dependence of deformation $\varepsilon$ on duration of service life of welded joints of steel 15Kh1M1F: 1 - metal of overheating region; 2 - base metal (initial structure — bainite $75 \%$, the rest - ferrite)

In the $\alpha$-phase crystals (structure of the steam pipeline) the dislocation displacement in the process of recovery occurs according to the directions of the diagonals $<$ III $>$, mainly along the totality of dodecahedral planes $\{110\}$. However (to a less extent), the slipping occurs also on the totality of planes $\{$ III $\}$, as well as $\{123\}$. It is necessary to reveal the main combinations of displacement of dislocations in the $\alpha$-phase crystals from 48 possible slipping systems to reduce their velocity. It was established that a characteristic feature of dislocation formation in crystals is short and medium dislocations with the presence of steps. The dislocations of one system, interacting with dislocations of other systems, form loops (Figure 4). The totality of loops is represented as a network of dislocations (Figure 5). The distribution of dislocations in the $\alpha$-phase crystal, at a metal deformation of $0.5-8.0 \%$, is not uniform. In the process of creep, the dislocations moving along the directions $<$ III $>$ and planes $\{$ II2 $\}$ are associated, which leads to the formation of cells corresponding in size (Figure 6). The considered structure is characterized by the presence of «walls» separating the regions with a high dislocation density of $10^{6} \mathrm{~cm}^{-2}$ with the regions where the dislocation density is relatively low and amounts to $10^{5} \mathrm{~cm}^{-2}$. The structural state depends on the normalized energy of packing defects and the deformation level $[9,10]$. With increase in time of service of welded joints, the normalized energy of the packing defects increases, and the number of inner dislocations

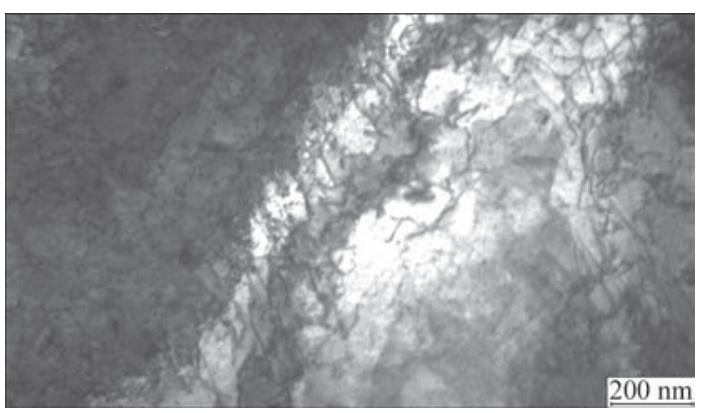

Figure 4. Microstrucutre of overheating region of welded joint HAZ of steel 12Kh1M1F (service life -276 thou h, $\varepsilon=3 \%$ ) 


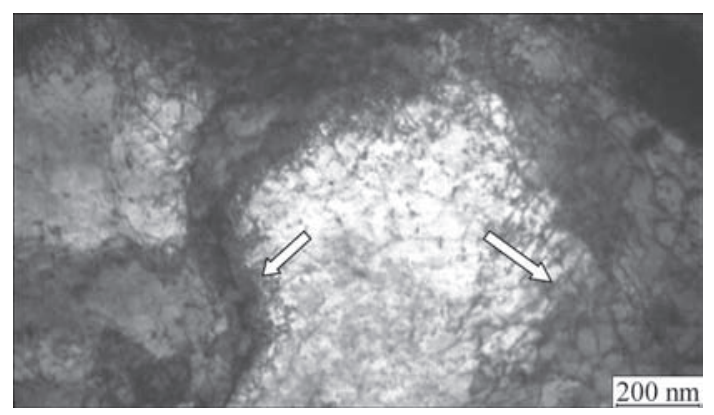

Figure 5. Dislocation structure of weld metal (alloy 10KhMF). Network of dislocations on separate fragments of subgrains of $\alpha$-phase (shown by arrows), $\varepsilon=3 \%$

in the $\alpha$-phase crystal decreases. With increase in the degree of deformation, the average sizes of cells are decreased and the difference in the orientation between neighboring cells is increased.

During operation of welded joints of T-pieces of steam pipelines over 270 thou $\mathrm{h}$ in the creep conditions, the structures, close to globular ones can be formed in the region of HAZ partial recrystallization (Figure 6). Such structures represent regions of bends on the dislocations and are characterized by the presence of deformation heterogeneity, and also contain cells with a different orientation. The dislocation displacement along one of the possible slipping planes is hindered by the newly formed dislocations moving in another system that crosses it, which leads to their common deceleration of displacement. The presence of the second phases also substantially inhibits the displacement of dislocations moving along the possible systems, which depends greatly on their shape and uniform distribution. The velocity of displacement of dislocations in the structure of welded joints is variable and depends on the peculiarities of diffusion movement of chromium and molybdenum, which is rational to study taking into account the formation of their segregations; coming from chromium and molybdenum transition from the $\alpha$-phase grains to carbides. In this case, the nature of deformation of base metal and weld metal is close to linear [5].

It was assumed that a change in the number of dislocations in the $\alpha$-phase crystal leads to the corre-

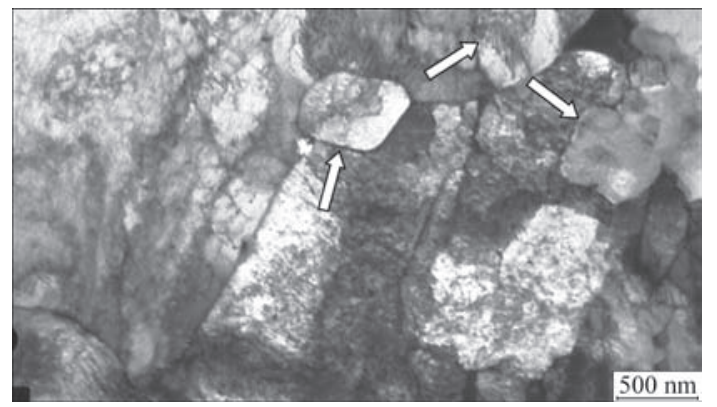

Figure 6. Structure of $\alpha$-phase crystal of overheating region of HAZ of welded joint of steel 12Kh1M1F. The cells different in size are revealed (arrows) (service life -276 thou h, $\varepsilon=7 \%$ ) sponding change in the stress $\sqrt{n \sigma_{1}}$ in it. To activate the sources of dislocations, both existing as well as new ones, the increment of the outer additional stress is not required under the steady creep conditions. There is a decrease in the level of inhibition of dislocations. The structure overheats (emergency steam dumping) were not taken into account. The change in the stress, at which the sources of new dislocations are activated, is $\Delta \sigma=\sqrt{\sigma}$, where $n$ is the number of dislocations in the crystal. A decrease in the density of dislocations in the central region of the $\alpha$-phase crystal, for example, up to $10^{4} \mathrm{~cm}^{-2}$ promotes the reduction in the stress level $\sigma_{1}$ in it. An increase in the strain hardening of the welded joints metal is not occurred.

The linear nature of the deformation, corresponding to the time of service of welded joints to about 270 thou $\mathrm{h}$, confirms that dislocations are displaced by creeping over and slipping at a velocity, close to linear.

Taking the frequency of action of the dislocation sources as $v / n$, let us write the expression for determining the deformation rate of the metal of welded joints [4]:

$$
\dot{\varepsilon} A \frac{v}{n}=A v\left(\frac{\sigma_{1}}{X \varepsilon}\right)^{2},
$$

where $A$ is the coefficient, which depends on the structural state; $X$ is the weakening coefficient; $n$ is the number of dislocation displacements.

Taking into account the number of dislocation sources in the crystal, which vary with time, let us introduce the corresponding clarification to the Mott expression. Let us present:

$$
A=\left(N_{1}+N_{2}\right) K^{2} b^{2} v
$$

where $N_{1}$ are the existing sources of dislocations; $N_{2}$ are the new sources of dislocations; $L$ is the path of dislocations displacement; $b$ is the Burgers vector.

It can be shown that in welded joints of the considered steels, the unsteady stage of creeping corresponds to approximately 50 thou h of their time of service.

As-applied to the considered welded joints, let us write the specified Dorn expression [9], which provided the plotting of the creep curve (Figure 7):

$$
\varepsilon=\varepsilon_{\text {st }}-\varepsilon_{0}=f\left(\dot{\varepsilon}_{\mathrm{st}} t\right)=f\left[\left(\frac{\sigma}{G}\right)^{n} \frac{D_{m} G b}{R T} t\right],
$$

where $D_{m}\left(m_{1} m_{2}\right)$ is, respectively, the diffusion coefficient of chromium and molybdenum; $n$ is the value of sensitivity of the steady creep-to-stress rate; $G$ is the displacement modulus; $\varepsilon_{0}$ is the deformation at the nonsteady stage of creep; $\varepsilon_{\mathrm{st}}$ is the deformation at the steady stage of creep. 
Let us note that the creep curves for the regions of HAZ , as well as of weld metal and base metal, should be plotted separately.

For metal of the steam pipelines of steels $15 \mathrm{Kh} 1 \mathrm{M} 1 \mathrm{~F}$ and $12 \mathrm{Kh} 1 \mathrm{MF}$ the creep limit is equal to $1 \%$ [7]. The metal of HAZ regions during the time of service of welded joints of $250-270$ thou h is deformed approximately from 0.7 to $7 \%[5,7]$. It was established that the deformation of the welded joints metal accumulates predominantly at the second stage of creeping (Figure 7) [7].

At the presence of a level of operating stresses and temperatures $\left(T_{\mathrm{e}}=545-585^{\circ} \mathrm{C}, P_{\mathrm{e}}=25 \mathrm{MPa}\right)$, the creep deformation is caused by creeping over of the dislocations. Wirthman's assumption is confirmed that creep is controlled by the ability of edge dislocations to bypass the obstacles by creeping over. At the established value of $A$ and $n \approx 5$, the dislocation creep model, which envisages the creeping over the edge dislocations, can be described by the more specified Wirthman's equation [10]: $\varepsilon_{\mathrm{st}}=\left(A D_{m} G b / R T(\sigma / G)^{5}\right.$.

It was established that the mechanism of deformation of welded joints metal in the steam pipelines depends on the thermally activated process of dislocation creeping over. An increase in the resistance to creep in the process of recovery is possible by simultaneous realization of the considered mechanisms of inhibition of dislocations displacement. The study of the recovery features will serve as a basis for studying the kinetics of recrystallization, which takes place during the time of service of steam pipelines over 290-300 thou h.

\section{Conclusions}

1. It was established that the deformation and diffusion processes as the constituents of the mechanism of recovery cause the weakening of welded joints metal of steam pipelines operating for a long time under the creep conditions.

2. It was revealed that weakening of the regions of HAZ metal , as well as weld metal and base metal of welded joints of steam pipelines, at their time

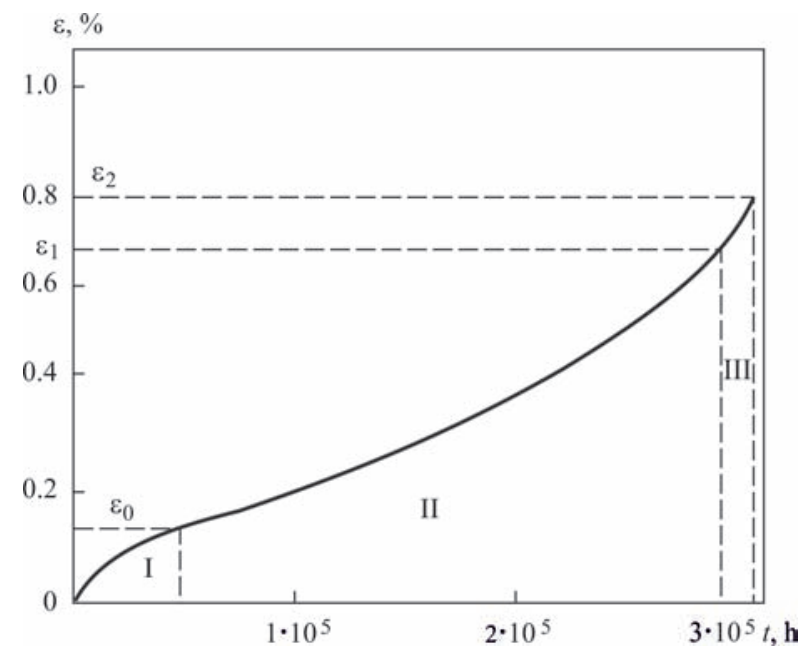

Figure 7. Curve of creep of weld metal (alloy 10KhMF): $\varepsilon_{0}$ - deformation corresponding to the service life of welded joint -50 thou h; I-III — regions corresponding to the stages of creeping

of service over 270 thou $\mathrm{h}$ amounts to $5-8 \%$, which depends on their structural state, as well as on the deformation and diffusion processes.

1. Dmitrik, V.V., Sobol, O.V., Pogrebnoj, M.A. et al. (2015) Peculiarities of degradation of metal in welded joints of steam pipelines. The Paton Welding J., 7, 10-15.

2. Dmitrik, V.V. (2000) Structure of welded joints from low-alloyed heat-resistant Cr-Mo-V pearlitic steels. Ibid., 4, 26-29.

3. Dmitrik, V.V., Syrenko, T.A. (2012) To the mechanism of diffusion of chromium and molybdenum in the metal of welded joints of steam pipelines. Ibid., 10, 20-24.

4. Rozenberg, V.M. (1973) Principles of high-temperature strength. Moscow, Metallurgiya [in Russian].

5. Dmitrik, V.V., Glushko, A.V., Syrenko, T.A. (2017) Structural changes in metal of welded joints after long-term service. The Paton Welding J., 7, 15-18.

6. Dmitrik, V.V., Glushko, A.V., Grigorenko, S.G. (2016) Features of pore formation in welded joints of steam lines in longterm operation. Ibid., 9, 51-54.

7. Khromchenko, F.A. (2003) Service life of welded joints of steam pipelines. Moscow, Mashinostroenie [in Russian].

8. Glushko, A. (2016) Research into defectiveness of welded joints of steam pipes operated over a long time. Eastern-Europ. J. of Enterprise Technologies, 6, 1(84), 14-20.

9. Gottstein, G., Shvindlerman, L.S. (1999) Grain boundary migration in metals: Thermodynamics, kinetics, applications. New York, CRC Press.

10. Humphreys, F.J., Hatherly, M. (1995) Recrystallization and related annealing phenomena. Oxford, Pergamon Press. 


\title{
PROPERTIES OF STEEL-COPPER BIMETAL PRODUCED BY BRAZING IN AUTONOMOUS VACUUM
}

\author{
I.P. SEREBRYANIK, M.G. ATROSHENKO, M.A. POLESHCHUK, A.L. PUZRIN and A.V. SHEVTSOV \\ E.O. Paton Electric Welding Institute of the NAS of Ukraine \\ 11 Kazimir Malevich Str., 03150, Kyiv, Ukraine. E-mail: office@paton.kiev.ua
}

\begin{abstract}
It is determined that brazing of copper on steel under conditions of autonomous vacuum in a contact zone promotes formation of an area of increased microhardness, which is eliminated by standard for steel heat treatment. It is shown that content of carbon in steel does not have significant effect on properties of a copper-steel transition zone. It is stated that interaction of liquid copper with steel does not result in formation of cracks in the joining zone under conditions of brazing in autonomous vacuum. It is determined that increase of time of contact of liquid copper with steel results in formation of brittle structures that decreases joint impact toughness. Failure of steel-copper joint takes place along copper in static tensile tests. At that strength properties of brazed layer exceed reference data for strained and annealed copper. 7 Ref., 2 Tables, 9 Figures.
\end{abstract}

Keywords: brazing of copper on steel in autonomous vacuum, steel-copper bimetal, structure and properties of transition zone

Steel-copper parts, combining strength of steel layer and high heat and electric conductivity of copper, find wide application in metallurgy, shipbuilding, mechanical enginnering and other branches of industry. These are, for example, the big friction bearings of ore-pulverizing mills, hearth-level electrodes of direct current arc furnaces, elements of metallurgical furnace molds. In many commercial machines supply of electric current in thousand and more amperes is carried out by bimetal steel-copper buses which combine structural strength of steel and high electric conductivity of copper.

Depending on designation the bimetal parts are produced in a wide range of thicknesses of cladding as well as base layer. In this connection different methods of copper to steel joining are used, namely explosion welding, diffusion welding, electroslag surfacing, arc and induction surfacing, filling and joint rolling.

A method of manufacture of the bimetal parts of such type by means of brazing of copper on steel under autonomous vacuum conditions was developed in recent time. It differs by high quality of joining and does not require application of special equipment [1].

Taking into account that the steel-copper parts are used, as a rule, in the aggregates with high energy consumption at increased temperatures under conditions of continuous thermal cycling, composition and properties of a copper-steel transition zone can be determining for working capacity of part and assembly in whole.

Different methods of arc surfacing of copper on steel can provoke appearance of microcracks in the joint zone, which are caused by high temperature of electric and plasma arc column as well as joint solidification of copper-steel liquid phase [2-5].

Brazing of copper on steel under conditions of autonomous vacuum is carried out in relatively low temperature not exceeding $1150{ }^{\circ} \mathrm{C}$ and it is only copper in liquid phase during formation of joint. This allows receiving high-quality bimetal joint [1].

Bimetal parts as a strengthening layer often use structural steels, which are close to each other on content of main components and significantly differ only by carbon content. Therefore, evaluation of effect of carbon content in steels on structure and properties of copper-steel transition zone was performed for rational designing of technological process of copper on steel brazing. Electrical steel, steel 20 and steel 45 [6] with carbon content $0.03,0.19$ and $0.42 \%$, respectively, were selected for the experiments.

Investigations were carried out on the samples presented in Figure 1.

Steel bodies of $42 \mathrm{~mm}$ diameter, produced from corresponding steel, include a groove of $4 \mathrm{~mm}$, in which a copper disk of $3 \mathrm{~mm}$ thickness was inserted. The samples were located in a sealed container, which after vacuumization was heated in furnace to $1150{ }^{\circ} \mathrm{C}$ temperature with $30 \mathrm{~min}$ isothermal holding. The microsections were made from the halves of the samples after brazing and cooling for performance of metallographic examinations of steel-copper transition zone. Figure 2 presents microstructures of the transition zones received in brazing of copper on electrical steel (Figure 2, $a$ ), steel 20 (Figure 2, b) and steel 45 (Figure 2, c). 


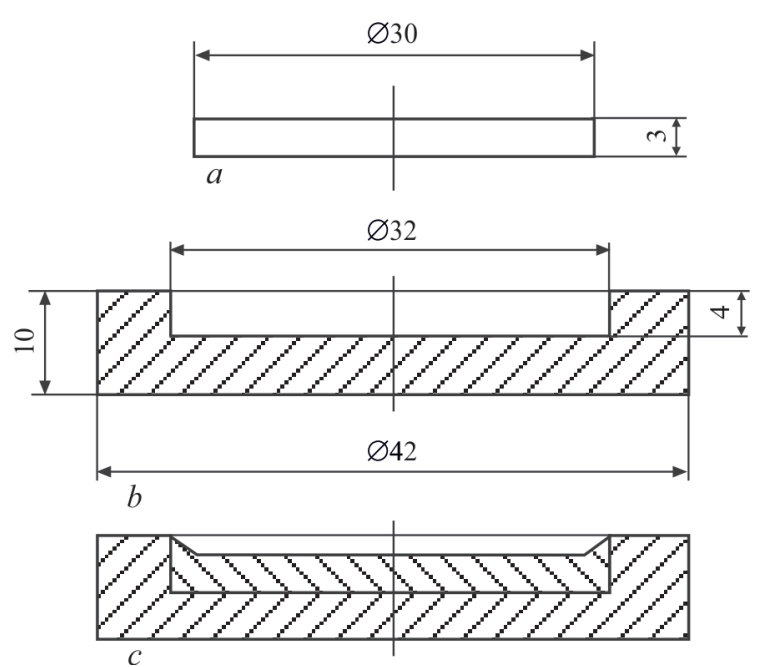

Figure 1. Sample for investigation of interaction of copper melt with steel: $a$ - disk from copper; $b$ - steel body; $c$ - sample section after copper solidification

As it is seen, steel inclusions are observed in all cases in copper at the fusion zone. Increase of carbon content in steel provokes decrease of the amount of such inclusions and, thus, there is reduction of copper penetration along the base metal grain boundaries. Copper melt penetrating in steel along the grain boundaries wraps and tears them (Figure 3).

Further dissolution continues in copper melt. Dendrite base of steel crystallite has, probably, the small-

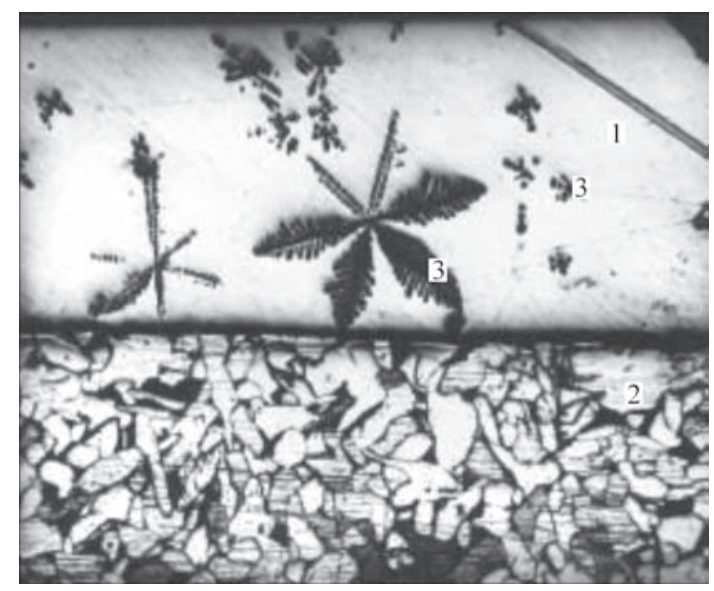

Figure 4. Steel dendrites in copper layer: 1 - copper; 2 - steel; 3 - steel dendrites

est solubility in the liquid copper, therefore, dendrites after solidification are located in the copper layer (Figure 4).

At steel-copper boundary the process of copper penetration and tear of the steel grains with time is again repeated and the fusion zone is displaced to steel side.

There is an opinion that steel cracks under effect of copper melt, which fills the cracks [2-5]. If such a process takes place then there should be on acute-angled area in the crack tip, which will be so narrow that

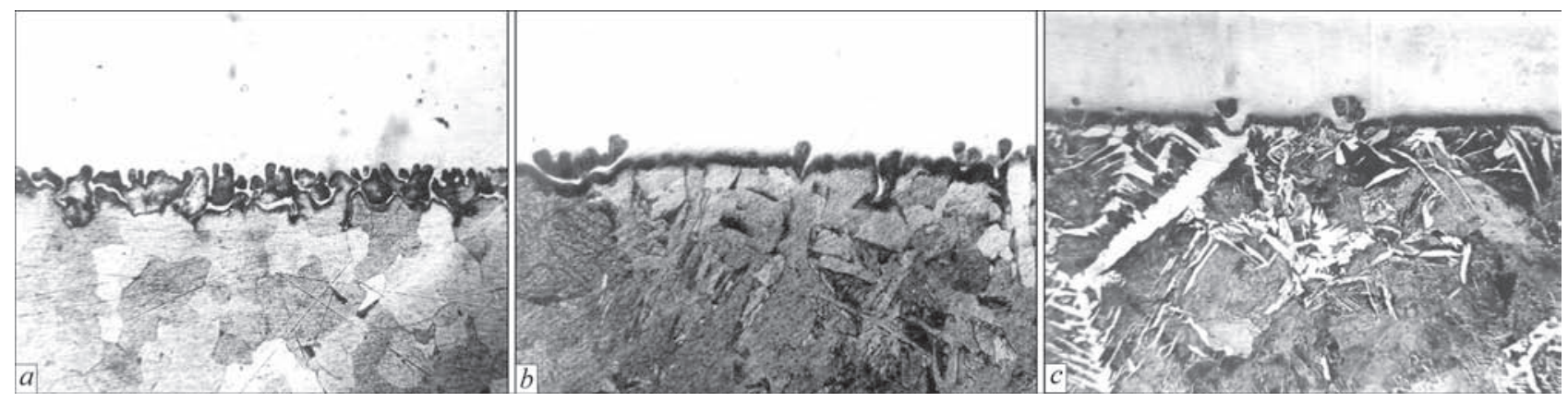

Figure 2. Microstructure $(\times 115)$ of metal of copper-steel joining zone: $a$ - electrical steel; $b$ - steel 20 ; $c$ - steel 45
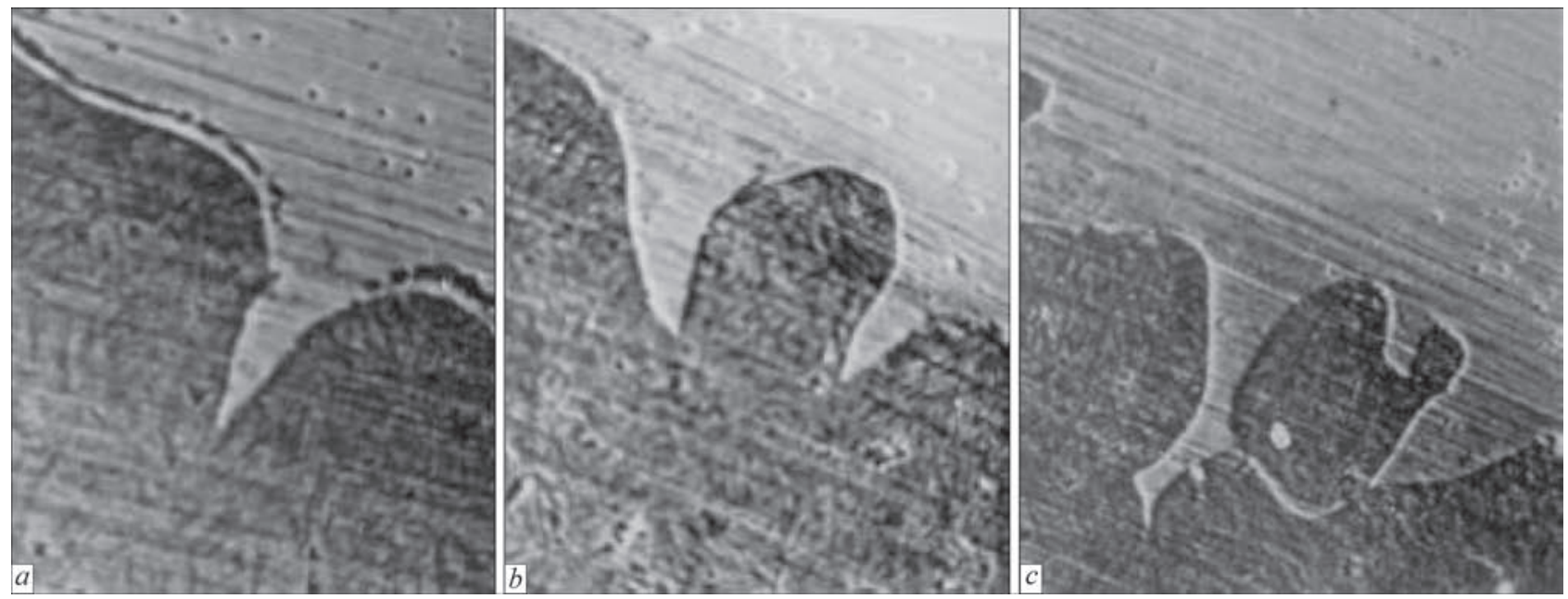

Figure 3. Stages of separation of steel particles by copper melt: $a$ - single penetration; $b$ - double-side penetration; $c$ — completion of steel particle tear 


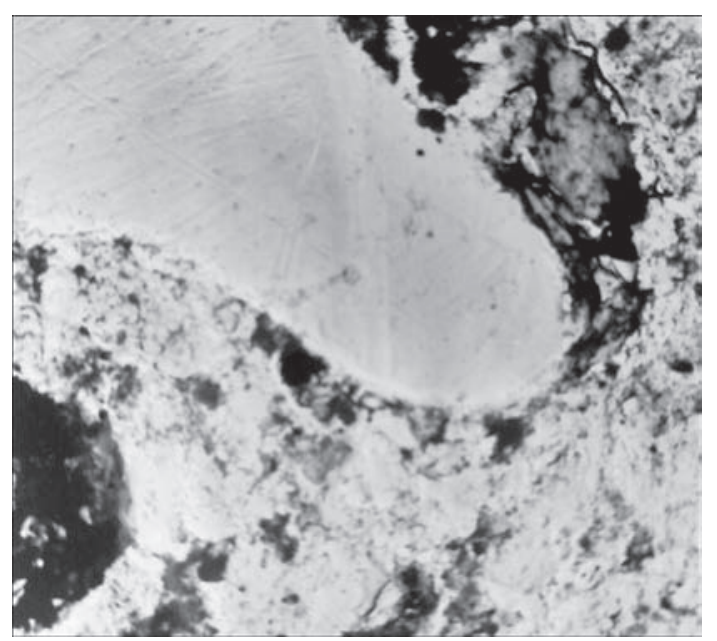

Figure 5. Microstructure $(\times 3000)$ of joining zone at brazing in autonomous vacuum of copper M1 on steel $20\left(T=1150{ }^{\circ} \mathrm{C}\right.$, isothermal holding $30 \mathrm{~min}$ )

due to capillarity conditions liquid copper can not fill it and it will remain empty. Presence of such cracks significantly reduces working capacity of the joint at alternating loads. In order to verify this assumption (type of copper tip penetrated into steel) the samples, received by brazing under autonomous vacuum conditions, were examined using electron microscope at $\times 3000$ magnification (Figure 5).

Tips of copper, penetrated into steel, have smooth curved configuration. There are no cavities. Thus, the hypothesis on steel cracking at contact with liquid copper was not proved by our experiments.

Measurements of microhardness of the steel-copper transition zone were carried out on PMT-3 device. Table 1 gives measurement results. There is a zone of increased microhardness close to the fusion line from steel side. Its extension for electrical steel makes around $80 \mu \mathrm{m}$, for steel 20 it is $50 \mu \mathrm{m}$ and for steel 45 around $25 \mu \mathrm{m}$. Such a zone in process of operation can cause appearance of additional stresses and reduce working capacity of the joint.

In order to eliminate this phenomenon the samples were subjected to heat treatment by standard normalizing mode for corresponding grade of structural steel.

Examination of microsections after heat treatment showed that microhardness of the transition zone was significantly reduced (see Table 1).

As was mentioned above, the fusion zone as a result of interaction of liquid copper with steel displaces into steel side.

Virtual depth of groove using indicator depth gage was registered for evaluation of value of this displacement in sample manufacture (see Figure 1). After brazing a point was made at $3.5 \mathrm{~mm}$ distance from sample upper edge on polished edge of the sample halves with the help of PMT-3 device. Distance from the reference point to visible fusion boundary was determined in the process of microhardness measurement. As a result of measurements it was determined that the displacement of the fusion line made 220-240 $\mu \mathrm{m}$ for electrical steel, $165-251 \mu \mathrm{m}$ for steel 20 and 150-180 $\mu \mathrm{m}$ for steel 45 . Such a difference in displacement values of the fusion line for steels with different content of carbon at interaction of liquid copper with steel during $30 \mathrm{~min}$ shall be declared as insignificant and can be neglected in development of technological processes of copper to steel brazing.

Table 1. Microhardness of metal of transition zone of joint received by autonomous brazing before and after heat treatment

\begin{tabular}{|c|c|c|c|c|c|c|c|c|}
\hline \multirow{4}{*}{ Joint compostion } & \multicolumn{8}{|c|}{ Distance from fusion line, $\mu \mathrm{m}$} \\
\hline & \multicolumn{8}{|c|}{ Copper } \\
\hline & \multicolumn{2}{|c|}{600} & \multicolumn{2}{|c|}{50} & \multicolumn{2}{|c|}{30} & \multicolumn{2}{|c|}{20} \\
\hline & Without $\mathrm{h} / \mathrm{t}$ & After $\mathrm{h} / \mathrm{t}$ & Without $\mathrm{h} / \mathrm{t}$ & After $\mathrm{h} / \mathrm{t}$ & Without $\mathrm{h} / \mathrm{t}$ & After $\mathrm{h} / \mathrm{t}$ & Without $\mathrm{h} / \mathrm{t}$ & After $h / t$ \\
\hline Electr. steel + M1 & 92 & 79 & 93 & 78 & 97 & 66 & 95 & 76 \\
\hline Steel $20+$ M1 & 113 & 87 & 113 & 89 & 115 & 78 & 105 & 92 \\
\hline Steel $45+$ M1 & 93 & 81 & 108 & 81 & 107 & 68 & 116 & 79 \\
\hline
\end{tabular}

Table 1 (cont.)

\begin{tabular}{|c|c|c|c|c|c|c|c|c|c|c|c|c|}
\hline \multirow{4}{*}{ Joint compostion } & \multicolumn{12}{|c|}{ Distance from fusion line, $\mu \mathrm{m}$} \\
\hline & \multicolumn{12}{|c|}{ Steel } \\
\hline & \multicolumn{2}{|c|}{10} & \multicolumn{2}{|c|}{20} & \multicolumn{2}{|c|}{30} & \multicolumn{2}{|c|}{50} & \multicolumn{2}{|c|}{100} & \multicolumn{2}{|c|}{1000} \\
\hline & $\begin{array}{c}\text { Wi- } \\
\text { thout h/t }\end{array}$ & After h/t & $\begin{array}{c}\text { Wi- } \\
\text { thout } \mathrm{h} / \mathrm{t}\end{array}$ & After h/t & $\begin{array}{c}\text { Wi- } \\
\text { thout } \mathrm{h} / \mathrm{t}\end{array}$ & After h/t & $\begin{array}{c}\text { Wi- } \\
\text { thout } \mathrm{h} / \mathrm{t}\end{array}$ & After $\mathrm{h} / \mathrm{t}$ & $\begin{array}{c}\text { Wi- } \\
\text { thout } \mathrm{h} / \mathrm{t}\end{array}$ & After h/t & $\begin{array}{c}\text { Wi- } \\
\text { thout h/t }\end{array}$ & After $h / t$ \\
\hline Electr. steel + M1 & 255 & 116 & 252 & 141 & 237 & 122 & 233 & 114 & 164 & 132 & 153 & 136 \\
\hline Steel 20 + M1 & 270 & 129 & 250 & 143 & 247 & 124 & 230 & 148 & 191 & 135 & 190 & 143 \\
\hline Steel 45 + M1 & 269 & 177 & 261 & 176 & 205 & 170 & 200 & 183 & 213 & 188 & 212 & 182 \\
\hline
\end{tabular}




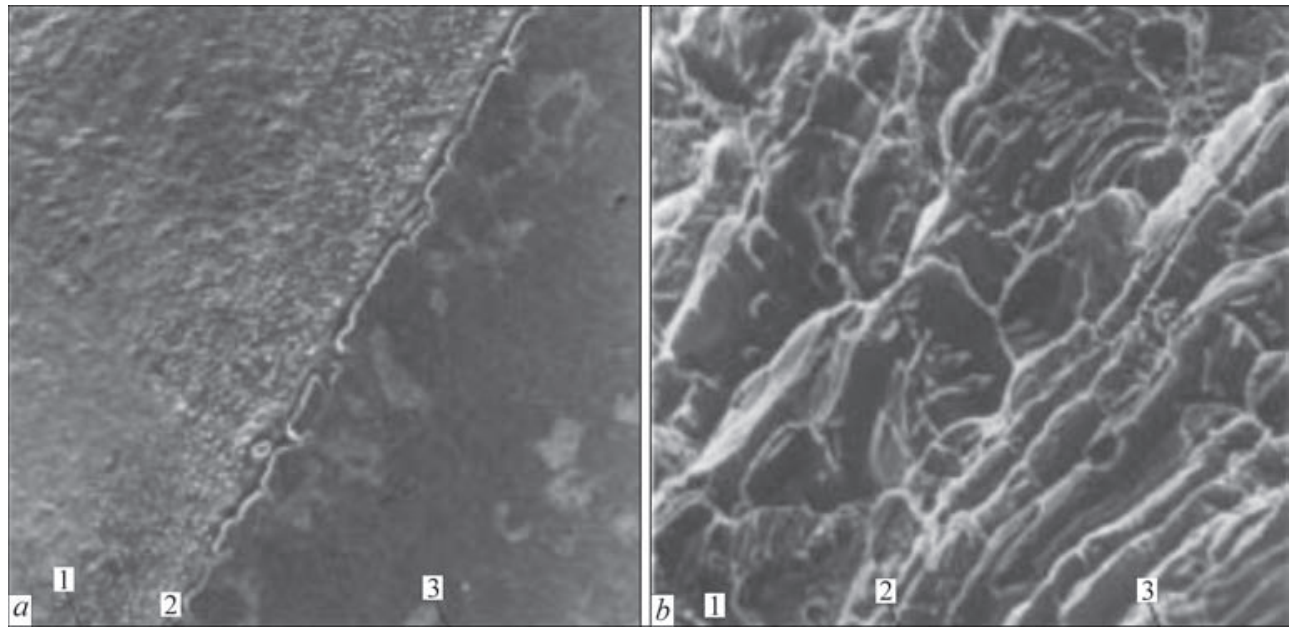

Figure 6. Transition zone of steel-copper joint produced by autonomous vacuum brazing at $T=1150{ }^{\circ} \mathrm{C}$ and 30 min isothermal holding: $a$ - microstructure $(\times 130)$; $b$ - fracture fractogram $(\times 3000)$; 1 - copper; 2 - fusion zone; 3 - steel
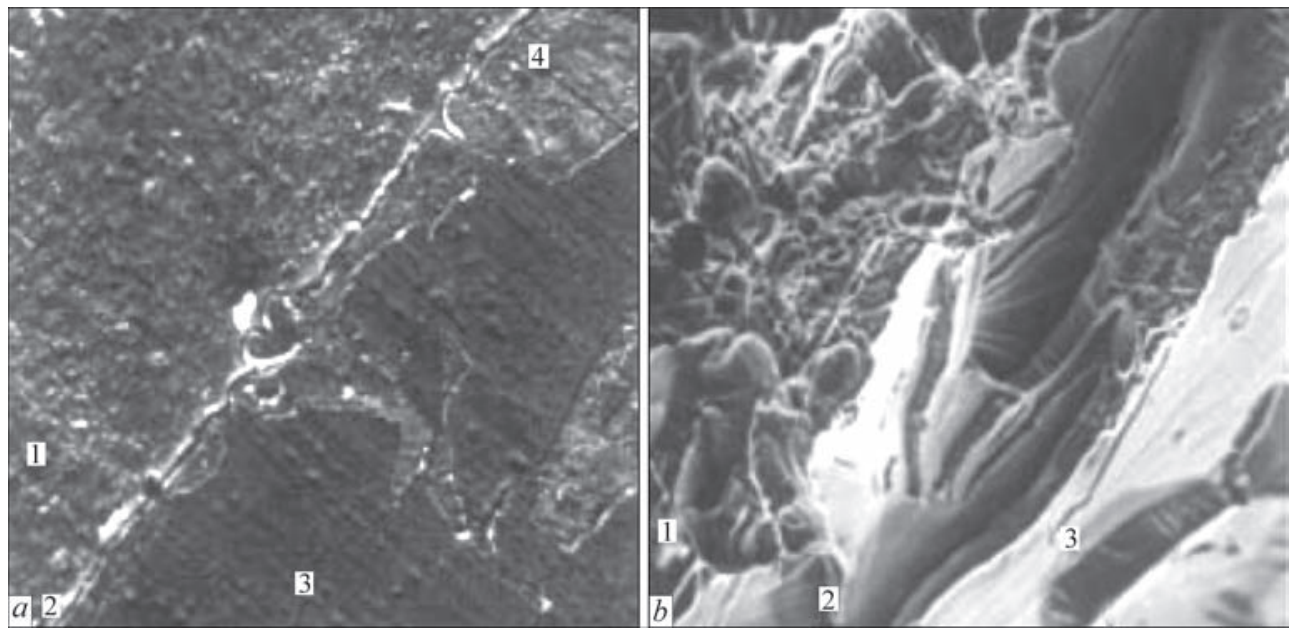

Figure 7. Transition zone of steel-copper joint produced by autonomous vacuum brazing at $T=1150{ }^{\circ} \mathrm{C}$ and $2 \mathrm{~h}$ isothermal holding: $a$ - microstructure $(\times 130)$; $b$ - fracture fractogram $(\times 3000)$; 1 - copper; 2 - fusion zone; 3 — steel; 4 — chain of pearlite grains in steel

Two samples of steel 20 of $150 \times 100 \times 50 \mathrm{~mm}$ size were made in order to determine the optimum time of contact of liquid copper with steel by autonomous vacuum brazing. At that the time of contact of liquid copper with steel at $1150{ }^{\circ} \mathrm{C}$ temperature for one sample made 0.5 and for another $2.0 \mathrm{~h}$. After brazing heat treatment, i.e. normalizing on standard for steel 20 mode, was used. The sharp-notch samples for impact

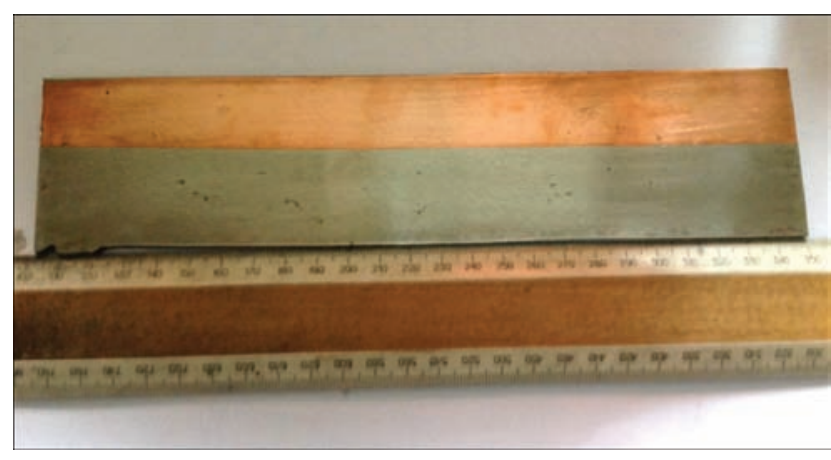

Figure 8. Template of steel-copper plate (thickness of copper layer $40 \mathrm{~mm}$ ) bending tests [7] were received from obtained joints in such a way that a failure plane was located across the joint zone. The samples were of $10 \times 10 \times 55 \mathrm{~mm}$ size, steel thickness $6 \mathrm{~mm}$; copper thickness $4 \mathrm{~mm}$; depth of a notch passing through both layers was $2 \mathrm{~mm}$.

An average value of impact toughness based on the results of tests of three samples made $15.7 \mathrm{~mJ} /$ $\mathrm{m}^{2}$ for holding time $0.5 \mathrm{~h}$ and $13.2 \mathrm{~mJ} / \mathrm{m}^{2}$ for $2.0 \mathrm{~h}$. The sample halves after testing were used for production of sections for fractographic and metallographic examinations. There are fine-dispersed inclusions in the copper layer on microsections of the samples with smaller holding time. Steel consists of a ferrite massif, in which small size grains of pearlite are uniformly

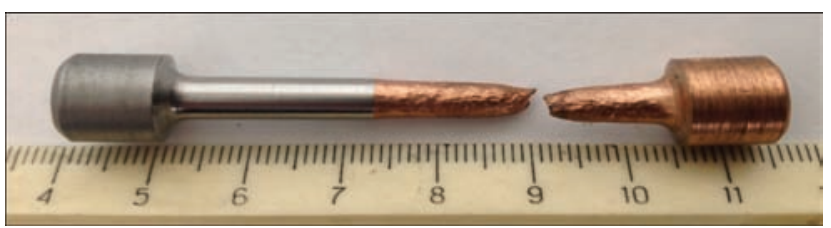

Figure 9. Sample after static tension test 
Table 2. Mechanical properties of steel-copper samples

\begin{tabular}{|c|c|c|c|}
\hline \multirow{2}{*}{ Object and method of investigation } & \multicolumn{3}{|c|}{ Mechanical properties } \\
\hline & $\sigma_{y}, \mathrm{MPa}$ & $\sigma_{\mathrm{t}}, \mathrm{MPa}$ & $\psi, \%$ \\
\hline Static tension test of steel-copper samples (fusion zone) & $\frac{112.6-127.2}{118.1^{*}}$ & $\frac{281.2-282.9}{282.4^{*}}$ & $\frac{71.1-73.8}{72.1^{*}}$ \\
\hline Strained and annealed copper (standard values) & 74 & 216 & 75 \\
\hline
\end{tabular}

located. Failure of copper and steel has tough nature (Figure 6) on the fractures of samples of this series.

The steps of chip are parallel to each other. This indicates that the failure front was uniformly propagated. In the samples with large holding time copper is saturated with fine-dispersed as well as coarse inclusions (Figure 7).

From the steel side along the fusion line there is a continuous chain of coarse pearlite grains. Copper failure has tough nature. At the same time steel failure is brittle and intragranular. Direction of flows indicates that the failure takes place from structural constituents located on the fusion line. With sufficient assurance its can be assumed that pearlite grains were the source of failure. Such nature of failure can have negative effect on joint working capacity and, thus, the time of contact of liquid copper with steel shall be reduced, if possible.

Based on carried investigations the optimum parameters of technological process were selected and autonomous vacuum brazing of plate from steel 20 of $400 \times 500 \times 50 \mathrm{~mm}$ size by copper M1 was carried out. The thickness of copper layer made $40 \mathrm{~mm}$ (Figure 8).

The samples of $40 \mathrm{~mm}$ for static tension tests were produced from the plate. It was done in such a way that the fusion line of copper with steel was located in the middle of sample test portion. During tests the failure took place along copper (Figure 9).

This indicates that a copper-steel contact strength is higher than the copper tension strength. Table 2 gives the results of mechanical tests.
Thus, mechanical properties of tested samples are higher than in strained and annealed copper following reference data.

\section{Conclusions}

As a result of carried work it was experimentally determined that the method of brazing in autonomous vacuum provides high-quality joining of copper with steels having various content of carbon and can be recommended for production of steel-copper products and bimetal billets.

1. Atroshenko, M.G., Poleshchuk, M.A., Shevtsov, A.V. et al. (2015) Physical and mechanical properties of transition zone of bimetal produced by autonomous vacuum brazing of copper on steel. The Paton Welding J., 11, 52-56.

2. Vajnerman, A.E. (1981) Mechanism of intercrystalline penetration in surfacing of copper alloys on steel. Avtomatich. Svarka, 6, 22-26 [in Russian].

3. Asnis, A.E., Prokhorenko, V.M., Shvindlerman, L.S. (1965) About mechanism of crack formation in welding and surfacing of copper on steel. Svarochn. Proizvodstvo, 11, 8-9 [in Russian].

4. Grin, A.G., Zharikov, S.V., Zalesny, D.I. (2016) Improvement of self-shielding flux-cored wire for welding of copper with steel. Vestnik Gos. Mashinostroit. Akademii, 2(16), 90-95 [in Russian].

5. Magnabosco, I., Ferro, P., Bonollo, F., Arnberg, L. (2006) An investigation of fusion zone microstructures in electron beam welding of copper-stainless steel. Mater. Sci. \& Engin., A 424, 163-173.

6. GOST 1050-2013: Metal products from non-alloy structural quality and special steels. General specification [in Russian].

7. GOST 10885-85: Sheet hot rolled two-layered corrosion-resistant steel. Specification [in Russian]. 


\title{
ELECTROSLAG SURFACING OF HIGH-CHROMIUM CAST IRON WITH 110G13L STEEL
}

\author{
Yu.M. KUSKOV, F.K. BIKTAGIROV, T.I. GRISHCHENKO and A.I. EVDOKIMOV \\ E.O. Paton Electric Welding Institute of the NAS of Ukraine \\ 11 Kazimir Malevich Str., 03150, Kyiv, Ukraine. E-mail: office@paton.kiev.ua
}

\begin{abstract}
The paper presents the results of metallographic examination of metal at test surfacing of 110G13L steel samples with high-chromium cast iron shot in current-supplying mould. Possibility of producing sound bimetal joints and features of formation of metal fusion zone at minimum and maximum penetration of base metal are shown. 10 Ref., 1 Table, 6 Figures.
\end{abstract}

Keywords : electroslag surfacing, current-supplying mould, surfacing shot, high-chromium cast iron, 110G13L steel, metal structure

Steel 110G13L has become wide spread at manufacture of different parts of ore mining and smelting equipment subjected to abrasive wear. However, if wear forces are not big in process of operation or thickness of strengthened layer is comparable with abrasive wear, the advantages of this steel do not become apparent and its wear resistance is the same as in common low-alloy steel. Therefore, in this case in order to increase life of worn parts produced form steel $110 \mathrm{G} 13 \mathrm{~L}$ it is desirable not simply restore their sizes, but replace worn part by the materials of increased wear resistance. Among such materials are, in particular, high-chromium cast irons (15-30\% of Cr) [1-4]. And, regardless the fact, that they are characterized with not only increased abrasive wear resistance, but sufficiently high mechanical properties (Table), deposition of such materials with arc surfacing methods is virtually impossible. Such a problem can be solved with the help of electroslag surfacing (ESS).

Numerous works on development of an optimum technology for restoration of parts of steel 110G13L were carried out at Donetsk National Technical University applicable to ESS with high-chromium cast of excavator bucket teeth [5-7]. At that, classical scheme of surfacing of located in the mould billet with electrode melting in slag was used. The authors of developed ESS technology have got a large experience of operation of parts deposited with high-chromium cast iron and have carried out sufficiently detailed study of fusion zone of steel 110G13L and high-chromium cast iron $[8,9]$. Based on the results of this experience and investigations it can be concluded that, firstly, producing the sound bimetal joints of steel and cast iron is sufficiently difficult problem even at electroslag surfacing; secondly, the parts restored using such a technology are good to be used only in absence of significant impact loads $[6,8]$.

Developed at the E.O. Paton Electric Welding Institute technology of electroslag surfacing with discrete material in current-supplying mould (CSM) has specific advantages of effect on the conditions of metal fusion and formation of their crystalline structure in comparison with the surfacing methods in conventional moulds using large-section consumable electrodes. These advantages are determined by the possibility to vary surfacing technological parameters in wider limits as well as by processes of molten metal inoculation (metallic pool) with material being deposited and rotation of the metallic pool caused by CSM design [10].

Therefore, aim of present work was investigation of the structure of deposited high-chromium cast iron and its fusion zone with steel 110G13L at ESS in CSM using discrete filler, namely cast iron shot as a surfacing consumable.

Surfacing was performed in CSM of $180 \mathrm{~mm}$ diameter. The base metal was the billets of $40 \mathrm{~mm}$ thick steel $110 \mathrm{G} 13 \mathrm{~L}$. The discrete filler was shot of 2.5-3.5 mm diameter from high-chromium cast iron (wt.\% $2.4 \mathrm{C} ; 27 \mathrm{Cr}$ ), received by air spraying of liquid metal jet. Surfacing efficiency is around $30 \mathrm{~kg} / \mathrm{h}$.

Properties of deposited and cast high-chromium cast iron $(\sim 3 \% \mathrm{C}$, $16 \% \mathrm{Cr}$ )

\begin{tabular}{|c|c|c|c|c|c|}
\hline \multirow{2}{*}{ Material } & \multicolumn{4}{|c|}{ Mechanical properties } & \multirow{2}{*}{} \\
\cline { 2 - 5 } & $\sigma_{\mathrm{t}}, \mathrm{MPa}$ & $\begin{array}{c}K \mathrm{CU}_{20}, \\
\mathrm{MJ} / \mathrm{m}^{2}\end{array}$ & $\begin{array}{c}\sigma_{\text {bend’ }} \\
\mathrm{MPa}\end{array}$ & $\begin{array}{c}\text { Bending } \\
\text { deflec- } \\
\text { tion, } \mathrm{mm}\end{array}$ & $\begin{array}{c}\text { Hardness } \\
\text { HRC }\end{array}$ \\
\hline Deposited cast iron & 820 & 1.3 & 1650 & 2.9 & $\sim 50$ \\
\hline Cast iron & 420 & - & 280 & 1.7 & $\sim 50$ \\
\hline
\end{tabular}




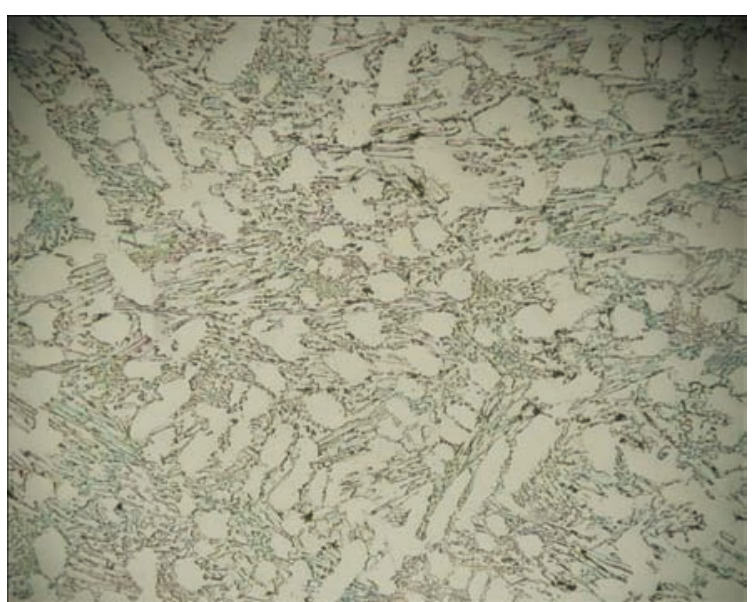

Figure 1. Microstructure $(\times 100)$ of deposited high-chromium cast iron of sample No.1

The samples cut out from the bimetal billets of different level of base metal penetration was investigated. Sample No.1 was of minimum penetration (1-2 mm) and sample No.2 with the maximum (5-7 mm) penetration. A microstructure of deposited layer (high-chromium cast iron) was revealed by electrolytic etching in $20 \%$ water solution of chromium anhydride at $15 \mathrm{~V}$ voltage during $5 \mathrm{~s}$. The microstructure of base metal (steel 110G13L) was revealed by etching in $4 \%$ alchoholic solution of nitrogen acid. The metallographic examinations were carried out using «Epikvant» microscope. Microhardness was measured on PMT-3 device at 100 g loading. Hardness was measured on TK-2M device on Rockwell method.

Examination results. Sample No.1. Microstructure of the deposited metal is primary austenite grains with chromium-carbide eutectic located along their boundaries (Figure 1). Hardness of deposited metal is HRC 44-46. There are also single zones with different structure from 0.5 to $2-3 \mathrm{~mm}$, located approximate-

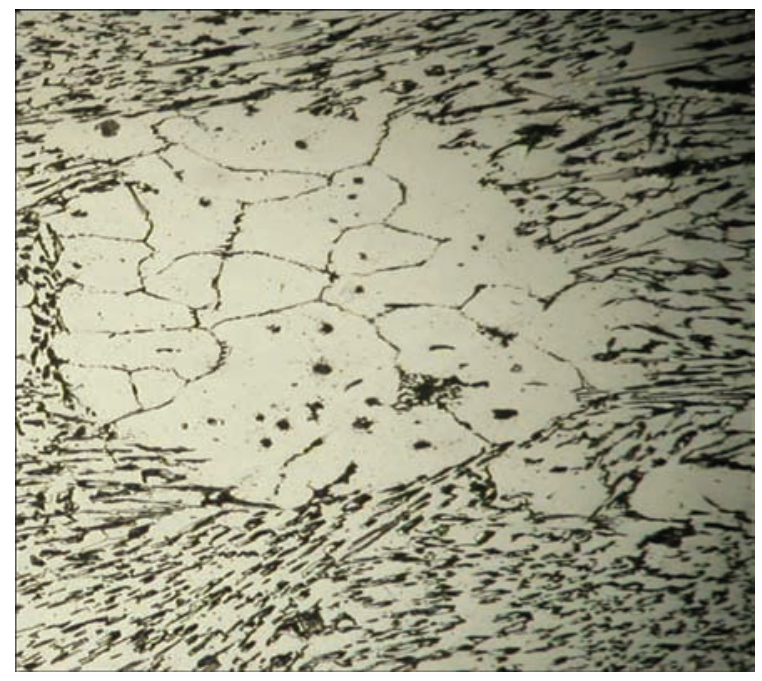

Figure 2. Microstructure $(\times 100)$ of inclusions with coarse austenite grains in deposited high-chromium cast iron of sample No.1

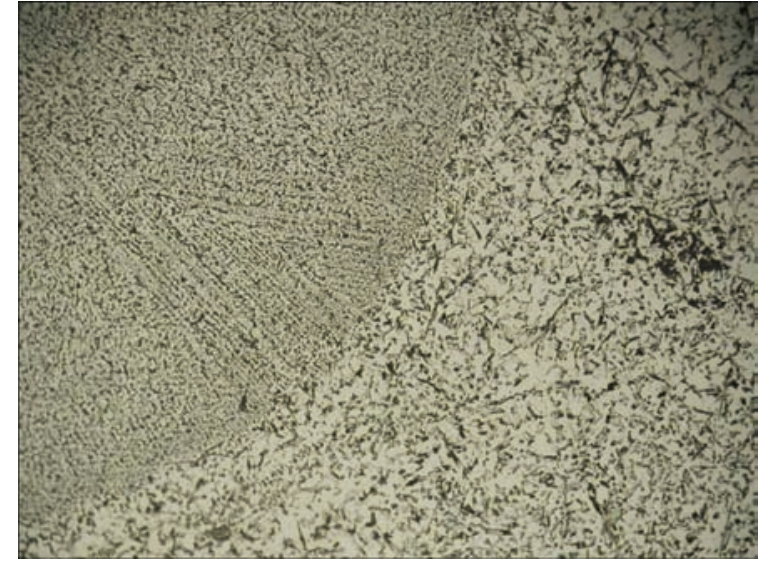

Figure 3. Microstructure $(\times 100)$ of inclusions with fine-crystalline structure in deposited high-chromium cast iron of sample No.1

ly at 5-6 mm distance from the surface of deposited layer and 1-3 mm from fusion zone. Apparently, these zones have similar reasons of origin. The zones with coarse austenite grains (Figure 2) appear due to presence in the shot of significant amount of granules of relatively big size $(\geq 3 \mathrm{~mm})$, structure of metal of which is preserved at their melting in the case of insufficient amount of heat coming to their surface.

The zones with microcrystalline structure (Figure 3) are molten shots of rather small diameter, metal of which does not have time to spread and mix with the rest deposited metal. Appearance of the zones of both types is related with disagreement of mass rate of surfacing shot feeding with its fractional composition and electrolytic mode of surfacing.

The microstructure of base metal is coarse elongated austenite grains, boundaries of which include carbide precipitations. With distance from the fusion line the size and amount of carbides reduce. It can be assumed that such structural changes are related with thermal surfacing cycle as well as mixing the base and deposited metals.

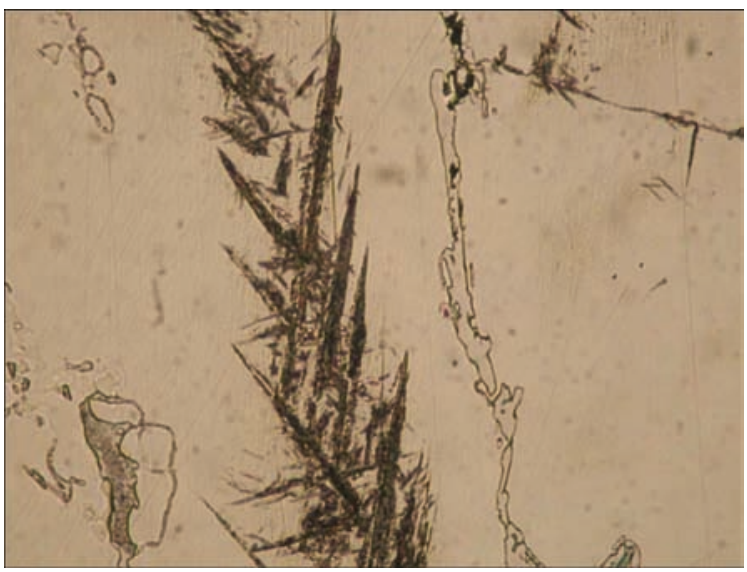

Figure 4. Acicular structure phase in fusion zone of base and deposited metals of sample No.1 $(\times 500)$ 


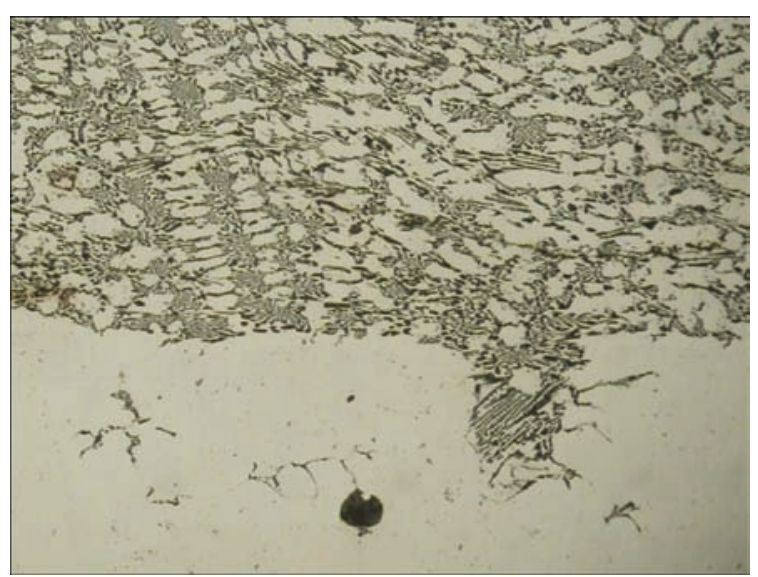

Figure 5. Microstructure $(\times 100)$ of fusion zone of sample No.2 (without etching of base metal)

Bimetal joint is formed by means of smooth transfer of deposited metal to base one, however, there are disordered precipitations of acicular phase (Figure 4) in separate places. Hardness of the fusion zone is low and makes only HRC 18-22 (at base metal hardness HRC 12-15). This assumes absence of significant accumulations of hard and brittle constituents as well as allows considering this zone resistant to increased impact loads. Comparison of the results of this investigation with the results, obtained on the samples deposited by large-section electrode of approximately same composition in conventional mould [10] shows that in the second case increased strength properties of the joints is possible only at additional alloying of cast iron with manganese (to $8 \%$ ) that deteriorates its wear resistance.

Sample No.2 Microstructure of the deposited metal (at thickness of deposited layer around $20 \mathrm{~mm}$ ) is similar to microstructure of sample No.1 metal. Significant changes are observed in the fusion zone of base and deposited metals. This zone contains local inclusions of different size structural constituents of high-chromium cast iron in the metal of base (Figure 5). Also there are defects of cast steel in form of pores (round dark color inclusions). Large amount of various phases (Figure 6) is formed due to significant mixing of steel and cast iron in the fusion zone. Nevertheless, hardness of this zone is relatively low, i.e. HRC 17. Therefore, bimetal joints with rather plastic transition zone can be received even at significant mixing of the base and deposited metals.

Carried investigations show that ESS of parts from 110G13L steel with shot of high-chromium cast iron

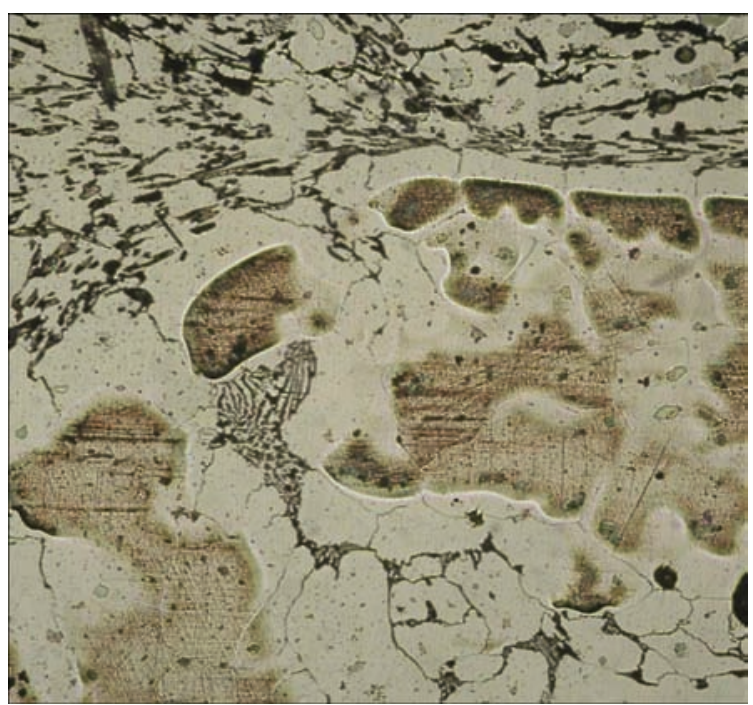

Figure 6. Microstructure $(\times 125)$ of fusion zone of sample No.2 (after etching)

in CSM provides the minimum penetration of metal of the base and allows getting quality bimetal joints with a plastic transition zone from steel to cast iron.

1. Garber, M.E. (1972) Castings from wear-resistant white cast irons. Moscow, Mashinostroenie [in Russian].

2. Tsypin, I.I. (1983) Wear-resistant white cast irons. Structure and properties. Moscow, Metallurgiya [in Russian].

3. Zhukov, A.A., Silman, G.I., Froltsov, M.S. (1984) Wear-resistant castings from complexly-alloyed white cast irons. Moscow, Mashinostroenie [in Russian].

4. Gavrilyuk, V.P., Tikhonovich, V.I., Shalevskaya, I.A., Gutko, Yu.I. (2010) Abrasion-resistant high-chromium cast irons. Lugansk, Knowledge [in Russian].

5. Ponomarenko, V.P., Shvartser, A.Ya., Stojko, V.P. (1984) Properties of alloys for electroslag surfacing of worn parts. In: New processes of surfacing, properties of deposited metal and transition zone. Kiev, PWI, 82-86 [in Russian].

6. Shvartser, A.Ya., Dorokhov, V.V., Ponomarenko, V.P. (1982) Development of methods of electroslag surfacing of excavator bucket teeth. In: Modern methods of surfacing and their application. Ibid., 70-77 [in Russian].

7. Shvartser, A.Ya., Valits, K.A., Stojko, V.P. (1985) Technical and economical efficiency of electroslag technology for restoration of excavator bucket teeth. In: Surfacing. Experience and efficiency of application. Ibid., 62-64 [in Russian].

8. Ponomarenko, V.P., Shvartser, A.Ya., Stroganova, G.V. (1985) Examination of fusion zone of high-chromium cast iron with high-manganese steel in electroslag surfacing. Metallovedenie i Termich. Obrab. Metallov, 11, 55-58.

9. Kiseleva, I.V., Dorokhov, V.V., Shvartser, A.Ya., Gerasimov, E.A. (1989) Regulation of length of transition zone by electroslag heating method. Problemy Spets. Elektrometallurgii, 4, 15-19 [in Russian].

10. Kuskov, Yu.M., Skorokhodov, V.N., Ryabtsev, I.A., Sarychev, I.S. (2001) Electroslag surfacing. Moscow, OOO Nauka i Tekhnologii [in Russian]. 


\title{
APPLICATION OF LEAK BEFORE BREAK CRITERION FOR PREVENTION OF AVALANCHE FRACTURE OF THE WALL OF VERTICAL WELDED TANKS
}

\author{
A.Yu. BARVINKO, Yu.P. BARVINKO, A.N. YASHNIK and V.N. MIRYANIN \\ E.O. Paton Electric Welding Institute of the NAS of Ukraine \\ 11 Kazimir Malevich Str., 03150, Kyiv, Ukraine. E-mail: office@paton.kiev.ua
}

\begin{abstract}
The paper deals with the possibility of improving the performance of oil storage tanks of 50-120 thou $\mathrm{m}^{3}$ capacity through application of normalized sheet steel 09G2SYuch-U390 and 09KhG2SYuch-U440 for design rings of tank wall. A relationship between the length of through-thickness fatigue crack in the butt welded joint of the studied steel and number of tank loading cycles was derived experimentally under the conditions of plane deformation at the initial stage of through-thickness crack propagation. Based on the obtained relationship, it was established that after formation of a through-thickness crack in the welded joint of the wall and appearance of oil leakage, there is sufficient time and conditions for its visual detection and taking measures for elimination of the detected defect. The possibility of application of this method to detect the through-thickness crack is proof of the fact that tanks with design rings from the studied steel satisfy the leak before creak criterion. 19 Ref., 5 Tables, 4 Figures.
\end{abstract}

Ke y w ords : oil storage tanks, fatigue crack, cyclic loading, butt welded joint, avalanche fracture, leak before break criterion

Development of industrial production requires constant increased attention to environment protection. This publication shows in the case of construction of tanks for storage of oil and oil products $(V=50-120$ thou $\mathrm{m}^{3}$ ) the possibility of improvement of environmental safety of these facilities by prevention of development of avalanche fractures in welded joints of the wall at application of normalized sheet steel of C390, C440 strength class with lower carbon content for design rings. In keeping with Ukrainian standards [1], the above facilities belong to the highest criticality class CC3, that is taken into account by introducing the reliability factor $\gamma_{r}=1.25$ into the strength condition. Alongside strength increase, seismic impact accounting standards at construction of new facilities were made more stringent. In the standards [2], some regions of the Carpathian mountings and Odessa region have the seismicity of 8-9 points with the middle (second) category of soils in the construction site, and one point higher at higher category, respectively. Alongside the above provisions, the standard [3] was complemented by an additional requirement for tanks with a protective wall: design of working tank wall should prevent the possibility of its avalanche fracture. Requirements to the quality of rolled sheets and their welded joints were increased. Ultimately, the adopted changes and additions to the normative acts are aimed at ensuring the normative efficiency and ecological safety of the constructed tanks during their entire design operating life. One of the main issues at achievement of the requirements made is ensuring the high performance of butt welded joints of the wall.

New quality normalized steels of C390 and C440 strength class for critical building structures have been developed and put into industrial production in recent years. Assessment of the correspondence of their mechanical characteristics to the requirements of valid standards on tank construction, performed by the E.O. Paton Electric Welding Institute of the NAS of Ukraine (PWI), allowed finding and proposing new approaches to solving a number of issues on improvement of the wall performance. Table 1 also gives the main characteristics of rolled sheets $16-40 \mathrm{~mm}$ thick of 390, 440 strength class, recommended by the USA, EU and Ukrainian standards [3-6] for the main metal structures of tanks of 20-120 thou $\mathrm{m}^{3}$ capacity. The main requirements of the standards for sheet steel are also given there: sheet delivery condition, carbon content, impact toughness $K C V_{-40}, \sigma_{y} / \sigma_{t}$ ratio.

One can see from the Table data, that API 650 standard [4] presents two steels: A537 and A678 with delivery of quenched and tempered (QT) sheet. Steels meet all the requirements, except for rather high carbon content: $0.24 ; 0.20 \%$. Eurostandard is represented by steels after normalizing rolling C420 and $\mathrm{C} 460$ [5] with carbon content of $0.18-0.22 \%$ and $\sigma_{\mathrm{y}} / \sigma_{\mathrm{t}}$ ratio equal to $0.81-0.62$ at not more than 0.75 norm [3]. The Table also gives an example of application of normalized steel 18G2AV/E440R-N, improved by ladle treatment (LT), for the wall of 75 
Table 1. Recommended steel grades for the main metal structures of large capacity tanks in keeping with USA, EU and Ukrainian standards

\begin{tabular}{|c|c|c|c|c|c|c|c|c|c|}
\hline $\begin{array}{c}\text { Name of the stan- } \\
\text { dard for tank design } \\
\text { (country of the } \\
\text { standard } \\
\text { validity) }\end{array}$ & $\begin{array}{l}\text { Designation of recom- } \\
\text { mended steel, sheet } \\
\text { thickness }\end{array}$ & $\begin{array}{l}\text { Normative doc- } \\
\text { ument for steel } \\
\text { delivery }\end{array}$ & $\begin{array}{c}\text { As-re- } \\
\text { ceived } \\
\text { condition* }\end{array}$ & $\begin{array}{l}\text { Carbon } \\
\text { content, } \\
\%(\max )\end{array}$ & $\sigma_{y}, \mathrm{MPa}$ & $\sigma_{\mathrm{t}}, \mathrm{MPa}$ & $\delta_{5}, \%$ & $\begin{array}{c}\mathrm{KCV} \text { in } \\
\text { keeping with } \\
\text { normative } \\
\text { document for } \\
\text { steel delivery, } \\
\mathrm{J} / \mathrm{cm}^{2} / T_{\text {test }},{ }^{\circ} \mathrm{C}\end{array}$ & $\sigma_{\mathrm{y}} / \sigma_{\mathrm{t}}$ \\
\hline \multirow{3}{*}{$\begin{array}{l}\text { API } 65011^{\text {th }} \\
\text { edition (USA) }\end{array}$} & $\begin{array}{l}\text { A537M class } 2 \\
\mathrm{C} 415, t \leq 45 \mathrm{~mm}\end{array}$ & $\begin{array}{c}\text { Specification } \\
\text { ASTM A537/ } \\
\text { A537M } \\
\end{array}$ & $\mathrm{Q} / \mathrm{T}$ & 0.24 & 415 & $550-690$ & 22 & $34 /-68$ & $0.75-0.60$ \\
\hline & $\begin{array}{l}\text { A678M grade B, } \\
\mathrm{C} 415, t \leq 45 \mathrm{~mm}\end{array}$ & $\begin{array}{c}\text { Specification } \\
\text { ASTM A678/ } \\
\text { A678M }\end{array}$ & $\mathrm{Q} / \mathrm{T}$ & 0.20 & 415 & $550-690$ & 22 & $34 /-68$ & $0.75-0.60$ \\
\hline & $\begin{array}{l}\text { A841M grade B class } 2 \\
\quad \mathrm{C} 415, t \leq 40 \mathrm{~mm}\end{array}$ & $\begin{array}{c}\text { Specification } \\
\text { ASTM A841/ } \\
\text { A841M } \\
\end{array}$ & TMCR & 0.15 & 415 & $550-690$ & 22 & $34 /-68$ & $0.75-0.60$ \\
\hline \multirow{2}{*}{$\begin{array}{l}\text { EN 1993-4- } \\
\text { 2:2007 } \\
\text { EN 14015:2004 } \\
\text { (EC countries) }\end{array}$} & $\begin{array}{l}\text { EN } 10025-3-S 420 \mathrm{~N} \\
\mathrm{C} 420,16<t \leq 40 \mathrm{~mm}\end{array}$ & EN 10025-3:2004 & $\mathrm{N}$ & 0.22 & $\begin{array}{l}420 \\
400\end{array}$ & $520-680$ & 19 & $25 /-20$ & $0.81-0.62$ \\
\hline & $\begin{array}{l}\text { EN 10025-3-S420NL, } \\
\text { C420, } 16<t \leq 40 \mathrm{~mm}\end{array}$ & EN 10025-3:2004 & $\mathrm{N}$ & 0.22 & $\begin{array}{l}420 \\
400\end{array}$ & $520-680$ & 19 & $\begin{array}{l}34 /-20 \\
25 /-40 \\
20 /-50 \\
\end{array}$ & $0.81-0.62$ \\
\hline \multirow{5}{*}{$\begin{array}{l}\text { Steels not includ- } \\
\text { ed into the list } \\
\text { of recommended } \\
\text { ones, but which } \\
\text { are applied in } \\
\text { tank construction }\end{array}$} & $\begin{array}{l}\text { 18G2AV/E440R-N, } \\
\text { C440, } 16<t \leq 30 \mathrm{~mm}\end{array}$ & PN-86/H-84018 & LT, N & 0.20 & 430 & $560-720$ & 18 & \begin{tabular}{|c|}
$83 /-40-$ \\
factory certif- \\
icate data
\end{tabular} & $0.77-0.60$ \\
\hline & $\begin{array}{c}\text { 06GB } \\
\mathrm{C} 390,8<t \leq 50 \mathrm{~mm}\end{array}$ & \multirow{2}{*}{$\begin{array}{c}\text { TU Y 27.1- } \\
05416923- \\
085: 2006\end{array}$} & \multirow{2}{*}{ LT, Q/T } & 0.08 & 390 & 490 & 22 & \multirow{2}{*}{$\begin{array}{c}123 /-40 \\
98 /-60 \\
74 /-70\end{array}$} & 0.80 \\
\hline & $\begin{array}{c}\text { 06G2B } \\
\mathrm{C} 440,8<t \leq 50 \mathrm{~mm} \\
\end{array}$ & & & 0.08 & 440 & 540 & 22 & & 0.81 \\
\hline & $\begin{array}{c}\text { 09G2SYuch-U } \\
\text { C390, } 8<t \leq 50 \mathrm{~mm}\end{array}$ & \multirow{2}{*}{$\begin{array}{l}\text { TU 14-1- } \\
\text { 5065:2006 Mod- } \\
\text { ification No.1 of } \\
\text { 01.03.2012 }\end{array}$} & \multirow[b]{2}{*}{ LT, N } & 0.13 & 390 & 530 & 18 & $\begin{array}{l}60 /-40 \\
30 /-70\end{array}$ & 0.74 \\
\hline & $\begin{array}{c}\text { 09G2SYuch-U } \\
\text { C440, } 20<t \leq 32 \mathrm{~mm} \\
\text { C440, } 32<t \leq 60 \mathrm{~mm}\end{array}$ & & & 0.11 & $\begin{array}{l}440 \\
410\end{array}$ & $\begin{array}{l}590 \\
570\end{array}$ & 18 & $\begin{array}{l}60 /-40 \\
30 /-70\end{array}$ & $\begin{array}{l}0.75 \\
0.72\end{array}$ \\
\hline
\end{tabular}

"Designations of as-received condition of steel: Q/T — quenching plus tempering; LT — ladle treatment; TMCR - thermomechanical controlled rolling; Q/HT — quenching with high tempering; N — normalizing; TH — thermal hardening.

thou $\mathrm{m}^{3}$ tanks [7]. After improvement, $K C V_{-40}$ values were equal to not less than $96 \mathrm{~J} / \mathrm{cm}^{2}$ that is almost two times higher than the initial values. Ukraine is represented by 06GB rolled sheets with $\sigma_{\mathrm{y}} / \sigma_{\mathrm{t}}=0.90-0.85$, delivered in QT condition, and two normalized steels 09G2SYuch-U390 and 09KhG2SYuch-440 [8] with carbon content of $0.11-0.13 \%$ and $\sigma_{\mathrm{y}} / \sigma_{\mathrm{t}}$ ratio of not more than 0.75 .

Steels 09G2SYuch and 09KhG2SYuch [9] were developed in 1982-1984 by PWI initiative, together with Metallurgical Works «Azovstal» (Ukraine) and «Severstahl» (Russia). Sheet steel 09G2SYuch was developed at the first stage. By its properties it should correspond to general purpose steels and should be an alternative of steels 09G2S, 16GS, 20K in fabrication of high pressure vessels. The main requirements to the new steel were higher strength (390 class), high cold resistance $\left(K C V_{-40} \geq 60 \mathrm{~J} / \mathrm{cm}^{2}\right)$, low sensitivity to overheating at electroslag welding of $40-120 \mathrm{~mm}$ thick sheets. Development of the new steel was based on low-alloyed general-purpose steel 09G2S. The ad- vantages of the new steel were ensured by its optimum alloying and production technology: increased manganese content, additional alloying with aluminium and cerium, in combination with ladle treatment. The process of new steel development, its production technology and results of its successful application for manufacture of high pressure welded vessels of 40-110 $\mathrm{mm}$ thickness are quite fully described by the steel developers in [10]. The achieved positive effect of application of steel 09G2SYuch allowed the authors to optimize its composition further on by additional alloying of steel with approximately $1 \%$ chromium. New steel 09KhG2SYUch of C440 strength class [11] was produced. Increase of chromium content in the steel significantly increased its impact toughness, improved its strength and cold resistance in the heat-affected zone (HAZ) at electroslag welding that allowed replacing post-weld normalizing of the vessels by high tempering $[10,11]$. New steels of improved modification have been designated 09G2SYuch-U and 09KhG2SYuch-U, 390 and 440 strength classes, 
and they were produced to TU specification [9]. In 2011, by the initiative of PWI and FGUP «I.P. Bardin TSNIIchermet» Modification No.1 to this specification was developed that allowed achieving mechanical properties of steels [8] in full compliance with the requirements of standards [3-5] for tanks for storage of oil and oil products.

In [12] it is shown that high ductility properties of normalized sheet steel 09G2SYuch-U allow eliminating high tempering of assemblies for tapping branch pipes and manholes at tank wall thickness of up to $30 \mathrm{~mm}$, and detecting through-thickness fatigue cracks at the initial stage of their propagation with application of leak before break criterion. In this publication, based on the results of performed experimental studies of welded joints of normalized sheet steel 09KhG2Syuch-U, including base metal, it is shown that similar capabilities are also available in the tank wall at application of this steel for design rings.

In Ukraine steel production in keeping with the specification [8] has been mastered by MW «Azovstahl», and PWI developed welding technology provides their mechanical properties on the level of those of base metal. Standard values of impact toughness of rolled sheets are $K C V_{-40} \geq 60 \mathrm{~J} / \mathrm{cm}^{2}$ for $20-32 \mathrm{~mm}$ thickness. At delivery of sheets $t=26 \mathrm{~mm}$ of steel 09G2Yuch-U for two tanks of 50 thou ${ }^{3}$ capacity, $K C V_{-40}$ certificate data were not lower than $148 \mathrm{~J} / \mathrm{cm}^{2}$.

The need for additional technical proposals for guaranteed prevention of avalanche fractures of welded joints of the wall of inner tank (for tanks with a protective wall) in the standard [3] is the consequence of the arisen need for construction of a considerable number of such tanks of 50-100 thou $\mathrm{m}^{3}$ capacity.
Elimination of dyking around the tanks in the absence of actual data on fulfillment of this function by the protective wall, necessitated envisaging additional measures on improvement of performance of the wall of the main (inner) tank. Allowing for new requirements of the normative documents, this work gives an analysis of the results of research performed at PWI of the possibility of prevention of avalanche fractures through application of leak before break criterion for design rings of the wall of tanks of 20-120 thou $\mathrm{m}^{3}$ capacity at application of normalized rolled sheets of steel 09Kh2SYuch-U.

Theoretical fundamentals of the possibility of elimination of avalanche fracture of the wall in metal tanks for liquid storage by its outflowing from the formed crack are given in [13], and an overview of the current status of this issue - in [14]. Work [13] deals with a surface fatigue crack of approximately $2 t$ length, which grows during cyclic loading, and reaches the wall opposite side. A leak of the stored liquid through the through-thickness crack develops, that allows visually detecting the defect. It is important to have enough time to detect the formed through-thickness crack before it has reached its critical size, and to take measures to eliminate the detected defect, i.e. prevent the avalanche fracture. Such an elimination of avalanche fracture was called «by the leak before break» criterion. In [14] it is noted that the literature data do not give sufficient information on the considered criterion as regards its application in tanks for storage of oil and other structures. In each individual case special experimental studies should be performed.

Reference [12] gives the results of investigation of welded joints of steel 09G2SYuch-U and their testing program. Considered investigations of welded joints
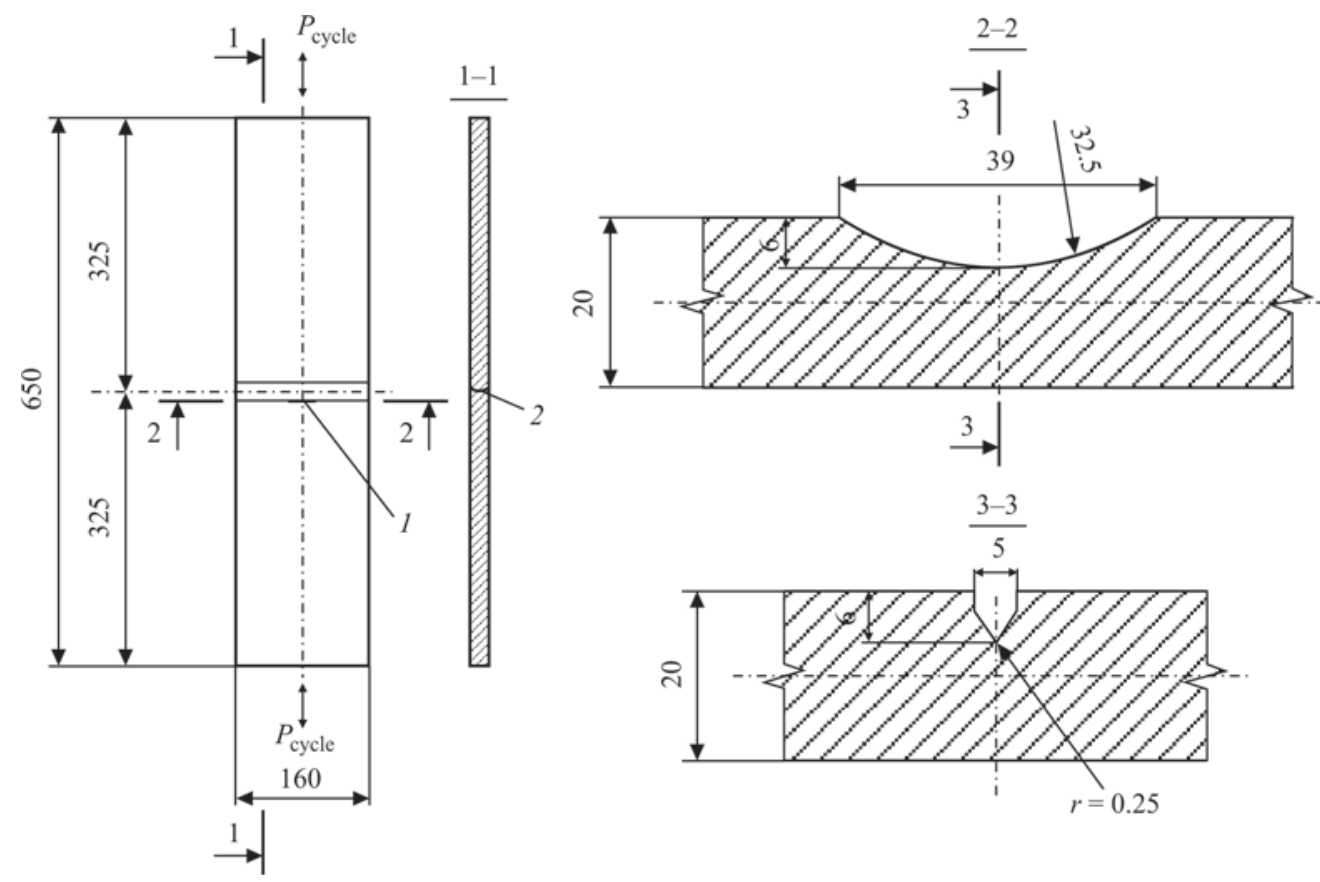

Figure 1. Schematic of a sample for testing welded joints of steel 09KhG2SYuch-U for resistance to fatigue crack propagation: 1 notch in the HAZ; 2 - weld reinforcement was removed on both sides 
Table 2. Chemical composition of studied steel 09KhG2SYuch-U, wt.\%

\begin{tabular}{|c|c|c|c|c|c|c|c|c|c|}
\hline \multirow[b]{2}{*}{ Steel grade } & \multirow[b]{2}{*}{$\mathrm{C}$} & \multirow[b]{2}{*}{$\mathrm{Si}$} & \multirow[b]{2}{*}{ Mn } & \multirow[b]{2}{*}{$\mathrm{Cr}$} & \multirow[b]{2}{*}{$\mathrm{Al}$} & $\mathrm{S}$ & $\mathrm{P}$ & $\mathrm{Cu}$ & $\mathrm{Ni}$ \\
\hline & & & & & & \multicolumn{4}{|c|}{ Not more than } \\
\hline $\begin{array}{l}\text { 09KhG2SYuch-U } \\
\text { TU 14-5065-2006 } \\
\text { (modification No.1) }\end{array}$ & $0.10-0.13$ & $0.50-0.80$ & $1.9-2.2$ & $1.0-1.30$ & $0.04-0.08$ & 0.030 & 0.030 & 0.30 & 0.30 \\
\hline 09KhG2SYuch-U (studied) & 0.10 & 0.50 & 1.84 & 0.96 & 0.03 & 0.002 & 0.002 & 0.05 & 0.12 \\
\hline $\begin{array}{l}\text { 09G2SYuch-U } \\
\text { TU 14-5065-2006 } \\
\text { (modification No.1) }\end{array}$ & $0.08-0.11$ & $0.30-0.60$ & $1.9-2.2$ & $\begin{array}{c}\text { Not more than } \\
0.30\end{array}$ & $0.04-0.08$ & 0.030 & 0.030 & 0.30 & 0.30 \\
\hline 09G2SYuch-U (data from [12]) & 0.11 & 60 & 2.1 & 0.11 & 0.08 & 0.011 & 0.015 & 0.05 & 0.21 \\
\hline
\end{tabular}

of steel 09KhG2SYuch-U were also performed by this program with addition and allowing for some features of the tested steel. The program included testing at cyclic loading of three samples with a transverse butt weld (Figure 1). Transverse butt weld simulated the vertical butt weld of the joint of $20 \mathrm{~mm}$ wall sheets with K-shaped groove. The composition and mechanical properties of sheet steel 09KhG2SYuch-U are given in Tables 2, 3. When making the weld, the root pass was welded with LB52U electrodes of $2.5 \mathrm{~mm}$ diameter, and filling passes - with FOX EV63 electrodes of $3.0 \mathrm{~mm}$ diameter. Cooling rate $w_{5 / 6}$ was equal to $10-15^{\circ} \mathrm{C} / \mathrm{s} . K C V_{-40}$ values in as-welded condition were equal to: 113.5-116.5 (fusion line) and 104.9$156.7 \mathrm{~J} / \mathrm{cm}^{2}$ (weld metal). For comparison the Tables give similar data for steel 09G2SYuch-U from [12].

The objective of the research consisted in establishing a relationship between the crack length and number of cycles of tank filling-emptying in the initial section of formation and propagation of a through-thickness fatigue crack in the vertical butt welded joint of steel 09KhG2SYuch-U of the tank wall and showing that the obtained relationship of fatigue crack propagation in the wall of an oil-filled tank allows safely detecting a fatigue crack by leak before break criterion before fracture, and timely taking measures on liquidation of the defected defects.

Maximum force $P_{\max }$ of cyclic loading of the sample was assumed, taking into account that the stress in the sample $\sigma=2 / 3 \sigma_{\mathrm{y}}$ of steel, and $P_{\min }=0.1 P_{\max }$. Stress $2 / 3 \sigma_{\mathrm{y}}$ corresponds, according to [3, 4$]$, to maximum design hoop stresses in the tank wall. Actual dimensions of the cross-section were allowed for in each sample. Initiation of a fatigue crack along the fusion line was induced by application of a sharp notch of more than $6 \mathrm{~mm}$ depth and $39 \mathrm{~mm}$ length (Figure 1). During its growth through the wall thickness, according to fatigue fracture diagram (FFD) (see Figure 2), the macrocrack passed the section of its stable development, moved to the unstable propagation section, and reached the opposite side. The latter section of critical propagation of a through-thickness crack under plain strain conditions (Figure 3, $a$ ), is characterized by a high rate of its propagation (see Figure 2). In the used samples the length of this section is limited by the extent of plane strain zone. One can see from Figure 3, $b$, that after the crack has reached the length of approximately $35 \mathrm{~mm}$, lines of steel contraction across the thickness (of the type of moiré fringes) appear at its tips that is indicative of transition of metal ahead of the crack into the plain stress state. This is the consequence of $\sigma_{\max }$ value abruptly becoming close to $\sigma_{y}$ value of steel at reduction of the area of the sample net cross-section. Development of the surface fatigue crack in the vertical welded joint on the real tank wall will proceed at an actually constant level of hoop stresses, right up to the formed through-thickness fatigue crack reaching its critical length $l_{\text {cr }}=$ $=2 a_{\mathrm{cr}} \approx 250-300 \mathrm{~mm}$. For this testing it is important for the process of initial growing of the crack through the thickness, its reaching the opposite surface of the sample and the initial stage of through-thickness crack propagation under the conditions of plane strain to be largely similar to running of this process in the

Table 3. Mechanical characteristics of rolled sheets of steel 09KhG2SYuch-U440 23 mm thick

\begin{tabular}{|c|c|c|c|c|c|c|c|c|}
\hline $\begin{array}{l}\text { Num- } \\
\text { ber }\end{array}$ & Melt number & $\begin{array}{c}\text { Sheet thick- } \\
\text { ness, mm }\end{array}$ & $\sigma_{y}, \mathrm{MPa}$ & $\sigma_{\mathrm{t}}, \mathrm{MPa}$ & $\delta_{5}, \%$ & $\psi_{z}, \%$ & $\sigma_{\mathrm{y}} / \sigma_{\mathrm{t}}$ & $K C V_{-40}, \mathrm{~J} / \mathrm{cm}^{2}$ \\
\hline 1 & Studied steel 09KhG2Yuch-U & 23 & $\begin{array}{l}472.1 \\
472.9\end{array}$ & $\begin{array}{l}768.6 \\
768.2\end{array}$ & $\begin{array}{l}22.5 \\
22.7\end{array}$ & $\begin{array}{l}47.8 \\
41.0\end{array}$ & 0.61 & $\begin{array}{l}205.0 / 135.7^{* *} \\
196.4 / 100.1^{* *} \\
199.0 / 121.1^{* *}\end{array}$ \\
\hline 2 & To TU 14-1 5065-2006 Modifica- & $20-32$ & 440 & 590 & 18 & - & $\leq 0.75$ & 60 not less than \\
\hline 3 & $\begin{array}{l}\text { tion 1. Delivery type: normalizing } \\
\text { 09G2SYuch-U }\end{array}$ & $20-32$ & 390 & 530 & 18 & - & $\leq 0.75$ & 60 not less than \\
\hline 4 & 09G2SYuch-U* Data from [12] & 20 & 415 & 550 & 29 & 56 & 0.75 & 156 \\
\hline
\end{tabular}




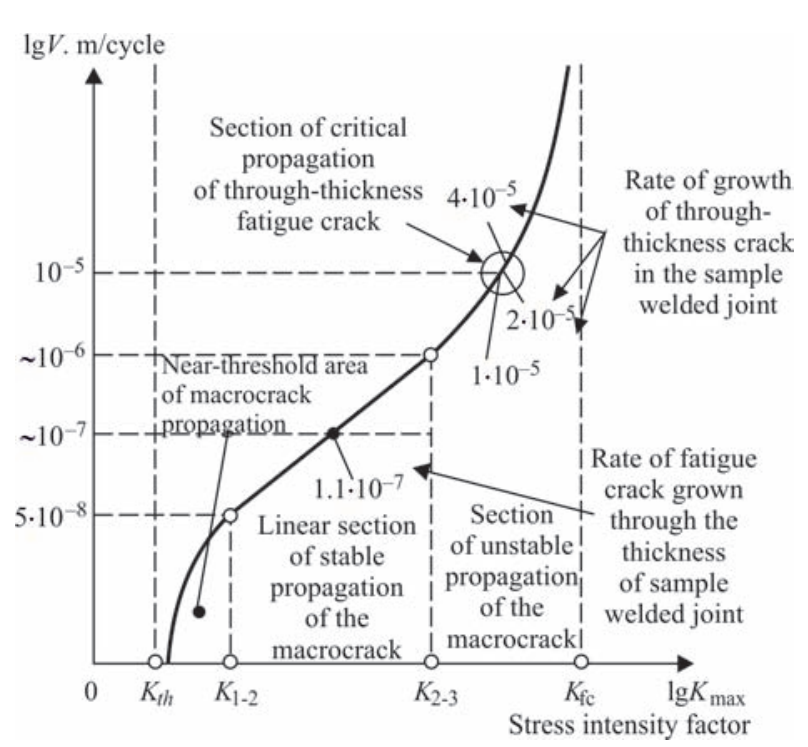

Figure 2. Sections of macrocrack propagation on fatigue fracture diagram [15]

welded joint on the tank wall. The accepted condition can be fulfilled at performance of $100 \%$ ultrasonic (UT) (radiographic) testing of the length of vertical design welds on the tank wall.

Results of measurements of the number of loading cycles and respective values of the surface crack length are given in Tables 4, 5.

Table 4 shows that at the initial notch length $\left(l_{\text {in.sur.c.c }}\right)$ of $39 \mathrm{~mm}$, at the moment of through-thickness crack formation the length of surface $\left(l_{\text {fin.surf.cr }}\right)$ crack was equal to $53 \mathrm{~mm}$. «Whiskers» formed on both sides (Figure 4) had the length of 6-7 mm. Moment of through-thickness crack formation was preceded by appearance of surface instability along the line of the crack reaching the surface. The zone of crack propagation was under plain strain condition. On the sample mirror surface elastic wave deformations were observed along the line of its appearance at each cycle of opening of the approaching crack. The through-thickness crack formed as a rupture of 5-7 mm length $\left(l_{\text {in.thr.cr }}\right)$. Release of potential energy accumulated in the sample with stopping of crack propagation occurred at 5-7 s. that is equal to 20-30 loading cycles. This was followed by the start of the process of growing of the length of

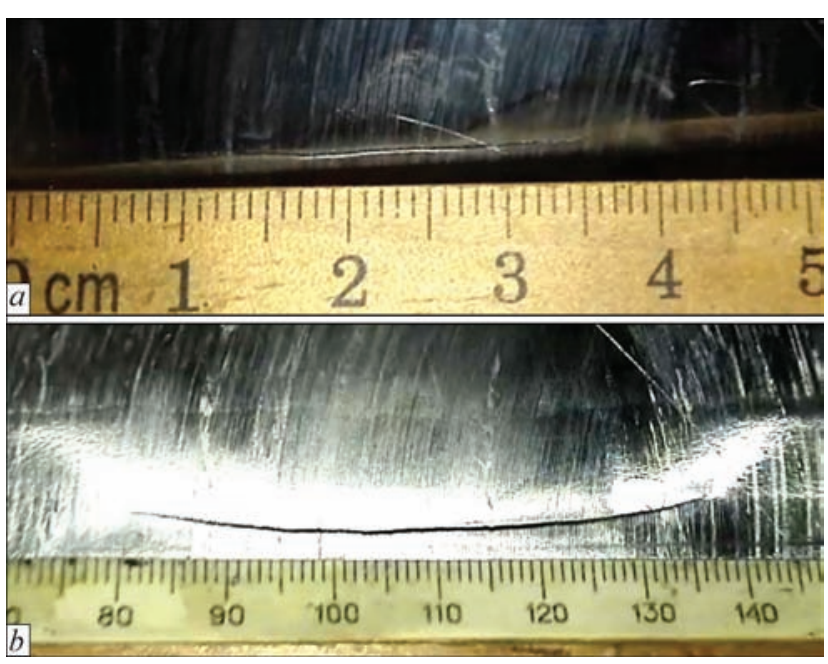

Figure 3. Fatigue crack propagation: growth under plane strain conditions $(a)$ and formation of steel contraction across the sample thickness at the tips of through-thickness crack at its length $2 a \geq 35 \mathrm{~mm}(b)$

already through-thickness crack up to critical size for this sample. This is the time of action of the leak before break criterion. As noted above, this time is limited on the sample also by the extent of plane strain zone. Data given in Tables 4, 5 on propagation of a crack from the notch and propagation of the through-thickness crack can be regarded as two successive stages. Given below is brief analysis of the data in Tables 4, 5 as regards propagation of the considered defect in the welded joint of steel 09KhG2SYuch-U.

First stage. According to the data in Table 4, the fatigue crack along the entire length $(39 \mathrm{~mm})$ of the sharp notch (Figure 1), initiated at the number of cycles $N_{\text {init.surf.cr }}=10.3$ thou (average from three samples). Taking into account the assumed safety factor for the loading cycle number $n_{z}=10$ [16], we have 1000 cycles. At the annual number of tank filling-emptying cycles $N_{\text {an }}=100$ [3], we have 10 years. At the assumed periodicity of technical and expert examination of tanks (5 and 10 years) [17], such a defect should be detected visually or at performance of ultrasonic testing and repaired. If the initial crack is overlooked, it will continue to propagate in the direction of wall (sample) thickness. One can see from Table 4

Table 4. Dependence of length $2 a$ of through-thickness crack from the side opposite to the notch, on the number of loading cycles $N$ (steel 09KhG2SYuch-U440, $t=200 \mathrm{~mm}$ )

\begin{tabular}{|c|c|c|c|c|c|c|c|c|c|}
\hline \multirow{3}{*}{$\begin{array}{l}\text { Sample } \\
\text { number }\end{array}$} & \multirow{3}{*}{$\begin{array}{l}\text { Steel grade, conditions of making } \\
\text { the welded joint }\end{array}$} & \multirow{3}{*}{$\begin{array}{c}\text { Initial crack } \\
\text { length } 2 a \text {, } \\
\text { mm, } \\
N=0.00\end{array}$} & \multicolumn{7}{|c|}{ Number of loading cycles $N$} \\
\hline & & & 100 & 150 & 200 & 250 & 300 & 400 & 600 \\
\hline & & & \multicolumn{7}{|c|}{ Length of through-thickness crack $2 a(\mathrm{~mm})$, allowing for initial length } \\
\hline 1 & \multirow{3}{*}{ 09KhG2SYuch-U, normalized } & 7 & 10 & - & 14 & - & 6 & 20 & 26 \\
\hline 2 & & 7 & 10 & - & 14 & - & 16 & 18 & 20 \\
\hline 3 & & 4 & 8 & - & 12 & - & 14 & 15 & 17 \\
\hline 4 & \multirow{3}{*}{ 09G2SYuch-U390*, normalized } & 8 & 10 & 11 & 12 & 11 & 14 & 20 & 25 \\
\hline 5 & & 10 & 12 & - & 14 & - & 16 & 20 & 30 \\
\hline 6 & & 12 & 14 & - & 18 & - & 24 & 27 & 32 \\
\hline
\end{tabular}


Table 5. Dependence of the length of surface fatigue crack in butt welded joint on the number of loading cycles (steel 09KhG2SYuch-U440, $t=20 \mathrm{~mm}$ )

\begin{tabular}{|c|c|c|c|c|c|c|}
\hline $\begin{array}{l}\text { Sample } \\
\text { number }\end{array}$ & Steel grade & $N_{\text {surf.init.cr, }}$ thou & $l_{\text {in.surf.cr }}, \mathrm{mm}$ & $N_{\text {thr.cr }}$, thou & $l_{\text {fin.surf.crf }}, \mathrm{mm}$ & $l_{\text {in.thr.cr }}, \mathrm{mm}$ \\
\hline 1 & \multirow{3}{*}{ 09KhG2SYuch-U440, normalized } & 10200 & 39 & 8100 & 53 & 7 \\
\hline 2 & & 10500 & 39 & 11800 & 53 & 7 \\
\hline 3 & & $7500^{* *}$ & 39 & 13500 & 51 & 4 \\
\hline 4 & \multirow{3}{*}{ 09G2SYuch-U390*, normalized } & 12100 & 41 & 11400 & 61 & 8 \\
\hline 5 & & 13300 & 38 & 9400 & 56 & 10 \\
\hline 6 & & 14600 & 47 & 5800 & 56 & 12 \\
\hline
\end{tabular}

that about 11.4 thou loading cycles $N_{\text {thr.cr }}$ are required up to formation of a through-thickness crack. At the initial depth of the fatigue crack of $2 \mathrm{~mm}$ the rate of crack growth by depth was equal to $1.1 .10^{-7} \mathrm{~m} / \mathrm{cy}$ cles. One can see from FFD (see Figure 2) that the growing process occurred in the section of stable crack propagation at constant increase of growth rate. Here there is also the possibility of timely visual detection of the crack at tank wall examination. Analysis of the process of initial development of fatigue crack in the welded joint of steel 09KhG2SYuch-U shows that presence of the crack through the entire wall thickness can be the consequence of only gross violation of the periodicity of tank examination, or its poor performance. Figure 4 shows a fatigue crack formed before reaching the opposite side from the notch tip, and its propagation in the form of «whiskers» at the notch tips.

Second stage. Table 5 gives the data of increase of the length of a through-thickness crack formed in the welded joint of the sample under plane strain conditions. Judging by the rate of its propagation on FFD (see Figure 2), this is the final stage of unstable propagation of a fatigue macrocrack. As noted above, the length of plane strain zone is substantially limited on the sample. At relatively high rate of through-thickness crack growing, here the cycle count goes to hundreds. By the data of Table 5, it can be stated that a crack grew from 7 up to $16 \mathrm{~mm}$ during 300 loading cycles. After 300-400 loading cycles signs of deformation began appearing on the surface of crack tips (Figure 3, a), which at more than $35 \mathrm{~mm}$ crack length developed into a contraction across sample thickness (Figure 3, b). The obtained good convergence of crack growth on the three samples is attributable, allowing for [18], to practically the same $K C V_{-40}$ values for all the welded joint zones.

It should be noted that the possibilities of application of leak before break criterion to detect through-thickness fatigue cracks in metal walls of tanks are quite limited. As applied to pressure vessels, defects of the type of through-thickness fatigue macrocrack are inadmissible [16]. Welded cylindrical tanks belong to those few facilities, the design of which and operating modes create the conditions for visual detection of a through-thickness fatigue macrocrack on the surface of welded joints of the wall by oil flowing out of it. The tank wall has a smooth cylindrical surface, completely open for visual examination. At up to $22 \mathrm{~m}$ wall height the stored product pressure on the wall is not more than $0.2 \mathrm{MPa}$, oil temperature in the tank is not higher than $50^{\circ} \mathrm{C}$. Oil and oil products feature a high permeability. Practical experience shows that already at the length of through-thickness crack of $3-5 \mathrm{~mm}$ their seeping through the crack is observed, with formation of dark spots (wetted areas) on the wall surface. Such oil spots are readily detectable on the open surface at examination. Proceeding from operating conditions, it was necessary to consider in greater detail the duration of the cycle of tank filling-emptying. For tanks of 50-100 thou $\mathrm{m}^{3}$ capacity, full cycle duration is equal to about $10 \mathrm{~h}$ (rate of oil rise in the tank is up to $4 \mathrm{~m} / \mathrm{h}$ ). Maximum number of cycles per year is not more than 100 [3], i.e. 1 cycle every 3.5 days or about 8 cycles per month. Number of cycles, at which plane strain was clearly recorded on the sample, can be assumed to be 300 . Through-thickness crack length $2 a=16 \mathrm{~mm}$ corresponded to this number. Allowing for safety factor $n_{z}=10$ [16], we have 30 cycles of controlled loading, that amounts to $30 \cdot 3.5 \approx 100$ days. In connection with the fact that the scope of experimental and laboratory data on the considered issue is limited [14], we believe it is possible to compensate the formed gap by applying $n_{z}=10$. Eventually, we get the estimated controlled time of not more than 10 days. This time is quite sufficient for visual detection of the oil spot, performance of welded

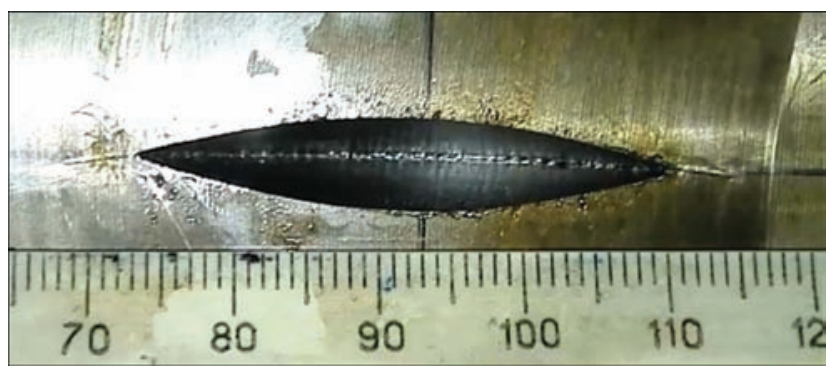

Figure 4. «Whiskers» at the crack tips from the notch side before reaching the opposite surface 
joint UT in the section of oil seepage, and taking measures on prevention of further crack growth. Detection and stopping of crack growth in the weld is a reliable method of prevention of avalanche fracture in the wall of tanks, both those with a protective wall and of conventional design, required by the standards [3].

Note that alongside sheet steels considered in this publication and in work [12], national metallurgy has recently mastered production of a number of new structural steels, in particular, C420M and C460M. These steels are manufactured in the condition after normalizing rolling, which allows producing rolled sheets with $\sigma_{y} / \sigma_{t}$ ratio of not less than 0.78 for C420 and not less than 0.83 for C460.

When considering the issue of application of these steels for tanks, the features of stressed state of the wall should be taken into account. Tank wall is a thinwalled cylindrical shell. At the diameter of 60-72 m and lower ring thickness of 26-28 mm, radial displacements of the wall reach 40 and $50 \mathrm{~mm}$ at the level of $1.0 \mathrm{~m}$, respectively. At these displacements, the welded assembly of wall-to-bottom transition is plastically deformed, that is allowed for by $\gamma_{n}=1.2$ coefficient during design. In addition, one should take into account that welding in the branchpipes and manholes into the lower ring is performed in a rigid contour. Under such conditions, in order to eliminate cold cracking in circumferential welds it is important for the steel to have a sufficient ductility margin. In view of what is stated in the standard [3], a requirement to $\sigma_{\mathrm{y}} / \sigma_{\mathrm{t}} \leq 0.75$ ratio was introduced for steels with $\sigma_{\mathrm{y}} \leq 440 \mathrm{MPa}$. It is also important for the rolled sheets to be delivered after normalizing, that ensures good quality of sheet rolling and eliminates angular deformations in the vertical welded joints of the wall. Considering all the above factors, the authors believe that at present, sheet steels of C390 and C440 strength class proposed for tanks by the standards [35], do not offer any acceptable alternatives to steels 09G2SYuch-U and 09KhG2SYuch-U.

The given investigation results lead to the following conclusions:

1. Mechanical properties of normalized sheet steels 09G2SYuch-U and 09KhG2SYu-U fully meet the requirements of standards for cylindrical steel tanks. Application of these steels essentially improves the efficiency and ecological safety of tanks.

2. Application of normalized sheet steels 09G2SYuch-U and 09KhG2SYuch-U for design rings of the wall of tanks of up to 20 thou $\mathrm{m}^{3}$ and greater capacity for storage of oil and oil products enables preventing avalanche fractures of the wall by visual detection of a through-thickness fatigue crack formed in the welded joint, by leak before break criterion (outflowing oil spot).

3. In the case of the considered steels, there are not less 10 days of safe operation for visual detection of the crack by leak before break criterion and taking measures to eliminate its possible propagation.

1. DBN V.1. 2-14-2009: General principles of ensuring reliability insurance and structural safety of buildings, constructions, building structures and foundations [in Ukrainian].

2. $D B N$ V.1. 1-12:2014: Construction in seismic regions of Ukraine [in Ukrainian].

3. DSTU B V.2.6-183:2011: Vertical cylindrical steel tanks for oil and oil products [in Ukrainian].

4. API STANDARD 650: Welded steel tanks for storage of oil products. 12th Ed., March, 2013 [in Russian].

5. EN 10025-3:2004: Hot rolled products of structural steels. Technical delivery conditions for normalized/normalized rolled weldable fine grain structural steels.

6. DBN V.2.6-198:2014: Steel structures. Codes of design [in Ukrainian].

7. Chernikov, O.P., Barvinko, A.Yu., Vasyutik, A.I. et al. (2014) Modern tank building in Belarus Republic. Montazhnye $i$ Spets. Raboty $v$ Stroitelstve, 12, 9-13.

8. TU 14-1-5065-2006: Modification 1: Thick plate from low-alloy steel of 09G2SYuch, 09G2SYuch-U, 09KhG2SYuch and 09KhG2SYuch-U grades [in Russian].

9. TU 14-1-5065-2006: Thick plate from low-alloy steel of grades 09G2SYuch, 09G2SYuch-U, 09KhG2SYuch and 09KhG2SYuch-U [in Russian].

10. Egorova, S.V., Sterenbogen, Yu.A., Yurchishin, A.V. et al. (1990) New general purpose cold-resistant steel with high resistance to overheating in welding. Avtomatich. Svarka, 2, 52-61 [in Russian].

11. Egorova, S.V., Yurchishin, A.V., Solina, E.N. et al. (1991) Cold-resistant 09KhG2SYuch steel of higher resistance for welded pressure vessels. Ibid., 12, 37-41.

12. Barvinko, A.Yu., Barvinko, Yu.P. (2016) On possibility of prevention of avalanche-like fractures of the wall of cylindrical tanks for oil storage by application of sheet steel with increased values of impact toughness. Tekh. Diagnost. i Nerazrush. Kontrol, 2, 44-49 [in Russian].

13. Broek, D. (1980) Fundamentals of mechanics of fracture. Moscow, Vysshaya Shkola [in Russian].

14. Bourga, R., Moore, P., Janin, Y., BN Wang, J. (2015) Leak before break: Global perspectives and procedures. Review Sharples Int. J. of Pressure Vessels and Piping, 129-130, 43-49.

15. Trufyakov, V.I. (1990) Strength of welded joints under alternating loads. Kiev, Naukova Dumka [in Russian].

16. Karzov, G.P., Leonov, V.P., Timofeev, B.V. (1982) Welded pressure vessels. Moscow [in Russian].

17. DSTU-N B A.3.1-10:2008: Recommendation for performance of diagnostics of vertical steel tanks [in Ukrainian].

18. Girenko, V.P., Dyadin, V.P. (1985) Dependence between impact toughness and criteria of fracture mechanics $\delta_{1 c}, K_{1 c}$ of structural steels and their welded joints. Avtomatich. Svarka, 9, 13-20 [in Russian].

19. DSTU EN 10025-4:2007: Hot rolled products of structural steel. Part 4: Technical delivery conditions for thermomechanical rolled weldable fine grain structural steels (EN 10025-4:2007, IDT). 


\title{
INFLUENCE OF ELECTRIC PARAMETERS OF SURFACING WITH DISCRETE FILLER IN CURRENT-SUPPLYING MOULD ON SPEED OF SLAG POOL ROTATION
}

\author{
Yu.M. KUSKOV \\ E.O. Paton Electric Welding Institute of the NAS of Ukraine \\ 11 Kazimir Malevich Str., 03150, Kyiv, Ukraine. E-mail: office@paton.kiev.ua
}

\begin{abstract}
Application of the most promising surfacing material — discrete filler — makes a significant difference in the processes of surfacing with current-supplying mould. Influence of electric parameters of surfacing on angular speed of slag pool rotation at application of three commercial flux grades was studied. It is found that ANF-29 flux allows producing a sufficiently large rotational effect both during the period of slag pool formation, and during surfacing. ANF-32 flux is less effective during the period of slag pool formation. AN-26 flux provides active rotation of the slag pool during surfacing, but this requires applying higher electric power to the pool. Angular speed of slag pool rotation is affected both by electric power applied to the slag pool, and surfacing current, but the latter has a determinant influence. 16 Ref., 1 Table, 2 Figures.
\end{abstract}

Ke y words : electroslag surfacing, current-supplying mould, fluxes, slag pool, angular speed of slag rotation, surfacing current, electric power, discrete filler

One of the directions for improving the quality of electroslag metal due to acceleration of heat and mass transfer reactions, and the conditions of liquid metal solidification, is making external impact on the melting zone (electrode edge-slag-metal pool). This impact is most often provided by mechanical [1, 2], electromagnetic [3, 4] and ultrasonic [5] methods.

Despite the fact that most investigations confirm the positive influence of external impact on the deposited metal structure and properties, it, nonetheless, has not found a broad application, chiefly, because of complication of the electroslag process technology.

This drawback can be eliminated at application of sectioned current-supplying mould (CSM) developed at PWI, in electroslag technologies. One of its main functions in service is slag pool rotation in the horizontal plane [6]. This rotation is performed by electromagnetic method due to a special design of the current-conducting section. As a result of interaction of longitudinal magnetic field of the mould with the fields of lines of force of working current ponderomotive forces arise inside the slag pool, which mechanically create a rotational effect in the slag. Slag pool rotation as a result of the forces of friction between the slag and liquid metal is transferred to the metal pool.

Other problems can also be solved alongside the earlier mentioned objectives achieved at electroslag surfacing (ESS) and electroslag remelting (ESR) in
CSM. In particular, slag rotation allows improving the conditions for equalizing of temperatures through the entire volume of the slag pool and accelerating stabilization of the electroslag process; eliminating formation of microarcs on slag-nonconsumable electrode interface (current-conducting section wall), that prevents fast local wear of the latter; applying discrete materials in electroslag technologies, uniformly distributed over the slag pool surface; thus creating approximately similar conditions for filler granules melting in the slag. Active movement of slag relative to the processed surface should have a positive influence on its sound joining with the surfaced metal.

Proceeding from the requirements made of fluxes (slags) for ESR as the electroslag process closest to ESS of end faces, they are divided into two main groups [7]: technological and metallurgical. Technological requirements include: ease of excitation and high stability of the electroslag process; possibility of achieving moderate rates of metal deposition, guaranteeing axial direction of solidification; minimum specific power consumption; good formation of deposited metal surface; easy separability of the slag crust; stability of slag composition at long-term storage and during ESS; minimum labour consumption in slag manufacture; absence of expensive and deficit components in the slag composition; molten metal protection from air access; ensuring a heat reserve over molten metal, preventing formation of shrinkage cavities and inner cracks in the ingot. 
As applied specifically to ESS of end faces in CSM, the following should be added to these requirements: it is desirable to apply relatively low-melting and «long» slags; the slags should have low viscosity and increased fluidity (particularly, for the case of «liquid» start); slag composition should ensure formation of skull of minimum thickness and higher electric conductivity for its "piercing» in the initial period of electroslag process stabilization at relatively low voltage of the power source.

Metallurgical requirements include formation of more ductile nonmetallic inclusions in the deposited metal, preferably of a round shape; higher desulphurizing capacity; and low water permeability.

Since the time of development of the technology of ESS and ESR in a current-supplying mould [8, 9], its different variants have appeared. At present four technological procedures have been proposed on the basis of the known CSM design, namely surfacing and remelting by liquid metal $[10,11]$; so-called two-loop circuit of electrode remelting with application of two power sources [12]; surfacing with feeding nonconducting [13] and current-conducting [14] flux-cored wire into the slag pool; surfacing by a two-loop circuit with application of an additional hollow graphite electrode and nonconducting billet (wire) [15].

We are not considering the advantages and disadvantages of newly proposed methods of surfacing in CSM in this paper. We will just consider the interrelation of the surfacing procedure and flux (slag) applied for it in terms of the possibility of providing a stable rotation of the slag pool.

First of all, it should be noted that the issues of slag pool rotation in all these procedures are not considered, just the technological features of the process are assessed. But as the electroslag process proper and movement of slag flows, occurring at its realization, are one electro-physico-chemical phenomenon, we should first of all understand, what are the reasons behind selection of flux for a particular proposed process of surfacing (remelting), and to what extent the criteria of this selection can be used for solving the posed task of ESS with discrete filler with provision of active rotation of the slag pool.

Based on available information, selection of flux for each proposed surfacing procedure either has some substantiation, or just flux of a known grade is used for surfacing.

ANF-94, ANF-32, AN-75 fluxes [10, 11] and different compositions based on fluorides and oxides are used for surfacing with liquid metal, depending on the deposited metal. The main difference of ESS with discrete material from liquid filler consists in that in the first case cold filler granules are fed into the slag pool, and in the second case these are portions of overheated metal. Temperature conditions of slag pool existence and physical properties of slag both in each local zone of the pool, and in its entire volume will differ in these technologies, respectively. Therefore, the flux, used in one surfacing procedure, will not necessarily be suitable for another one, particularly in terms of creation of an active rotary effect in the slag pool.

As regards surfacing with feeding of a small volume of current-conducting or nonconducting wire into the slag pool $[13,14]$, application of relatively refractory flux ANF-6, apparently, does not always allow producing a sound joint of the base and deposited metals, and the surfacing process proper, as claimed by developers of the procedure, should be conducted in a narrow range of applied electric power. Apparently, for this reason, the authors started performing all the subsequent operations with the same flux, but with additional feeding of a hollow graphite electrode of a special shape of the working edge into the central part of the slag pool [15]. In this case, the entire volume of the slag pool (particularly under the electrode) is heated quite well. So far, just surfacing of end faces of cylindrical parts of relatively small diameter of 30-90 mm (mainly, about $30 \mathrm{~mm}$ diameter) has been checked. Applicability of this flux for surfacing larger diameter items and with feeding discrete filler into the slag pool causes some doubt.

Electrode remelting by a two-loop circuit [12], similar to surfacing with liquid filler, allows providing a more uniform thermal field in the slag pool, that, naturally, does not meet the conditions of ESS with discrete filler. Therefore, for this procedure, the requirements to flux selection will be somewhat different, more stringent.

Proceeding from the above, as well as taking into account the earlier performed research [16], assessment of the influence of slag composition on angular speed of slag pool rotation was performed on ANF-29, ANF-32 and AN-26 fluxes. Alongside the established technological capability of application of these fluxes, their potential as a liquid slag environment, capable of rotating during surfacing at feeding surfacing discrete filler on its surface, should be evaluated.

Procedure of experiment performance was assumed to be similar to the one described in [16]. The distance from the processed end face of the billet to the upper edge of forming section $L$ changed gradually from the initial one equal to $94 \mathrm{~mm}$ (70 mm for AN-26 flux), to smaller dimensions due to feeding of remelted steel shavings into the slag pool, for building-up the deposited layer at the billet end face, respectively. Slag pool rotation in the horizontal plane was assessed by lowering onto its surface small pieces 
Influence of the fraction of current $I(\%)$ in electric power $N$ applied to the slag pool on the speed of slag pool rotation $n$

\begin{tabular}{|c|c|c|c|c|}
\hline \multirow{2}{*}{ Flux } & \multicolumn{2}{|c|}{ Surfacing mode, kA } & \multirow{2}{*}{$n$, rpm } & $\begin{array}{c}I \text { fraction in } \\
N, \%\end{array}$ \\
\cline { 2 - 3 } & $I, \mathrm{kA}$ & $N, \mathrm{~kW}$ & & \\
\hline \multirow{2}{*}{ ANF-29 } & 1.34 & 52.4 & 36 & 2.64 \\
& 0.82 & 50.8 & 25 & 1.56 \\
\hline \multirow{2}{*}{ ANF-32 } & 2.00 & 44.0 & 48 & 4.55 \\
& 1.93 & 42.5 & 46 & 4.54 \\
\hline \multirow{2}{*}{ AN-26 } & 2.06 & 98.9 & 40 & 2.08 \\
& 1.77 & 72.9 & 24 & 2.43 \\
\hline
\end{tabular}

of charcoal and measuring their angular displacement with a stopwatch. Average value from three to five tests was taken as the measurement result. A greater number of measurements were conducted at low speeds of pool rotation (lower heat saturation of slag), because of formation of local cooling zones on its surface, preventing stable rotation of charcoal pieces.

Influence of electric power $N$ applied to the pool and surfacing current $I$ on slag pool rotation was assessed separately. Measurement results are given in Figures 1 and 2.

Analysis of these results leads to the following conclusions.

For ANF-29 and ANF-32 fluxes with relatively similar chemical composition, change of the speed of slag rotation $n$ depending on the value of electric power $N$ applied to the slag pool at the stage of its formation and stabilization of the electroslag process ( $L=94 \mathrm{~mm}$ ), differs markedly (see Figure 1). For ANF-29 flux direct dependence $N-n$ approximately corresponds to proportional relationship (at $N$ change from 50 to $60 \mathrm{~kW} n$ changes from 25 to $30 \mathrm{rpm}$ ). At the same time, similar to ANF-32 flux, under the same conditions (IV stage of the power source, $L=94 \mathrm{~mm}$ ) of experiment performance power change from 60 to $80 \mathrm{~kW}$ (about $33 \%$ ) leads to angular speed of slag pool rotation changing from 7 to 9 rpm (approximately $29 \%)$.

After minimum $L$ values have been achieved (due to feeding shavings to the slag pool and deposited layer building-up: $22 \mathrm{~mm}$ for ANF-29, $28 \mathrm{~mm}$ ANF-32, and $25 \mathrm{~mm}$ for AN-26, respectively), gradual transition from power source IV stage to lower stages (III and II) was performed. At these $L$ values the inclination of straight lines for ANF-29 and ANF-3 fluxes becomes similar. $N-n$ dependence for AN-26 flux is characterized by a more abrupt change of $n$ at reduction of the applied electric power.

As noted above, formation and speed of slag pool rotation are determined, chiefly, by working currents of surfacing. And although the trend of direct dependencies of $N-n$ and $I-n$ is approximately the same (see Figures 1,2), the influence of current component in

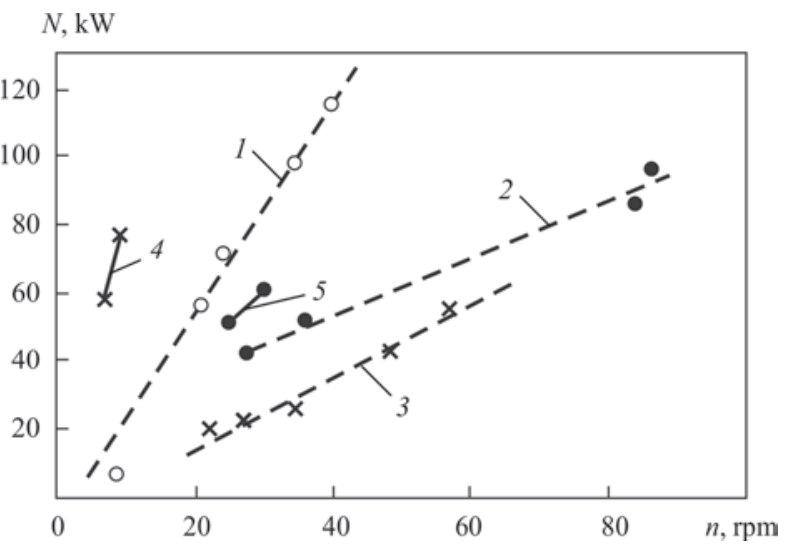

Figure 1. Influence of electric power $N$ applied to the slag pool on its rotation speed $n$ : 1 - AN-26; 2 - ANF-29; 3 - AHF-32; 4 - $\operatorname{ANF}-32(L=94 \mathrm{~mm}) ; 5-\operatorname{ANF}-29(L=94 \mathrm{~mm})$

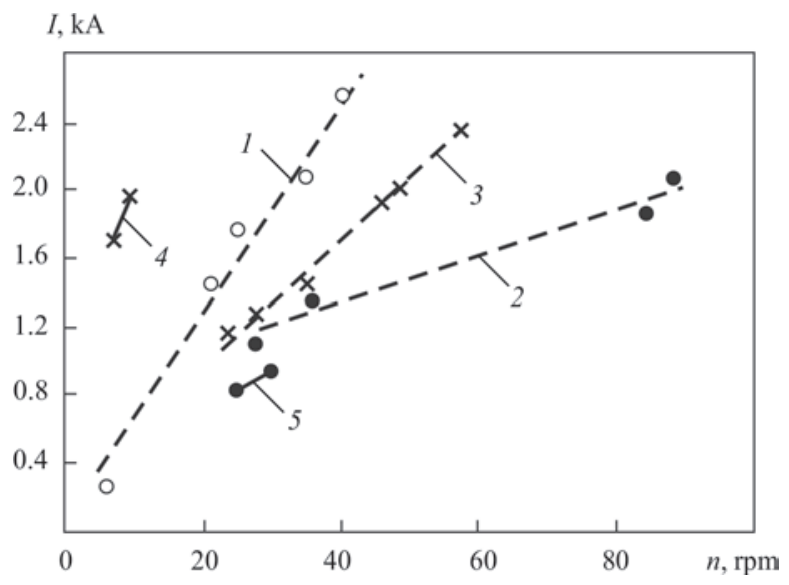

Figure 2. Influence of surfacing current $I$ on speed $n$ of slag pool rotation (designations are the same as in Figure 1)

the electric power applied to slag of different chemical composition can be assessed, proceeding from the following data (Table).

\section{Conclusions}

1. Ensuring optimum rotation of the slag pool, both in the initial period of its formation (characterized by the time, required for minimum angular movement of the melt around the mould perimeter), and at stabilization of the electroslag process (unchanged value of surfacing current before feeding the filler into the slag pool, constant speed of pool rotation, fast immersion of the filler into the slag pool without formation of conglomerates of slag and surfacing material on its surface) is an important characteristic of fluxes, applied for ESS in the current-supplying mould.

2. Angular speed of slag pool rotation depends both on electric power, applied to it during performance of electroslag process in CSM, and directly on surfacing working current. Surfacing current plays the most significant role in this effect.

3. Of the three fluxes considered in the experiments the best conditions for performance of slag pool rotation can be obtained, when using ANF-29 flux. Slag 
pool set when melting ANF-29 flux, allows achieving sufficiently high rotational effect both in the period of slag pool formation, and during the surfacing process. ANF-32 flux is similar to ANF-29 flux as to its ability to rotate the slag pool, when conducting a stable electroslag process, but it is less effective during slag pool formation. AN-26 flux can provide active rotation of the slag pool during surfacing, but it requires application of higher electric power to it.

1. Vachugov, G.A., Chumanov, V.I., Khasin, G.A. et al. (1975) Influence of rotation of remelted electrode on electroslag remelting process. Problemy Spets. Elektrometallurgii, 28, 31-36 [in Russian].

2. Kodama, H., Kandro, I., Akahori, K. et al. (1987) Properties of cladded rolls produced by method of electroslag surfacing with rotation. In: Proc. of 8th Intern. Conf. on Vacuum Metallurgy, Special Kinds of Surfacing and Metallurgical Coatings, 9, 139-145.

3. Maksimovich, B.I. (1962) Effect of electromagnetic rotation of slag pool on crystallization of metal in electroslag remelting of high-alloy steels and alloys. Elektrotermiya, 5, 9-12 [in Russian].

4. Topilin, V.V., Klyuev, M.M., Fomicheva, N.P., Grebtsov, Yu.G. (1968) Refining of macrostructure of ingots in electroslag remelting of alloys. Problemy Spets. Elektrometallurgii, 1, 23-28 [in Russian].

5. Kudelkin, V.P., Klyuev, M.M., Filippov, S.I. et al. (1969) Impact of ultrasonic oscillations on crystallization in electroslag remelting. Izv. Vuzov. Chyorn. Metallurgiya, 11, 64-70 [in Russian].
6. Ksyondzyk, G.V. (1975) Current-supplying mold insuring rotation of slag pool. Problemy Spets. Elektrometallurgii, 27, 33-40 [in Russian].

7. Podgaetsky, V.V., Kuzmenko, V.G. (1988) Welding fluxes: Refer. Book. Kiev, Naukova Dumka [in Russian].

8. Ksyondzyk, G.V., Frumin, I.I., Shirin, V.S. (1964) Currentsupplying mold. USSR author's cert. 264427 [in Russian].

9. Ksyondzyk, G.V., Frumin, I.I., Shirin, V.S. (1969) Device for electroslag remelting. USSR author's cert. 337026 [in Russian].

10. Kuskov, Yu.M. (1969) Electroslag surfacing of cylindrical billets with liquid filler material in current-supplying mold. Avtomatich.Svarka, 6, 52-53 [in Russian].

11. Medovar, B.I., Chernets, A.V., Medovar, L.B. et al. (1995) Electroslag surfacing with liquid filler metal. Problemy Spets. Elektrometallurgii, 1, 6-11 [in Russian].

12. Tsykulenko, A.K., Lakuman, I.A., Medovar, L.B. et al. (2000) Two-loop circuit of electroslag remelting of consumable electrode. Ibid., 3, 16-20 [in Russian].

13. Sokolov, G.N., Lysak, V.I. (2005) Surfacing of wear-resistant alloys on press tools and instruments for hot forming of steels. Volgograd, RPK Politekhnik [in Russian].

14. Sokolov, G.N. Zorin, I.V., Tsurikhin, S.N. (2004) Technology of electroslag surfacing of mandrels of tube-rolling unit. Svarshchik, 1, 15 [in Russian].

15. Sokolov, G.N. (2007) Formation of composite structure of deposited metal for operation in thermoslag impact conditions and development of ESS of press tools and instruments: Syn. of Thesis for Dr. of Techn. Sci. Degree. Volgograd [in Russian].

16. Kuskov, Yu.M. (2018) Influence of flux composition on the process of electroslag surfacing of end faces with discrete feeding of filler material. The Paton Welding J., 1, 33-37.

Received 12.01.2018 


\title{
MODERN HARDWARE-SOFTWARE COMPLEXES FOR TRAINING OF WELDERS
}

\section{L.M. LOBANOV ${ }^{1}$, N.M. MAKHLIN ${ }^{1}$, A.E. KOROTYNSKY ${ }^{1}$, V.E. VODOLAZSKY ${ }^{1}$ and V.Yu. BURYAK ${ }^{1}$}

${ }^{1}$ E.O. Paton Electric Welding Institute of the NAS of Ukraine

11 Kazimir Malevich Str., 03150, Kyiv, Ukraine. E-mail: office@paton.kiev.ua

${ }^{2} \mathrm{SE}$ «Scientific and Engineering Center of Welding and Control in Nuclear Power Engineering

of Ukraine of the E.O. Paton Electric Welding Institute of the NAS of Ukraine

11 Kazimir Malevich Str., 03150, Kyiv, Ukraine. E-mail: electro@paton.kiev.ua

\begin{abstract}
The article presents the results of development of technical means of semi-virtual type for training welders and welding production specialists at the SE «Scientific and Engineering Center of Welding and Control in Nuclear Power Engineering» (SEC WCNPE) in cooperation with the E.O. Paton Electric Welding Institute of the NAS of Ukraine and the G.E. Pukhov IPME of the NAS of Ukraine. The level of development of technical means, attained at the present time, for training and certification of welders and welding production specialists was considered, which allows predicting the expansion in the fields of application of modern information technologies, including those reproducing the mixed reality at maximum adaptation of virtual space to the real welding equipment and providing the remote access of telecommunication systems. It was shown that simplification of training and its approximation to the conditions of real welding processes is possible by using a new generation of welding simulators, in which modern information technologies are widely applied. 15 Ref., 3 Figures.
\end{abstract}

Ke ywords : virtual reality, information technologies, arc welding simulators, training, welding equipment, certification of welders

The technical means of training (simulators) can be classified according to the welding method, conditions of its realization, degree of simulation of real process and tools.

By the degree of simulation of welding process, all technical means of training can be subdivided into [1,2]:

- computer simulators in which simulation of the welding zone and welding arc is carried out in the virtual space by means of computer graphics and image synthesis;

- simulators, providing simulation of the process of welding with a low-amperage arc without melting of electrode and formation of a weld pool;

- simulators using the elements of real welding process and welding equipment.

At present the simulators of all three types are presented at the world market of training equipment and technical means for training of welders.

For the computer simulators (mainly, of the development and production of companies from the USA, EU countries, Canada, Australia, Japan), a prominent example of which is the products of the Company SOLDAMATIC (Spain), the maximum degree of using the virtual effects during simulating the welding process is characteristic[3-8]. In the simulators of this type, the reproduction of a welding situation, i.e. zone of arc burning, edge preparation, weld and molten pool, is carried out by imaging them on the display of a personal computer (PC) or on the screen of a special welding helmet with built-in virtual reality glasses. However, computer simulators have a number of drawbacks, limiting their capabilities:

- absence of a clear relationship between the parameters of welding process, welded joints and welding tools, which can be represented only conditionally by means of computer graphics;

- inevitability of using a system of special sensors and special welding helmets or similar devices with built-in virtual reality glasses, as well as the presence of communications, providing their connection with a PC or similar processors, which creates certain inconveniences for trainees and limits their capabilities of moving in space;

- need in preparatory operations for setting the limits of deviations from standard values of welding process parameters;

- need in the subsequent adaptation to real welding tools and processes;

- difficulties in the process of developing the necessary professional psychomotor skills in trainees who do not have initial training;

- high cost (from € 7000).

In the opinion of many specialists, the simulators of the second and third types are characterized by the 
widest functional and didactic capabilities, providing the approximation of training process to the conditions of real welding process, as well as low-amperage and arc simulators for welder [1, 9].

The main feature of low-amperage arc simulators is the maximum approximation of the simulating welding process to the real one due to the existence of a low-amperage arc, the current of which is 4-6 A, and the power does not exceed $250 \mathrm{~V} \cdot \mathrm{A}$, as a result of which the heat-affected-zone is formed in the simulator of a welded workpiece without melting of base and electrode metals.

The low-amperage arc simulators represent hardware-software complexes, in which by means of PC the direct measuring and evaluation of such continuously changing parameters of the welding process in time as current, voltage and arc length, welding speed, angles of inclination of the electrode simulator of welding tool with respect to the simulator of the workpiece welded is provided. The direct measurements in low-amperage arc simulators are performed with the help of a system of sensors of different physical nature included in their composition. The signals from the information outputs of these sensors, proportional to the parameters of welding process, are supplied to the inputs of multichannel matching module of the simulator, which performs frequency correction and adjustment of levels of input signals to the range of input voltages of the analog-to-digital converter (ADC). From the outputs of the matching module channels, the normalized analog signals are supplied to the inputs of a multichannel ADC, providing the conversion of the input analog signals into

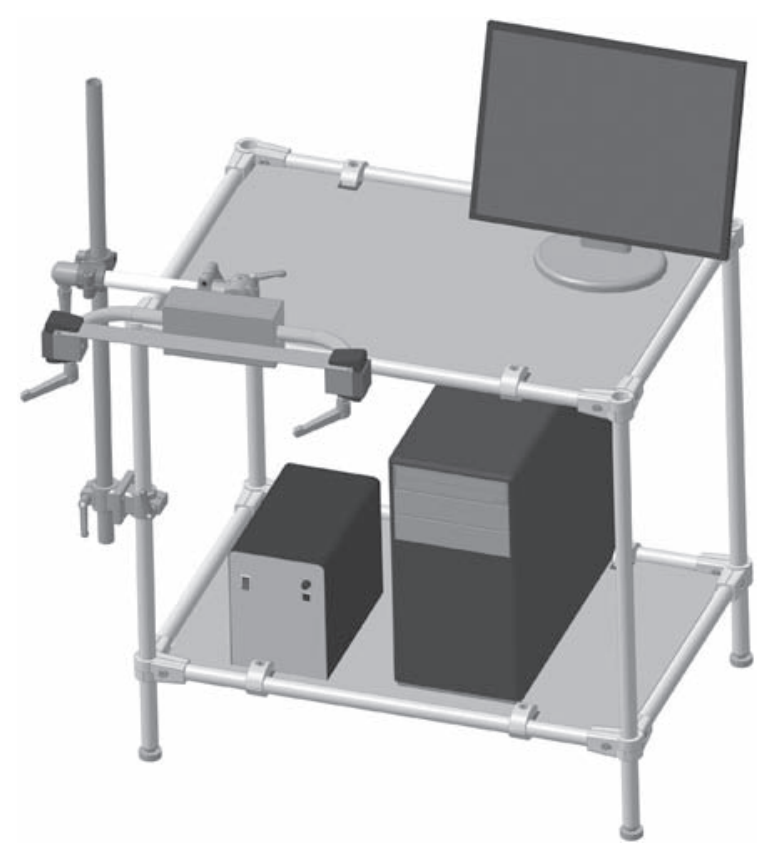

Figure 1. Simplified appearance of simulator MDTS-05M1 of modification OBTs $650 \mathrm{UKhL} 14.2$ a digital code, supplied to the bus of PC data for the further processing and analysis. The result of the direct processing of the signals, received by the PC, is the information (displayed in numerical, graphical or tabular form) about the actual values of currents passing in the welding circuit and the circuits being a part of it, arc voltage, arc gap length, electrode inclination angles of the welding tool simulator. The mathematical processing of the data received by the PC also provides obtaining the information on the actual values of welding speed, effective heat power of the arc and energy input. The actual values of welding parameters obtained as a result of processing of data, received by the PC, are compared with their limit values, preset before the start of training session. In case of coming the actual value of the monitored parameter beyond the PC areas, regulated by the training task, the PC automatically generates the audio speech feedback signals with the trainee, reproduced by audio means, for example, headphones.

Among the known examples and models of the low-amperage arc welder simulators, at the present time the widest functional, technological and didactic capabilities are peculiar to the low-amperage arc welder simulator MDTS-05M1, designed and manufactured at the SEC WCNPE. It allows simulating the processes of manual arc welding with coated electrodes (MMA), welding with nonconsumable electrode (TIG) and welding with consumable electrodes (MIG/MAG). A somewhat simplified general view of the MDTS-05M1 simulator of the OBTs 650 UKhL4.2 modification is shown in Figure 1, and the basic parameters of the MDTS-05M1 simulator are shown below.

\section{Basic parameters of the MDTS-05M1 simulator}

Welding arc current, A . . . . . . . . . . . . $4.5 \pm 0.3$ Open-circuit voltage, $\mathrm{V}$, not more than $\ldots \ldots \ldots \ldots \ldots 65$ Number of information channels of the technological interface unit BTI-05M1 OBTs 650.05.00.000 . . . . . . . 6 Capacity of the analog-digital converter integrated into the technological interface unit BTI-05M1 OBTs650.05.00.000,

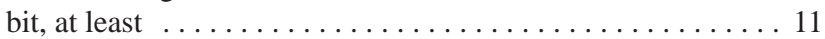

Controllable and preset welding mode parameters:

speed of welding (speed of electrode movement),

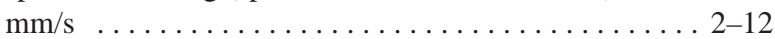

length of the arc gap:

in the mode of simulating welding with a consumable electrode, mm .................... 1-6 in the mode of simulating welding with a nonconsumable electrode, $\mathrm{mm}$.......... . 0.5-4.0 angles of inclination of the electrode across and along the weld, $\operatorname{deg} \ldots \ldots \ldots \ldots \ldots \ldots \ldots \ldots \ldots \ldots$

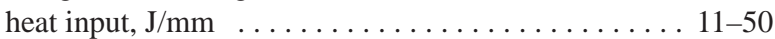
arc voltage, $\mathrm{V} \ldots \ldots \ldots \ldots \ldots \ldots \ldots \ldots . \ldots . \ldots 20-45$ average speed of electrode movement during manual arc welding (in the mode of simulation of electrode melting), $\mathrm{mm} / \mathrm{s} \ldots \ldots \ldots \ldots \ldots \ldots \ldots \ldots \ldots . . .4 .4 .0$ 
Speed of filler wire feed to the welding zone

(welding arc), $\min ^{-1} \ldots \ldots \ldots \ldots \ldots$. . . . . . . . . 10-20

Duration of training session, s . . . . . . . 90, 180, 240, 360

Rated voltage of single-phase AC mains of $50 \mathrm{~Hz}$

frequency, V . . . . . . . . . . . . . . . . . . . . . 220

Consumed electric power (without taking into account the power consumed by the computer and its peripheral devices), $\mathrm{kV} \cdot \mathrm{A}$, not

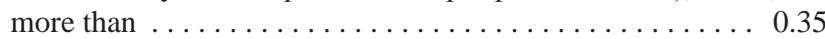

The MDTS-05M1 simulator provides the feasibility of mastering the skills of arc exciting and supporting it in the technologically justified range of length, uniform movement of arc along the preset trajectory, as well as maintaining the inclination angle of the electrode to the surface welded, providing a regulated thermal mode of a weld pool. In TIG welding, a further mastering of the technique of filler material feeding into the weld pool is possible.

An important part of the software of the MDTS05M1 simulator is the educational and methodological documentation (EMD), which includes a training program, a test program, a library of theoretical material on the realized welding processes and a library of reference data containing the types and sizes of characteristic welded joints, as well as the types of basic defects in these joints.

The technical solutions, capabilities of the hardware part, information resources and structure, including methodical one, the software of the MDTS05M1 simulator found its wide application both as technical means for training the personnel of welding production in the educational institutions of vocational education and training centers for training and improving the skills of welders in Ukraine, Russia, Kazakhstan, Macedonia, Belarus and other countries. Only in Russia there are more than 1200 simulators of this type in operation, while in a number of educational institutions, training and certification centers of the Russian Federation, on the basis of the MDTS-05M1 simulators the whole training classes and laboratories for training welders in MMA-, TIG- and MIG/MAG welding were created. The experience in using the MDTS-05M1 simulator confirms its high operational safety, economy and efficiency both for professional selection and initial professional training of welders, as well as for improving their skills, production training and testing, and in a number cases — for admission control also.

The traditional approach to training welders using real welding processes is associated with a significant consumption of metal, welding consumables and electric power. It is possible to intensify and qualitatively improve the process of training skills with simultaneous reduction in the operating costs only with the use of hardware and software means of a high sci- entific and technical level, providing the combination of the real and virtual reality. To the greatest extent, the arc welding simulator TSDS-06M1, designed and manufactured at the SEC WCNPE, corresponds to this approach.

The simulator TSDS-06M1 provides:

- scale reproduction of real processes of arc welding;

- measurement of instant and averaged values of process parameters with comparison of the possible deviations from the preset or standard values in dynamics;

- computer registration and processing of the obtained information, its documentation, storage and reproduction in digital, graphical or table form;

- performing feedback with the trainee (tested);

- automatic and unambiguous evaluation of actions and skills of the trainee or tested welder during the welding processes realization.

According to the structural design, the TSDS06M1 simulator is in many respects similar to the MDTS-05M1 simulator, but differs from the latter in the number and parameters of sensors of the measuring system and the schematic-circuit solutions. The general view of the TSDS-06M1 simulator is shown in Figure 2, and its basic parameters are given below.

\section{Basic parameters of the TCSD-06M1 arc welder simulator}

Rated welding current of power module, A . . . . . . 300 Load duration of (LD) at a rated welding current and

cycle duration $T_{c}=5 \mathrm{~min}, \% \ldots \ldots \ldots \ldots \ldots \ldots \ldots$

Open-circuit voltage, $\mathrm{V}$, not more than $\ldots \ldots \ldots \ldots \ldots \ldots 65$

Voltage of supplying single-phase mains of $50 / 60 \mathrm{~Hz}$

frequency, V . . . . . . . . . . . . . . . . . . . . $220 \pm 33$

Controllable and preset parameters:

welding current (as-preset, at an accuracy of $\pm 5 \mathrm{~A}$ ):

in MMA welding, A . . . . . . 80, 100, 120, 140, 160, 180

in TIG welding, A . . . . . . . . 80, 100, 120, 140

in MAG welding, A . . . . . . . . . . . . . $125 \pm 10$ arc voltage:

in MMA welding, $\mathrm{V} \ldots \ldots \ldots \ldots \ldots \ldots \ldots \ldots . .21-28$

in TIG welding, $\mathrm{V} \ldots \ldots \ldots \ldots \ldots \ldots \ldots \ldots \ldots$. . . . . . . . . . . . . . . . . .

in MAG welding, $\mathrm{V} \ldots \ldots \ldots \ldots$. . . . . . . 20-22

length of arc gap:

in MMA welding, $\mathrm{mm} \ldots \ldots \ldots \ldots \ldots \ldots 2-5$

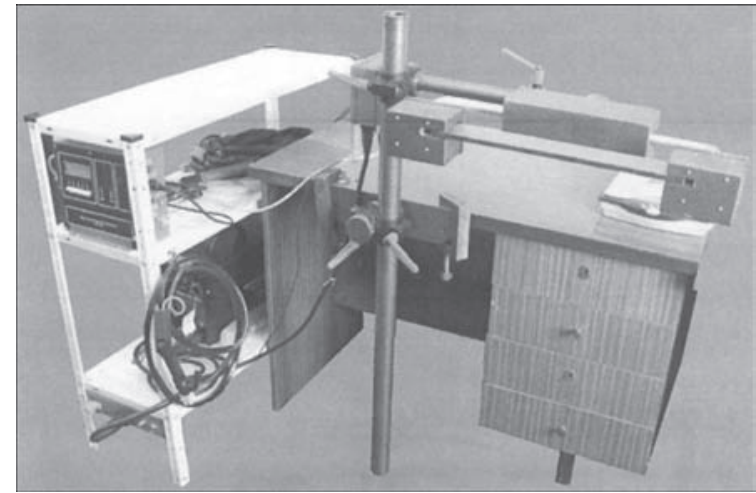

Figure 2. General appearance of simulator TSDS-06M1 
in TIG welding, $\mathrm{mm}$. . . . . . . . . . . . . . . . 0.5-4.0

electrode wire feed speed in MAG welding,

$\mathrm{mm} / \mathrm{s}(\mathrm{m} / \mathrm{h}) \quad \ldots \ldots \ldots \ldots \ldots \ldots . .2 .92-3.33(105-120)$

inclination angles of welding tool electrode

(in flat and overhead positions of welded

specimen), deg $\ldots \ldots \ldots \ldots \ldots \ldots \ldots \ldots \ldots \ldots \ldots \ldots \ldots \ldots$

welding speed:

in MMA welding, $\mathrm{mm} / \mathrm{s}(\mathrm{m} / \mathrm{h}) \ldots \ldots \ldots$. . . . 5 (3.6-18.0)

in TIG welding, $\mathrm{mm} / \mathrm{s}(\mathrm{m} / \mathrm{h}) \ldots \ldots . .0 .5-2.5(1.8-9.0)$

in MAG welding, $\mathrm{mm} / \mathrm{s}(\mathrm{m} / \mathrm{h}) \ldots .4 .04 .5$ (15.0-20.0) heat input:

in MMA welding, $\mathrm{J} / \mathrm{mm}$. . . . . . . . . . . . . . 70-410

in TIG welding, $\mathrm{J} / \mathrm{mm} \ldots \ldots \ldots \ldots$. . . . . . 60-300

in MAG welding, $\mathrm{J} / \mathrm{mm}$. . . . . . . . . . . . . . . 80-120

inert gas (argon) consumption in TIG welding,

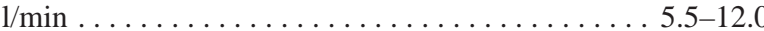

duration of training (testing)

session, s ................. 90, 180, 240, 360

Electrical power consumed by the power module,

$\mathrm{kV} \cdot \mathrm{A}$, not more than . . . . . . . . . . . . . . . . 5.0

Number of information channels of the technological

interface unit BTI-06M (OBTs 611M.05.00.000) . . . . . . . 8

Capacity of each channel of the analog-digital converter built-in

into the technological interface unit BTI-06M

(OBTs 611M.05.00.000), bit, not less than . .......... 12

Consumed electric power (without taking into account

the power consumed by the power module, computer and its

peripheral devices), $\mathrm{kV} \cdot \mathrm{A}$, not more than $\ldots \ldots \ldots \ldots .0 .50$

The TSDS-06M1 simulator complex includes an arc power supply module, a technological interface unit, a positioner, a PC with peripheral devices, a set of welding tools, a protective mask with a light filter, a set of welding specimens, headphones, a lightweight rack for mounting the arc power supply module in it, a unit of the technological interface and accessories of the simulator, as well as a specialized software. As a power supply module of the arc, the standard, specialized or universal welding power sources predominantly of inverter type with small modifications can be used. The positioner of the TSDS-06M1 simulator provides a fixing the welding specimen in the current conductor of the positioner; ability of installing a welding specimen in different spatial positions; realization of a special scheme of connecting the welding specimen to one of the poles of a welding power source; formation of signals proportional to the currents passing in welding specimen; ability of calibrating the circuit of measuring currents passing in welding specimen. The set of welding tools of the TSDS-06M1 simulator includes manual tools of a welder based on a widely used standard electrode holder for MMA welding, a torch for TIG welding and a torch for MIG/MAG welding. Welding tools are equipped with a three-axis sensor of angular positions of the electrode relative to the gravity vector. The set of welding specimens of the TSDS-06M1 simulator contains plate specimens for producing butt and fillet welds, as well as position welds of pipes and other rotating bodies. The shape and geometric dimensions of welding specimens provide their repeated use in training, testing, admission control or prequalification training. The same specimens can also be used for the qualification procedure of welders.

The software of the TSDS-06M1 simulator complex, as well as the software of the MDTS-05M1 simulator, is developed on the LabVIEW platform, which provides:

- input of initial welding data in the dialog mode;

- imaging of monitored parameters on the PC display;

- realization of feedback with a trainee (tested) by automatic supply of the speech signals («prompts»);

- control of welding process as a whole and according to certain parameters;

- statistical processing of results of the training session, testing, admission control or certification tests;

- obtaining the estimates of level of skills in welding techniques and the quality of works due to the availability of the expert system elements;

- documenting the results of the training session (testing, admission control or qualification tests);

- transfer of current information in the «online» mode through the channels of standard information systems and networks (for example, the Internet);

- remote establishment of requirements for testing, admission control or qualification tests.

The software of the TSDS-06M1 simulator includes training, testing and admission control programs for welders and the corresponding EMD, which is addressed not only to welders, who are directly involved in welding works, but also to other specialists of welding production. If necessary, the software of the TSDS-06M1 simulator can be supplemented also with the program of qualification of arc welding operators.

The curriculum (training program) is developed on the basis of the reproductive method, has a hierarchical structure and represents a two-level system of practical studies. The basic aim of the first, local level for the trainees is to achieve stable results in formation of certain skills in making the real processes of MMA-, TIG- and MIG/MAG welding. Moreover, these results should correspond to the preset values of the parameters of welding process and welding techniques. The aim of the second, integrated level of studies is to achieve and maintain the totality of skills and abilities formed at the local level, providing a stable repeatability of real welding processes in general with a preset level of quality.

It should be emphasized that automatic determination of coordinates of the welding arc spot and the actual welding speed when mastering maintaining of the 
welding speed (speed of electrode movement) within the preset limits of welding speed is one of the most essential components in the professional training of welders. Providing a reliable control of these components is one of the most complex and still insufficiently solved tasks in the development of arc simulator welding systems (SWS). And although there are a number of ways to evaluate the speed of manual welding and devices for their realization [2, 10, 11], the multiple attempts to apply these methods did not lead to the desired result corresponding to the requirements to the modern SWS because of their technical or economic aspects. This caused the E.O. Paton Electric Welding Institute together with the SEC WCNPE to conduct investigations, theoretical and experimental works on the search for easy-to-realize, inexpensive and accurate methods for determining the coordinates of a moving arc and evaluating the welding speed, as well as the principles of designing devices for realizing such methods. As a result of the mentioned investigations and works, a comparatively easy-to-realize resistometric method for determining the coordinates of a moving arc and evaluating the welding speed, as well as a device for its realization [12,13], was developed. This method is based on the method for determining the coordinate of a measuring probe in a conducting medium $[14,15]$, developed by V.V. Vasiliev and L.A. Simak at the G.E. Pukhov IPME, and further developed at the E.O. Paton Electric Welding Institute and SEC WCNPE for the arc SWS as-applied to a moving welding arc spot or its simulator. Taking into account the advantages of the resistometric method for determining the linear coordinate of a welding arc spot and measuring the welding speed, this method and digital devices for its realization were successfully used in all modern hardware-software simulator complexes (welding simulators) of the MDTS and TSDS series and widely represented in Ukraine and in a number of near and foreign countries.

Since the training complexes MDTS-05M1 and TSDS-06M1 are fully compatible with the modern digital channels and systems for transmission, storage, reception and reproduction of information (including the Internet), the opportunity appears to realize not only the remote training of welders on their basis (including with the use of real welding processes), but also the remote testing, qualification and certification of welding personnel. Such opportunities of a single information space will allow international and national centers of personnel certification not only to record the protocols of testing, admission control and qualification, but also to monitor their conductance, correspondence of knowledge and skills of the train-

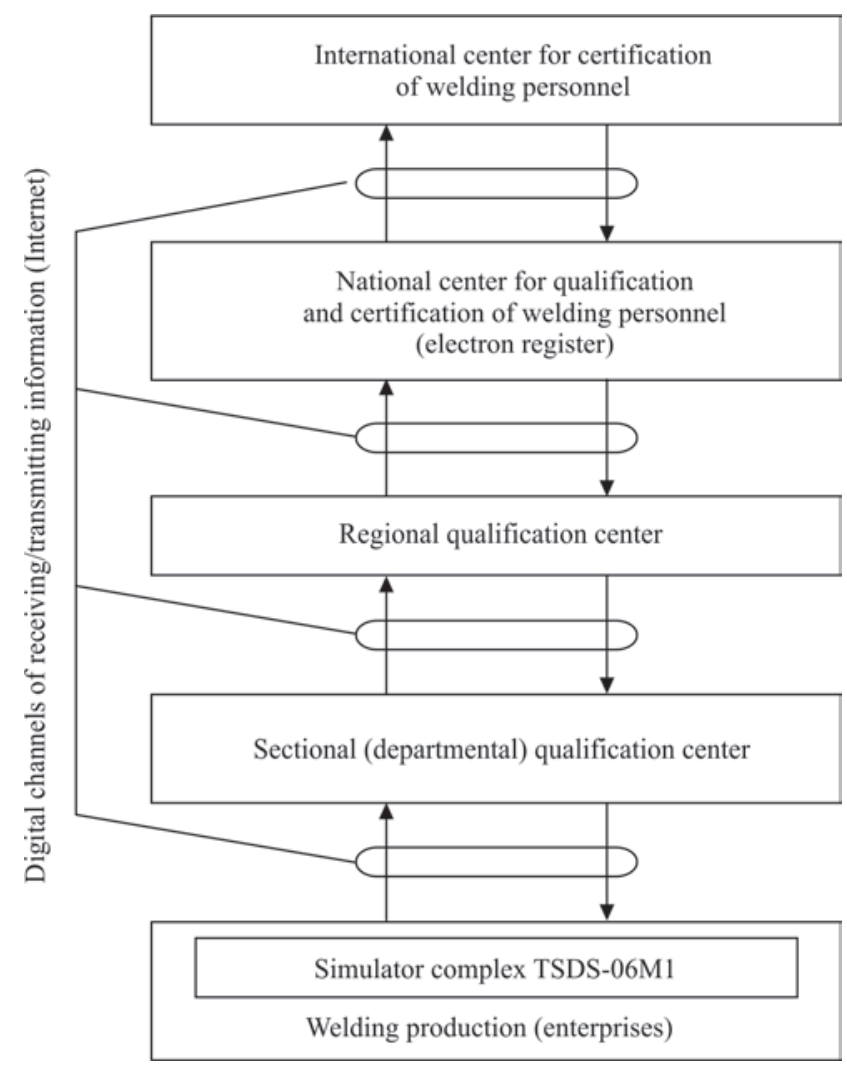

Figure 3. Structural scheme of system of remote qualification and certification of welding personnel (using the simulator TSDS06M1)

ees (tested) to the national and international requirements. At the same time, due to replenishment of the EMD with the norms of the international educational standards and rules, during prequalification training the account for their specifics is simplified. Moreover, the procedures of testing, admission control and personnel qualification themselves can be performed in training or qualification centers, which are located at significant (almost any) distances from certification centers, issuing permission documents.

The scheme of system of remote qualification and certification of welding personnel is shown in Figure 3.

It should noted especially that modernization of the existing simulation systems and the further development of additional means for training welders and specialists of welding production are possible only on the basis of analysis and generalization of practical experience in application of such technical means of training and qualification in the establishments and institutions of vocational education of all levels, training and qualification centers, as well as directly in production.

The accumulated experience in practical application of information technologies and the technical means developed in the last decades in training, improvement and qualification of welders and specialists in welding production creates favorable prerequisites 
for solving the urgent problems of training welding personnel in the CIS countries and in other countries, which corresponds to the modern requirements.

\section{Conclusions}

1. The arc hardware-software complexes (welding simulators) using information technologies, developed at the E.O. Paton Electric Welding Institute together with SEC WCNPE, provide expansion of technological and didactic capabilities of modern technical means for training welders and specialists in welding production, intensification and simplification of the training process and its approximation to the conditions of real welding processes.

2. The level of development of technical means of professional selection, training, improving skills, testing, admission control and improvement of qualification of welders and specialists in welding production, achieved up to nowadays, allows predicting the expansion of the areas of application of modern information technologies, including those reproducing the mixed reality with the maximum adaptation of virtual space to real welding equipment, as well as the use of telecommunication systems, providing the remote access through the global network.

3. While creating welding simulators of a new generation, the technologies of virtual reality combined with real welding equipment, real welding tools and simulators of welded products will get the advanced development, allowing creating almost any training situation with the support of a real-time mode and an effective system for evaluation of actions of trainees. Moreover, it is assumed that in welding simulators of a new generation the microprocessor devices and systems as well as digital systems of technical vision will find a wide application.

In conclusion the authors consider it necessary to note that in the development and introduction of hardware-software complexes (welding simulators) MDTS-05M1 and TSDS-06M1 V.L. Kobryansky, A.G. Skirta, I.V. Vertetskaya, M.I. Skopyuk, A.F. Muzhichenko, A.G. Siparenko, V.A. Bogdanovsky, V.M. Gavva, A.D. Cherednik, V.E. Popov, D.S. Oliyanenko, A.A. Mukha, S.F. Tarkhov, V.A. Fedotov took part and in mastering of industrial production of these simu- lators A.A. Sviridenko, N.M. Pasichny, V.N. Andrejchenko, V.E. Ivanov, A.U. Mnukhin, V.P. Tishchenko, G.I. Pisarev, A.V. Naumenko participated.

1. Paton, B.E., Korotynsky, A.E., Bogdanosvky, V.A. et al. (2010) Information technologies in education of welders and specialists of welding production: Methodology and technical means. Svarka i Diagnostika, 3, 37-44 [in Russian].

2. Vasiliev, V.V., Simak, L.A., Bogdanovsky, V.A. et al. (2003) Simulation modeling and training-education systems in electric welding. Kiev, NASU [in Russian].

3. Koboyashi, K., Kato, H., Shimamoto, S. (2004) Modified training system for manual arc welding by using mixed reality and investigation of its effectiveness. J. Japan Society for Precision Engineering, 70(7), 941-945.

4. Heston, T. (2008) Virtually welding: A tour of welding simulators that could help the manufacturing word rethink welding training. Fabricator, 38(3), 56-59.

5. Porter, N., Cote, J., Gifford, T., Lam, W. (2006) Virtual reality welded training. J. of Ship Production, 22(3), 126-138.

6. Hasimoto, N., Kato, H., Ikehara, R. (2006) Training system for manual arc welding by using mixed reality-reduction of position-perception error of electrode tip. J. Japan Society for Precision Engineering, 72(2), 249-253.

7. Product description Fronius virtual welding. www.fronius. com/cps/rde/xchg/SID-BFA25696-036863A3/fronius_international/hs.xsl/79_15490_ENG_HTML.htm

8. (2018) Fronius Company as a pioneer of implementation of digital and communication technologies. Avtomatich. Svarka, 2, 59-61.

9. Keitel, S., Ahrens, C., Moll, H. (2014) Computer-based technologies and their influence on welding education. Ibid., 10, 51-55.

10. Danilyak, S.N. (1990) Problems of design of measuring transducers for control of heat content of welding pool and speed of welding simulators. Modeling in simulating systems. Kiev, Naukova Dumka [in Russian].

11. Bigdash, V.D. (1990) Devices of welding rate control in welding simulating systems. In: Modeling in simulator systems. Kiev, Naukova Dumka, 143-150 [in Russian].

12. Paton, B.E., Korotynsky, O.E., Bogdanovsky, V.O. et al. (2009) Method of evaluation of welding arc movements parameters in arc simulating systems. Pat. 86609, Ukraine [in Ukrainian].

13. Lobanov, L.M., Makhlin, N.M., Korotynsky, A.E. et al. (2018) Resistometric method of welding speed measurement for simulating welding systems. The Paton Welding J., 1, 8-13.

14. Vasiliev, V.V., Grezdov, G.I., Simak, L.A. et al. (2002) Modeling of dynamic systems: Aspects of monitoring and signal processing. Ed. by V.V. Vasiliev. Kyiv, NASU [in Russian].

15. Simak, L.A. (1984) Method of automatic determination of probe coordinates in conducting medium on the base of differential transformations. Elektronnoe Modelirovanie, 6, 90-91 [in Russian]. 


\section{ON THE OCCASION \\ OF THE $175^{\text {th }}$ BIRTHDAY ANNIVERSARY OF N.N. BENARDOS, THE INVENTOR OF ELECTRIC ARC WELDING}

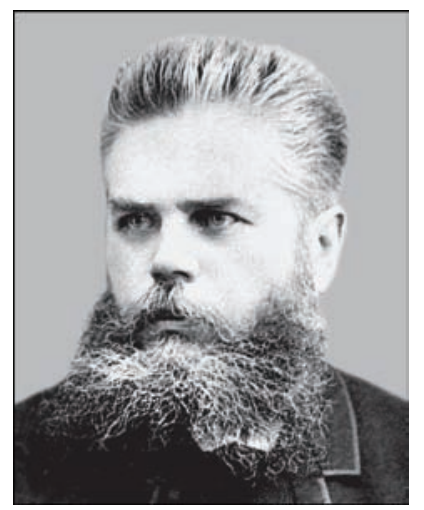

The life of N.N. Benardos began in village Mostovoye of Kherson province (now Nikolaevsky region), which was called Benardosovka by the name of the inventor grandfather, the general Pantelejmon Benardos.

In the workshops, where Benardos was working in the young years, there were no large heating furnaces. Therefore the inventor tied to heat metal edges by an electric arc before their forging. In this case the metal was fused partially and joined by small areas.

By creating the electric circuit between two electrodes the workmen waited for the appearance of arc, by which the necessary workpiece was heated. One day Benardos during his experiments guessed to transform the workpiece itself into one of electrodes by its including into the closed electric circuit. As a result, the arc began independently to melt the part surface and, thus, the scientist made his the most famous discovery, namely a method of electric welding. N.N. Benardos named his invention as «electrohefest», derived from the name of Hephaestus, the Greek God of war, fire, the patron of blacksmith's handcraft.

The first welds by using a carbon electrode were welded by Benardos in Paris in 1881 and presented at the Paris International Electrical Fairy, where the «electrohefest» was recognized as the main exhibit and received a gold medal.

After the thorough testing and improving his method up to the feasibility of industrial application the ten-year Privilege No.11982 was issued to N.N. Benardos by the Department of Trade and Manufacturing of the tsarist Russia on December 31, 1886.

The method, invented by N.N. Benardos, was rather simple. Its principle in the description to the Privilege was presented in the following way: «The subject of invention is pertained to the method of joining and separation of metals by the action of electric current... based on direct formation of an electric arc between the metal treatment place, being one electrode, and another electrode, fed by the handle to this place and connected with a proper pole of electric arc. Using this method the following works can be carried out: joining of parts between each other, separation or cutting the metals into parts, drilling and making holes and cavities and deposition by layers».

In 1885 in Petersburg the first in the world welding company was organized: the Association «Electrohefest» on service and implementation of Benardos's invention. It soon acquired the world recognition. The manufacturers of many countries, who were producing locomotives, boilers, metal structures and other products, came to Petersburg to become familiar with the new technological process. Before the very eyes of specially coming famous German Prof. R.Ruhlman Benardos performed the repair of the factory boiler during 1 hour, which was planned to be repaired during three weeks.

In the middle of the 1890s the new technological process was implemented at the more than 100 factories of West Europe and USA. For example, the French locomotives of Schneider had weak frames, which could not be subjected to the traditional methods of treatment. Only the application of N.N. Benardos's electric welding could solve the problem and allowed the locomotives to pass the record 174000 versts without traces of any damages. Nevertheless, the opponents appeared, pointing out, for example, to a bright and dangerous electric arc light for eyes and skin.

Due to this, the Society «Electrohefest» began at once to apply the various means for protection against the radiation. It should be noted that the model of welder's suit of Shaturskaya sewing worshop was called «Benardos». 


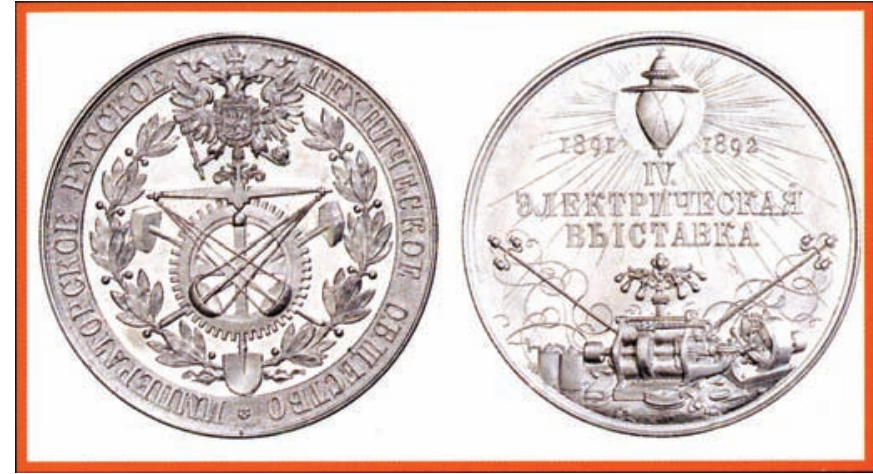

Gold metal of all-Russian Electrical Exhibition

N.N. Benardos worked continuously for the «electrohefest» improving. At the IV All-Russian Electrical Exhibition, held in Saint-Petersburg in 1892, 30 different inventions of Benardos, formed into a separate exposition, was demonstrated. N.N. Benardos was awarded the highest award of the Exhibition: a gold medal.

On May 1 of the same year N.N. Benardos was awarded the highest award of the Imperator Russian Technical Society: a gold medal «For the successful application of electric arc for brazing of metals and deposition of one metal on another one», and in May, 1893 he was elected its full member.

N.N. Benardos paid a special attention to the improving the quality of welded joints. For this purpose he applied the shielding gases. He attained the weld improved quality by rolling the fused edges by rollers. The inventor offered and tested a great number of electrodes. His drawings of hollow electrodes, filled with a charge of mixture of metallic powders and fluxes, unique designs of disc-type and spiral electrodes are preserved, and the welding with a carbon electrode was named «The Benardos's method».

He developed the methods of arc cutting, underwater welding and cutting, welding in vertical surface. The inventor expressed the idea of welding in a gas jet and under flux. He invented the unique methods of spot and seam resistance welding. The list of his discoveries includes 196 inventions. He received patents in France, Belgium, Great Britain, Austro-Hungary, Sweden, Italy, Germany, USA, Norway, Denmark, Spain, Switzerland, tsarist Russia.

Benardos developed many designs of welding automatic machines, he suggested and realized ideas of mechanization of welding process by the products rotation. His electric arc welding machines amazed by their service life. One of them operated at the Goujon factory above 30 years and was dismantled only in 1931.

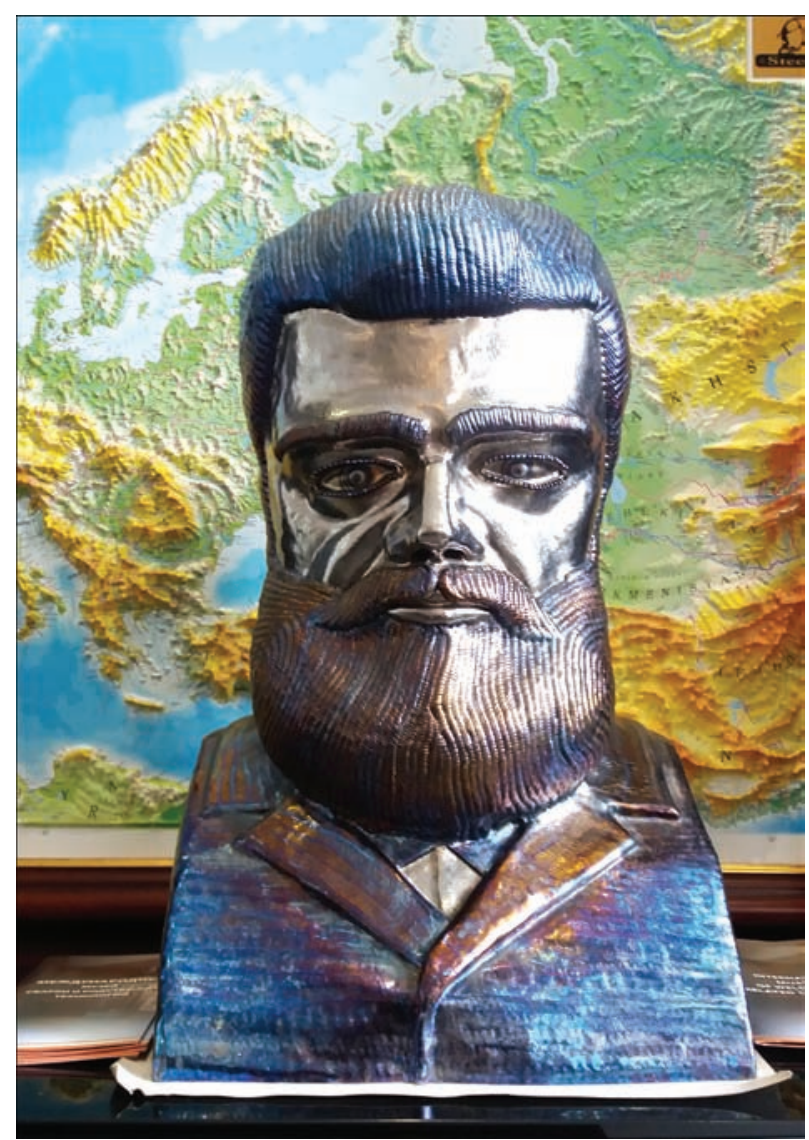

Bust of N.N. Benardos, author G.G. Dochkin

The last years of N.N. Benardos's life were rather difficult. In 1898 Benardos moved to Fastov town of Kiev province, because the life in Petersburg was almost beyond his pocket. Nevertheless he patented by the last money the method of preparation of spongy lead for the accumulator plates, and in 1890 he received the privilege for the method of harrows manufacture by the method of stamping from a sheet. In 1899 the Electrotechnical University in Petersburg awarded him with a title of the honorary electrical engineer, bringing his invention to the same level with outstanding invention of radio by A.S. Popov.

In spite of the public recognition, he was poor as usual. After the long years of hesitations Benardos dared to ask the Council of Russian Technical Society to grant him a life-time pension. After three years, in September 21, 1905 Benardos died. None of the journals informed officially about his death.

But the electric welding, invented by N.N. Benardos, is undoubtedly the best monument to its inventor. The genius invention of Benardos found its unexpected application in the art. As an example, a sculptural bust of the inventor, created by Grigoriy G. Dochkin, the talented Ukrainian welder, can be presented. It is manufactured by using the titanium argon arc welding without post mechanical treatment. 


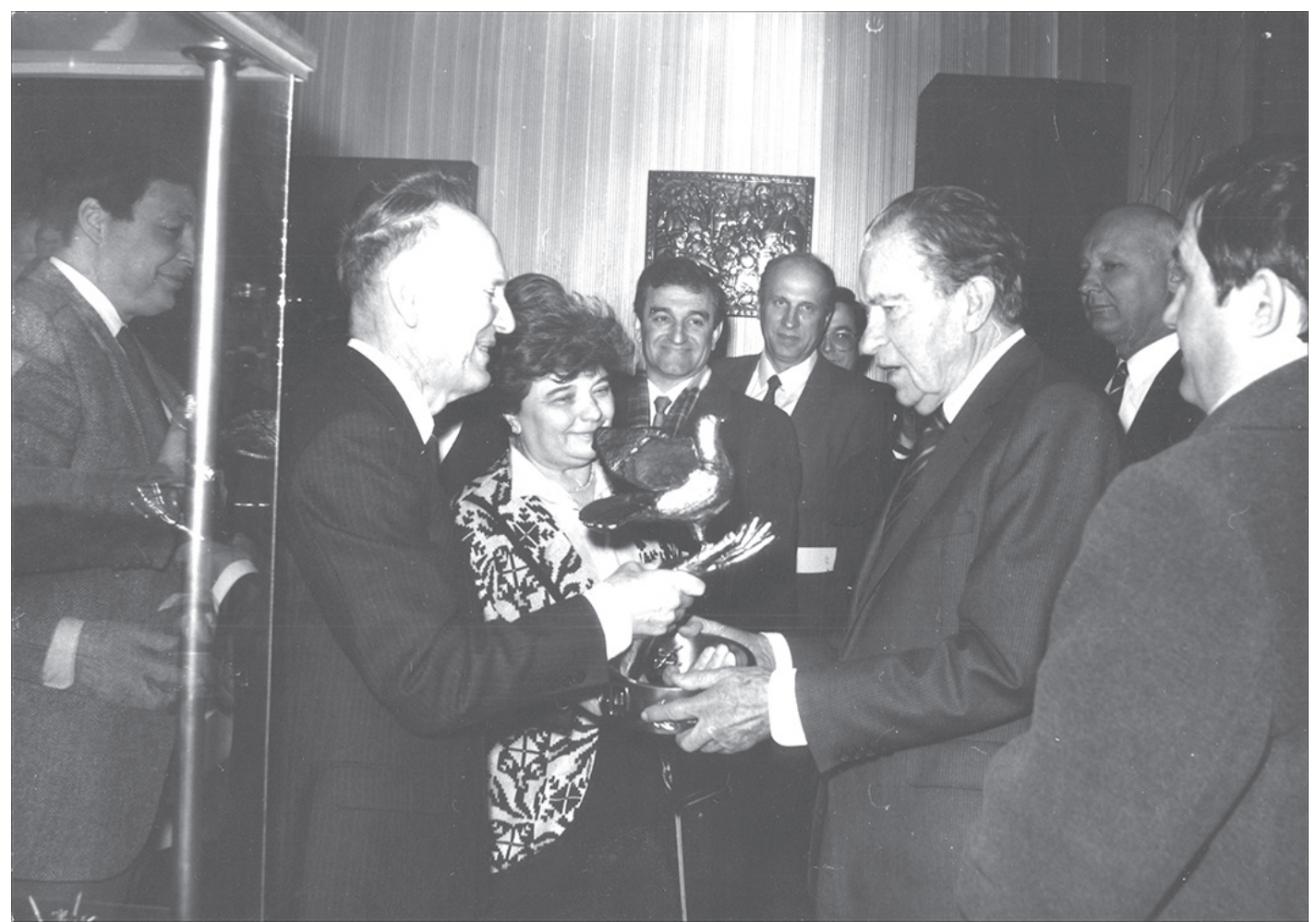

Academician B.E. Paton presents «Dove of peace» work of G.G. Dochkin to Richard Nixon (PWI, 1994)

The passion of G.G. Dochkin for an art welding began since the time when the young specialist had to weld the separate titanium parts for the space «Lunokhod». By selecting the different welding conditions, he noted such a material property as the change in color depending on temperature and heating duration. These peculiarities astonished Grigoriy and since that moment the small pieces of metal in hands of Dochkin began to transform into various sculptural masterpieces in the form of tiny insects, animals and flowers. By giving these compositions different color and exquisiteness of forms, the specialist with a high level of skill could transform his personal passion into a professional work by developing an own technique of art welding. Among the Dochkin's works, there is a titanium ring-basement with inscriptions «USA» and «USSR». On this basement a woman's hand is arranged, from which a dove of peace is flying up. This masterpiece was given as a gift to Mr. Richard Nixon, the American President, during his visit to the E.O. Paton Electric Welding Institute of the NAS of Ukraine.

Hundreds of millions of tons of the metal structures, from piles and beams up to nuclear reactors and spaceships, are manufactured at the present time by different methods of arc welding. The better achievements of the modern science are put into service of the welding engineering. It is created and developed by the new generations of scientists and inventors, whose memory of gratitude to N.N. Benardos, the inventor of arc welding, will be preserved for ever.

A huge amount of inventions and newest technologies created a sophisticated world, accelerated its progress and allowed the science and technology of many countries to have a thriving development. The inventors quite often become popular. Such names as Nicola Tesla and Tomas Edison, Dmitry Mendeleev and Igor Sikorsky are known to each pupil in any civilized country. However, the another situation is also possible, when the invention of genius is used in the whole world, but his name is little known not only during his lifetime, but undeservedly moved aside to the second plan in history. Moreover, some inventions became so ordinary, that people do not simply pay attention to them, but in spite of this their importance became not less significant.

Information was prepared by «Steel Work» Company 


\section{UNIQUE COMPLEX FOR AUTOMATIC ARC WELDING AT LARGE DEPTH}

The technology and equipment allows automatic welding of structural elements, which seal from the inside the lower part of heat exchanger column, using a method of wet arc welding with fluxcored wire.

Work originality lies in development of automatic welding machine, which can operate when it is immersed in $119 \mathrm{~mm}$ diameter pipe at $200 \mathrm{~m}$ depth in liquid heat-carrying agent medium.

$>$ The complex was successfully tested on GDE company object, London.

Welding complex can be used in welding, surfacing and cutting of vertical steel product pipelines operating in water medium.
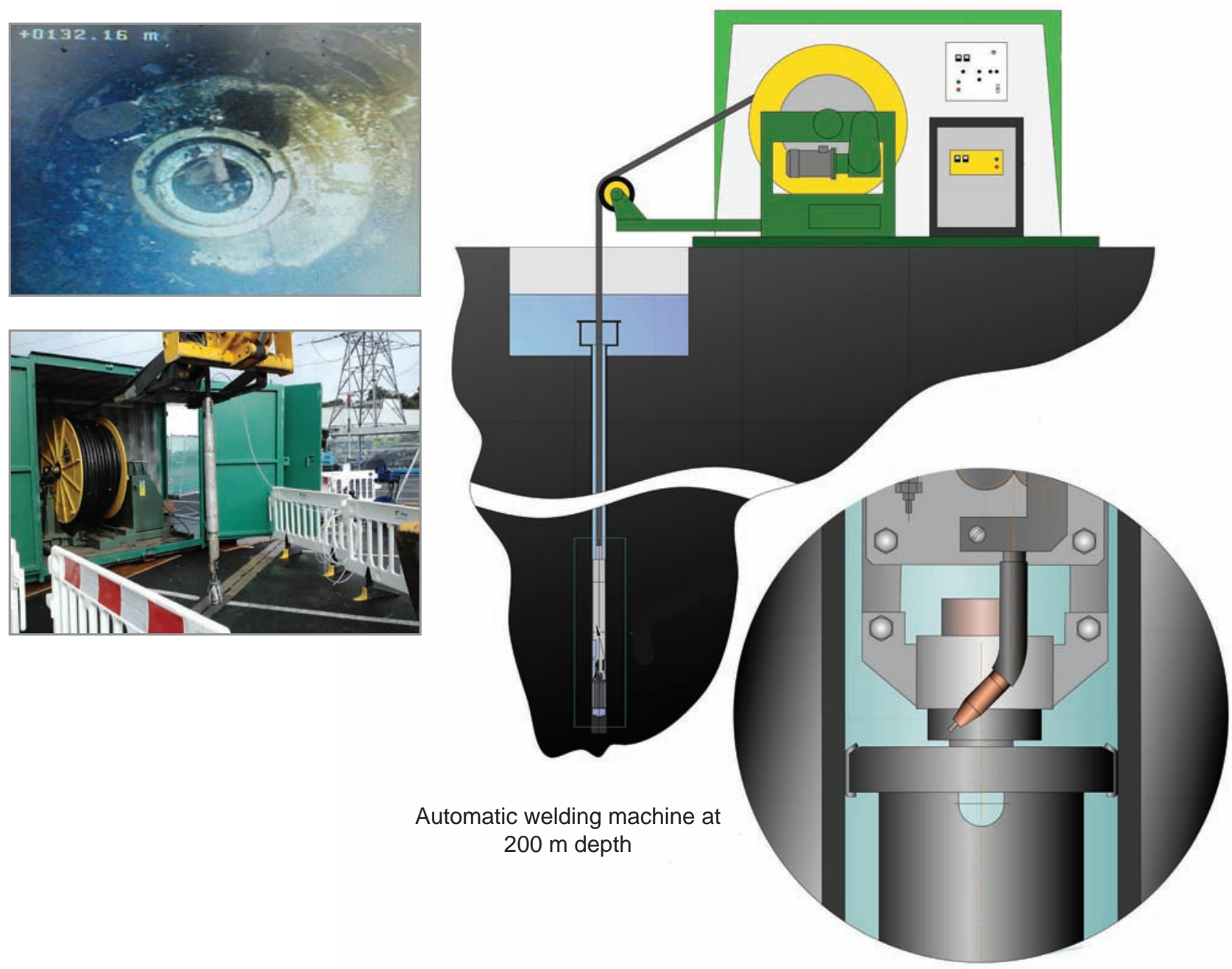

Developed by the E.O. Paton Electric Welding Institute of the NAS of Ukraine. E-mail: office@paton.kiev.ua 


\section{EQUIPMENT FOR \\ ELECTRON BEAM WELDING}

PWI has been engaged in EBW since 1958. The first commercial units were put into operation at the beginning of the $60^{\text {th }}$. Necessity in EBW has expanded with time on nuclear power engineering, instrument making, aircraft-, ship and space machine building.

\section{Covered tasks include:}

$>$ designing mechanical and electrical sections of machines

$>$ development of electron guns, power sources and control systems

$>$ assembly and testing of complete machines and power units

$>$ putting the produced machines into commercial operation

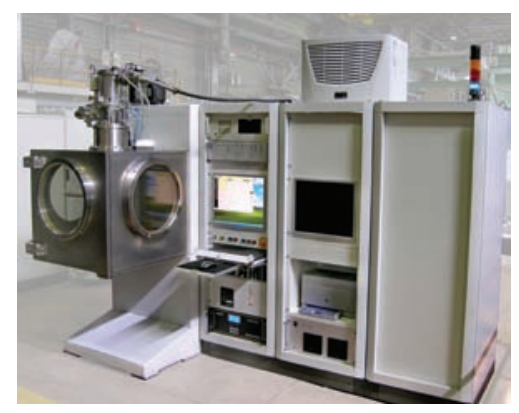

\section{Small-size unit of SV 112 type}

Chamber volume

$0.3 \mathrm{~m}^{3}$

Accelerating voltage

$60 \mathrm{kV}$

Capacity of power unit to

\section{$15 \mathrm{~kW}$}

Mid-size unit of KL 138 type

Chamber volume

Accelerating voltage

$40 \mathrm{~m}^{3}$

Capacity of power unit to

$60 \mathrm{kV}$

$60 \mathrm{~kW}$
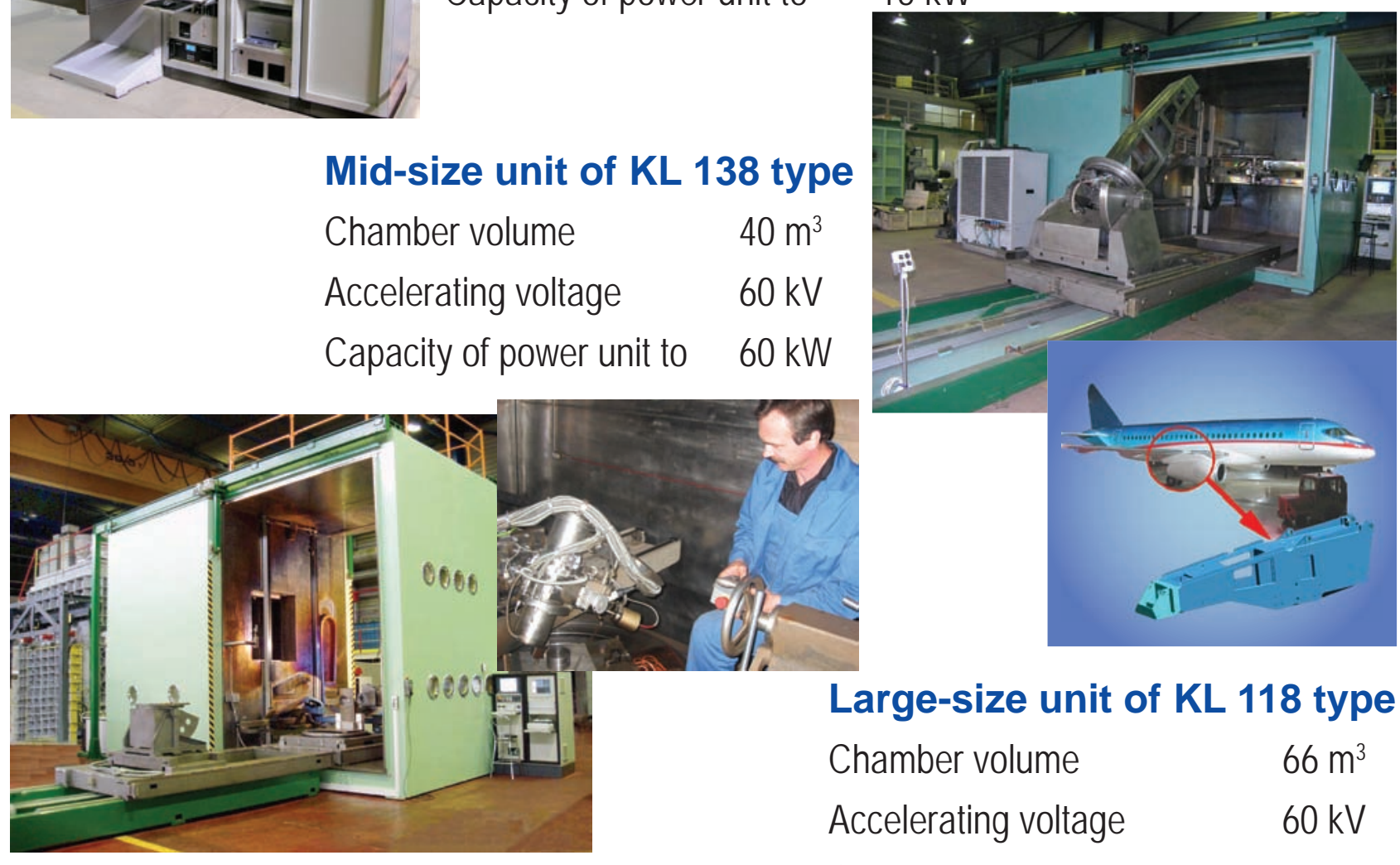

Large-size unit of KL 118 type

Chamber volume $66 \mathrm{~m}^{3}$

Accelerating voltage $60 \mathrm{kV}$

Capacity of power unit to $60 \mathrm{~kW}$

About 100 sets of different EBW equipment, including the units with vacuum chamber volume to $100 \mathrm{~m}^{3}$, have been put into operation for the last 10 years. 


\section{ELECTRON \\ BEAM \\ WELDING}

FOR AIRCRAFT I NDUSTRY

\section{Engines}
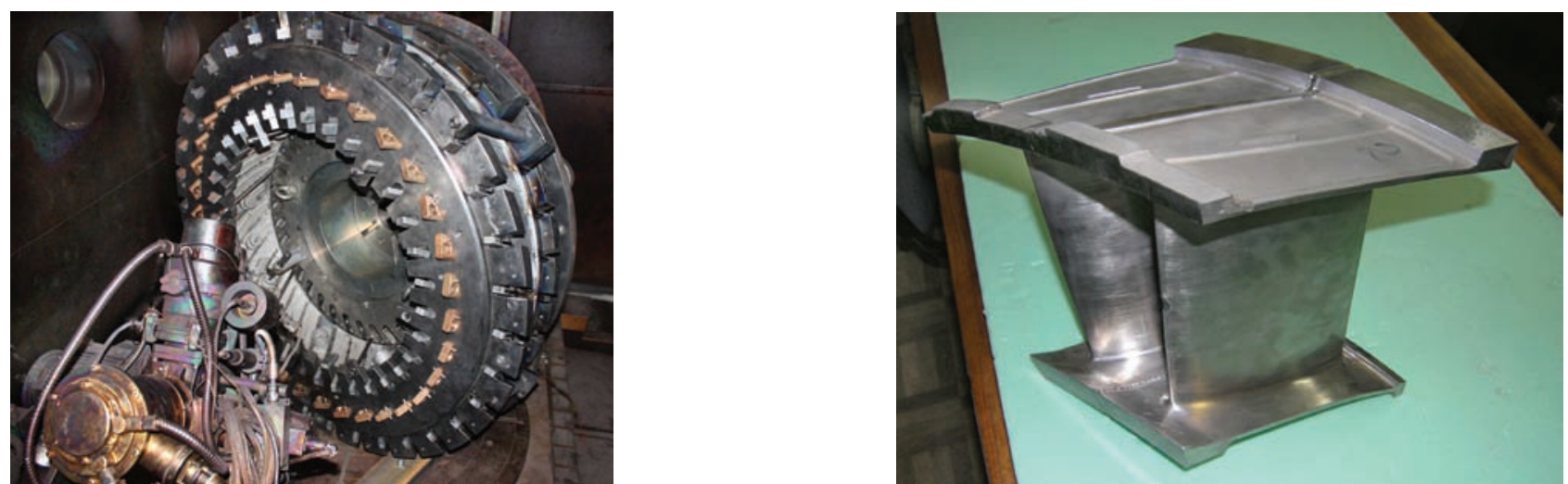

Hemispheroid Tank
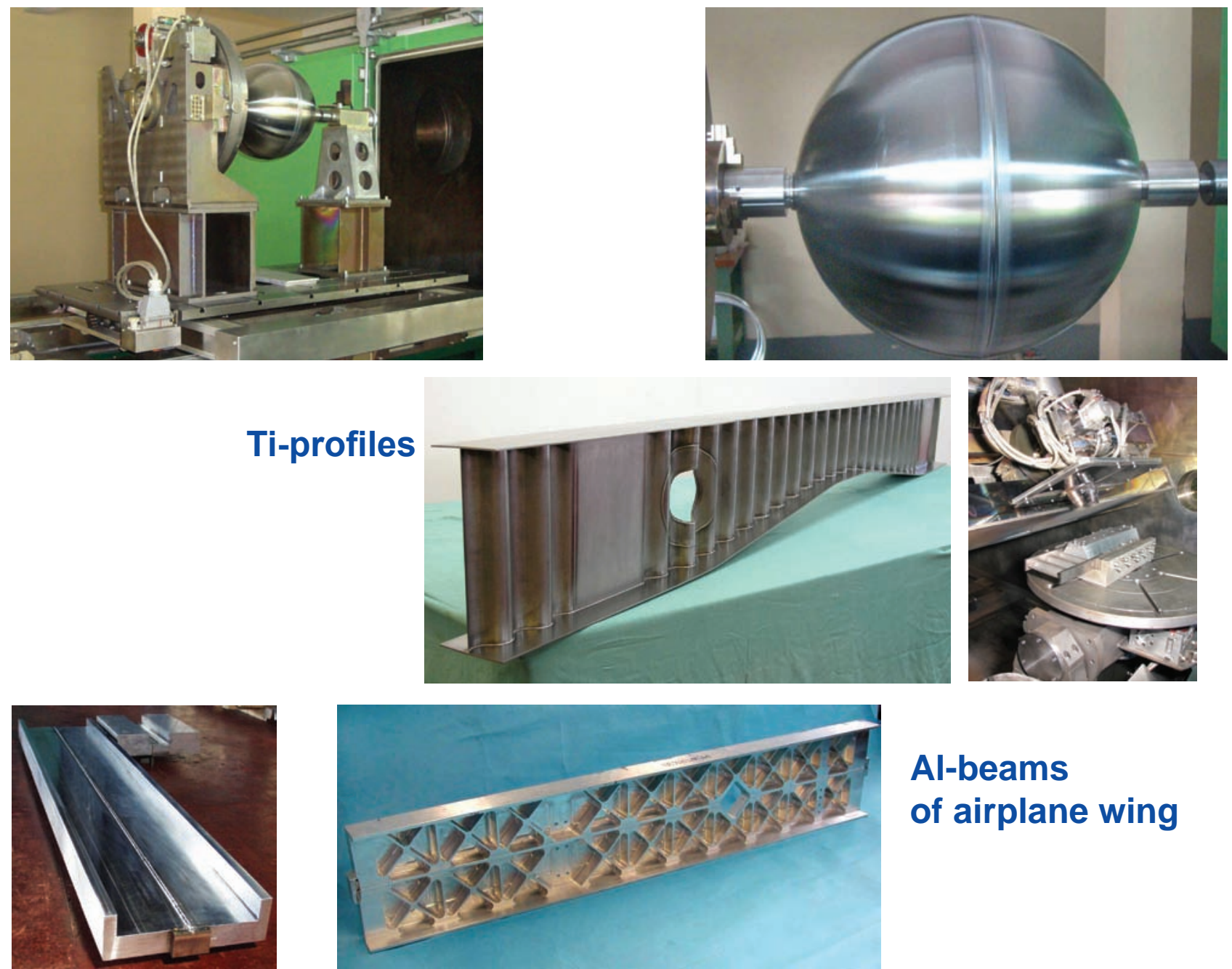

Al-beams

of airplane wing

Developed by the E.O. Paton Electric Welding Institute of the NAS of Ukraine. E-mail: office@paton.kiev.ua 
ELECTRON

BEAM

WELDING

FOR ENGINE REPAIR

\section{Blades and Vanes Repair}
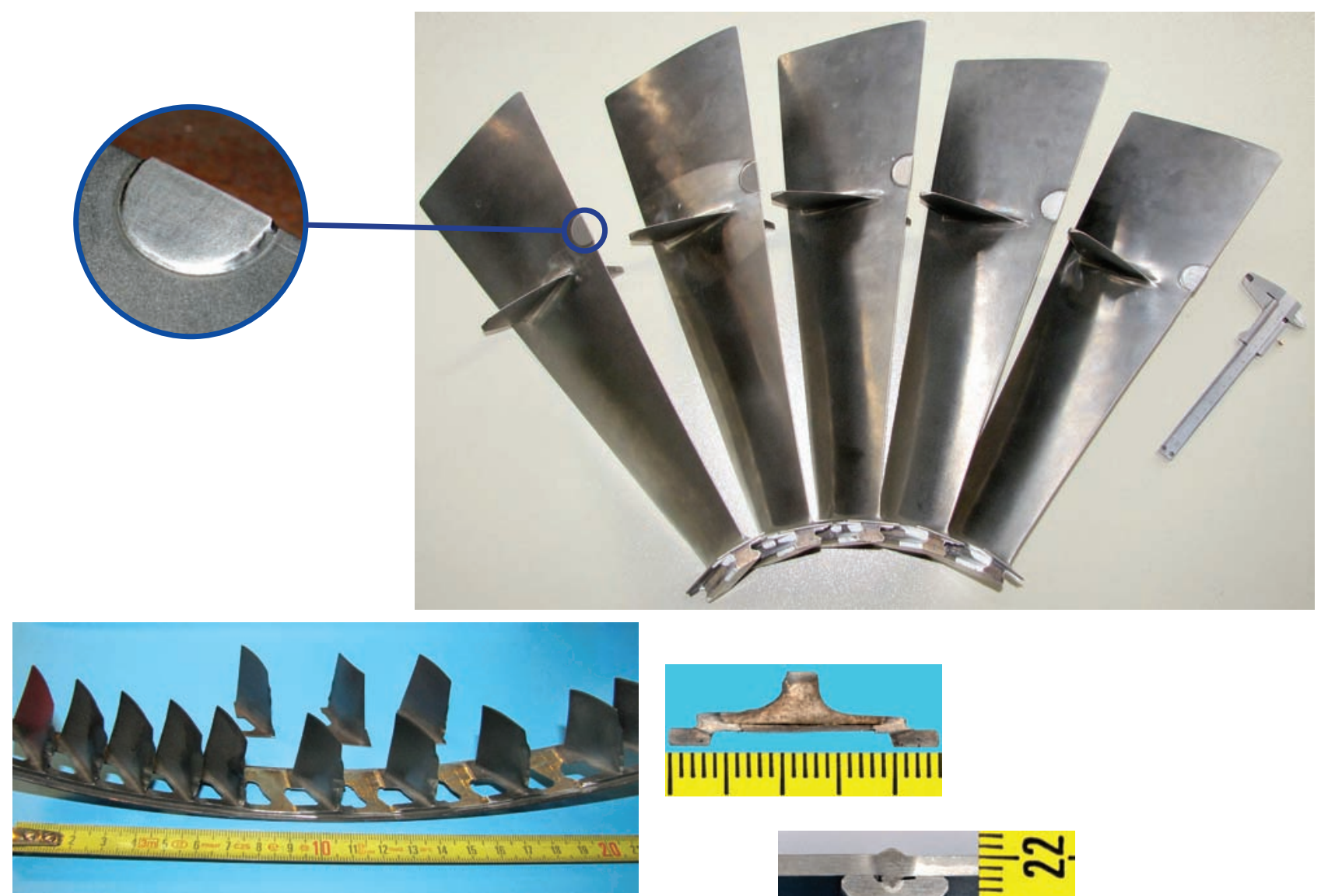

Hydraulic Cylinders Repair

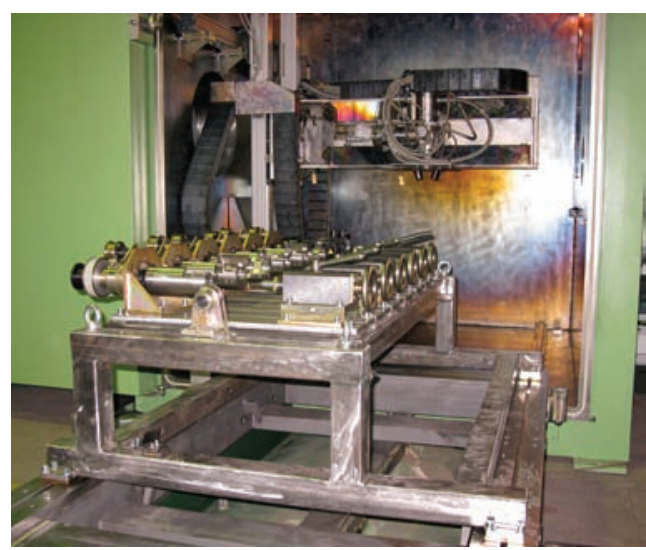

Welded joints

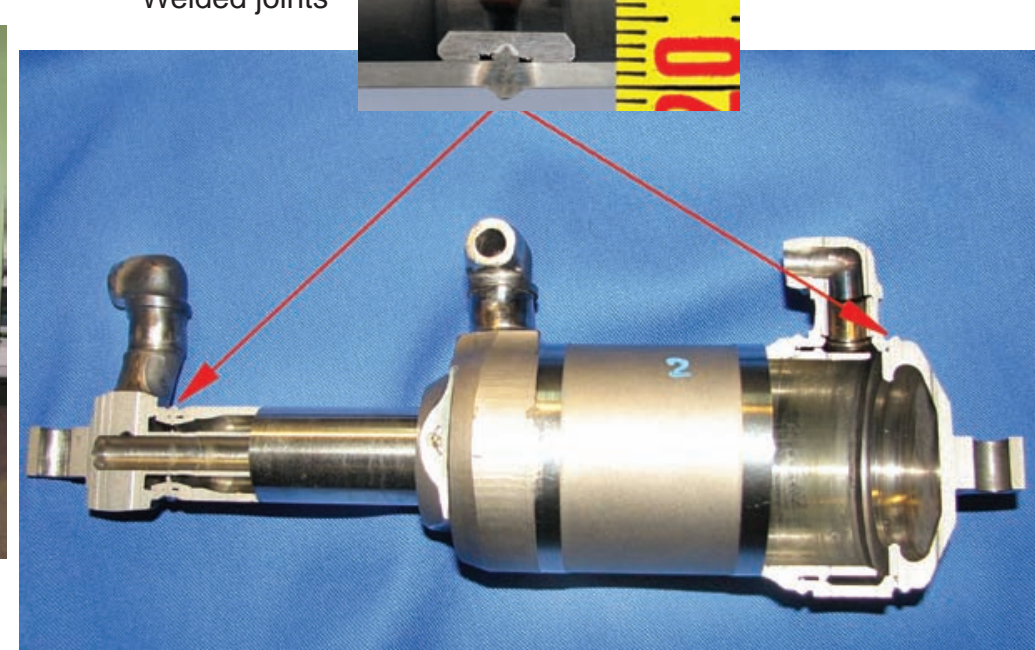

Developed by the E.O. Paton Electric Welding Institute of the NAS of Ukraine. E-mail: office@paton.kiev.ua 


\section{ussir Gech Mo \\ MANUFACTURE OF MULTILAYER BELLOWS}

PWI has developed the technology and equipment for laser welding of thin-wall pipes of stainless steel for manufacture of multilayer bellows, which carry and divide liquid and gaseous media, including aggressive ones.

Following the developed technology the bellow consists of several laser-welded thin-wall pipes (from 3 to 10 layers) of $0.15-0.20 \mathrm{~mm}$ thickness each. The bellow will keep working capacity in such a multi-layer bellow structure, even if one welded joint breaks in process of operation.

\section{Development advantages:}

$>$ reduced amount of rejects from $50 \%$ in argon-arc welding to $0.5 \%$ in laser welding

$>4$ times rise of productivity

$>$ cyclic strength, corrosion resistance and other characteristics of laser-welded multilayer bellow 1.5-4 times exceed the characteristics of single layer bellow made by argon-arc welding (depending on number of layers and bellow sizes).

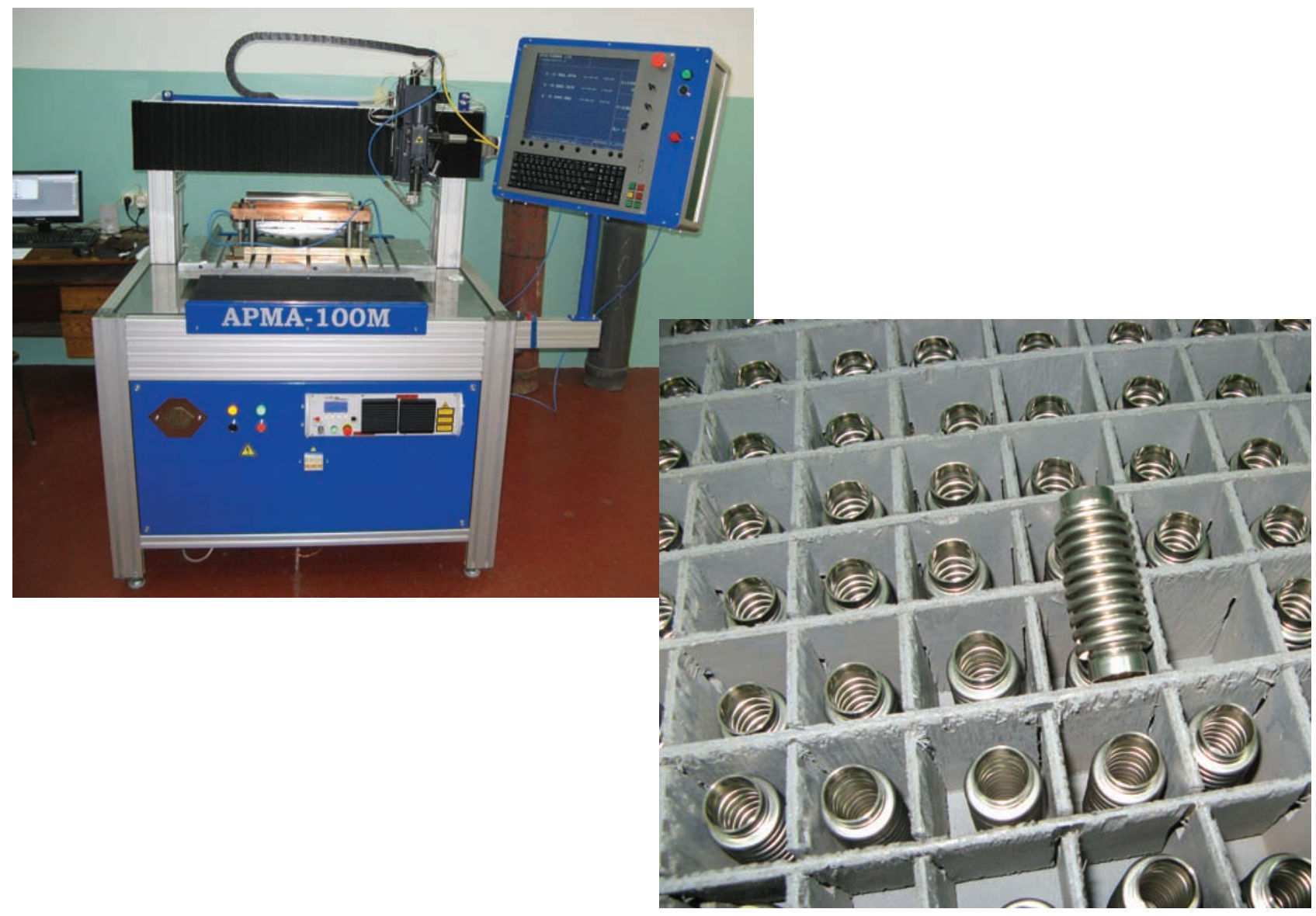

